\title{
Tonal marking of absolutive case in Samoan
}

\author{
Kristine M. Yu ${ }^{1}$
}

Received: 31 March 2016 / Accepted: 3 April 2020 / Published online: 24 April 2020

(C) The Author(s) 2020

\begin{abstract}
Samoan is an ergative-marking, (reportedly) non-tonal Polynesian language in which ergative case is marked segmentally, but absolutive case has been said to be unmarked. This paper shows that in fact, a high edge tone co-occurs with absolutive arguments, based on converging evidence from the phonetic and phonological analysis of intonational patterns in the spoken utterances of a systematically varied set of syntactic structures. This empirical observation raises puzzles that probe the nature of the syntax-prosody interface and the relation between tone and intonation: what is the relation between this absolutive high edge tone and: (i) other case markers in Samoan, which are all segmental?, and (ii) other high edge tones in Samoan that co-occur with fronted expressions and coordination? I propose that: (i) the absolutive high edge tone is a tonal case marker that may be related to an apparently moribund stressed, segmental absolutive particle ['ia], (ii) the high tones that co-occur with absolutives, fronting, and coordination are all syntactically determined and each inserted in the spellout of distinct syntactic configurations, and (iii) there is another class of edge tones which reliably co-occur with pauses-intonational phrase boundary tones - that are not inserted in spellout but by the phonological grammar. While my proposal may seem surprising at first, I show that it fits the current data better than any alternative.
\end{abstract}

Keywords Samoan · Prosody · Intonation · Syntax-phonology interface · Austronesian · Tone $\cdot$ Phonetics $\cdot$ Case $\cdot$ Morphology $\cdot$ Ergativity

K.M. Yu

krisyu@linguist.umass.edu

1 Department of Linguistics, University of Massachusetts Amherst, Amherst, MA, United States 


\section{Introduction}

This paper shows that in the ergative-marking, purportedly non-tonal language Samoan, high edge tones reliably co-occur with absolutive arguments, ${ }^{1}$ which have previously been thought to be unmarked (Chung 1978:54-56; Ochs 1982:649; Collins 2014:94). To illustrate: consider (1) from Collins's (2016) paper providing a VP-fronting account of verb-initiality in Samoan. My empirical claim entails that a high edge tone (annotated as $\mathrm{H}_{\mathrm{abs}}$ ) reliably appears preceding the object in a basic VSO transitive clause, e.g., preceding [le maile ula] 'the mischievous dog' in (1a). An $\mathrm{H}_{\mathrm{abs}}$ also reliably appears preceding the subject in [VO]S word order, e.g., preceding [le teine] 'the girl' in (1b). No high edge tone appears before the bare NP object [maile ula] 'mischievous dogs' in (1b).

(1) Absolutive $\mathrm{H}$ in $\mathrm{VSO} /[\mathrm{VO}] \mathrm{S}$ word order alternation under a VP-fronting account of VSO (Collins 2016: (3)) ${ }^{2}$
a.
[su?e
$\left.\left\langle D P_{i}\right\rangle\right]$ pea
e le
teine $\mathbf{H}_{\text {abs }}$ [le
PRES search
continually ERG DET.SPEC girl ABS DET.SPEC
maile ula $]_{i}$.
dog mischievous
'The girl continually searches for the mischievous dog.'

b. e $\left[\text { su?e }[\text { maile ula }]_{N P}\right]_{V P}$ pea $\mathbf{H}_{\text {abs }}$ le teine.

PRES search dog mischievous continually ABS DET.SPEC girl

'The girl continually searches for mischievous dogs.'

The first part of this paper supports my empirical claim of an $\mathrm{H}_{\mathrm{abs}}$ in Samoan with converging distributional evidence from the phonetic and phonological analysis of intonational patterns in the spoken utterances of a systematically varied set of syntactic structures. The second part of this paper argues that the analysis of the $\mathrm{H}_{\text {abs }}$ that best fits the currently available data is that it is a tonal case marker inserted in spellout as a reflex of the structural configuration of absolutive case. Neither the empirical claim of an $\mathrm{H}_{\mathrm{abs}}$ nor the theoretical claim that it is a tonal case marker is new: both were first proposed in Yu (2011). And since Yu (2011) was published, Calhoun (2015), Yu and Özyıldız (2016), Calhoun (2017), and Yu and Stabler (2017) have continued to address and discuss both claims.

What isn't under discussion is the implicit claim that tone can mark case: tonal morphemes are not uncommon in natural language and can signal morphosyntactic relationships such as tense/aspect, gender, number, and case (Hyman 2011b). In particular, tonal case markers have been reported to occur in Somali (Saeed 1993:148),

\footnotetext{
${ }^{1}$ I use 'absolutive' in this paper as a descriptive gloss of what Collins $(2014,2016)$ recognizes as the default, syncretic marking of nominative NOM and accusative ACC.

${ }^{2}$ The following abbreviations are used in examples in this paper: ABS absolutive; Adv adverb; Agt agent; CONJ conjunction; COORD coordination; DET determiner; DIR directional particle; DU dual; DISJ disjunction; ERG ergative; EXC exclusive; GEN genitive; GENR general; $\mathrm{H}_{\mathrm{abs}}$ absolutive high edge tone; $\mathrm{H}_{\text {coord }}$ coordination high edge tone; $\mathrm{H}_{\text {front }}$ fronted expression high edge tone; $\mathrm{H}$ high edge tone; INA verbal suffix -a/ina; NEG negation; NSPEC nonspecific; O object; OBJ object; OBL oblique; PERF perfective; PNI pseudo noun incorporation; PRES present; S subject; SG singular; SPEC specific; TAM tense-aspect marker; TOP topic marker; V verb.
} 
Maban, Nilotic languages, e.g., Maasai and Shilluk (Dryer 2013), Tibeto-Burman languages, e.g., Loloish/Yi and Kuki-Chin languages (Henderson 1967; Sun 1996; 2010), and languages of West Africa, e.g., Igbo (Hyman 2011b:203-204). (See supplementary material in OSF repository for details.) Rather, the discussion in the literature on Samoan prosodic interfaces has centered on two related questions that probe the nature of the syntax-prosody interface and the relation between tone and intonation: (i) what is the relation between the $\mathrm{H}_{\mathrm{abs}}$ and other case markers in Samoan, which are all segmental?, and (ii) what is the relation between the $\mathrm{H}_{\mathrm{abs}}$ and other high edge tones in Samoan that co-occur with fronted expressions $\left(\mathrm{H}_{\text {front }}\right)$ and coordination $\left(\mathrm{H}_{\text {coord }}\right)$ ?

This paper builds on Yu and Özyıldız (2016), Yu and Stabler (2017) in proposing that: (i) $\mathrm{H}_{\mathrm{abs}}$ is a tonal case marker that may be related to an apparently moribund stressed, segmental absolutive particle ['ia], and that (ii) $\mathrm{H}_{\mathrm{abs}}, \mathrm{H}_{\text {coord }}$, and $\mathrm{H}_{\text {front }}$ are all syntactically determined and each inserted in the spellout of distinct syntactic configurations (absolutive case, fronted expressions, coordination). What this paper contributes beyond Yu and Özylldız (2016), Yu and Stabler (2017) is the actual empirical data that a high edge tone co-occurs with absolutive arguments, which is taken for granted in those papers (unpublished, previous versions of this paper are cited as $\mathrm{Yu}$ (2016) in Yu and Özyıldız (2016) and Yu (2017) in Yu and Stabler (2017)), as well as a detailed discussion showing that the proposal here fits the current data better than other alternatives. These alternatives include proposals from Calhoun $(2015,2017)$ that: (i) there is no relation between $\mathrm{H}_{\mathrm{abs}}$ and other case markers because $\mathrm{H}_{\mathrm{abs}}$ is not a case marker; (ii) instead, $\mathrm{H}_{\mathrm{abs}} \mathrm{H}_{\text {front }}$, and $\mathrm{H}_{\text {coord }}$ are some among many sentencemedial prosodic boundary tones ('H-') unified by their association to the right edge of phonological phrases. Calhoun (2015) proposes that these phonological phrases come from mapping between syntactic and prosodic constituents, while Calhoun (2017) updates the proposal, implying that they are mapped from information structure rather than syntax.

In adjudicating between these proposals, I challenge common working assumptions about the syntax-prosody interface: that (i) edge tones are invariably prosodic boundary tones that come into the syntax-phonology interface via the mapping between syntactic and prosodic domains, and (ii) a unified analysis of edge tones is prima facie preferred.

First, I point out that an edge tone is not necessarily triggered by a prosodic domain edge, although it may happen to appear at the periphery of a prosodic domain such as the edge of a prosodic word. The term 'edge tone' is often taken to be interchangeable with the term '(prosodic) boundary tone' and associated with a "major prosodic boundary," i.e., above the level of a prosodic word - a phonological phrase boundary or intonational phrase boundary (Ladd 2008:44, 47, 100). But in this paper, I use 'edge tone' purely descriptively to refer to what conditions where the tone appears in the surface realization: to roughly distinguish between tones whose phonetic alignment is determined by stress position (pitch accents) and tones whose alignment is determined by morphosyntactic/prosodic word edges (edge tones) (Bruggeman et al. 2017, Sect. 1.1), see Sect. 4.6. Free of the assumption that edge tones are necessarily triggered by prosodic domains, we are free of the task of forcing a very general, unified characterization of the prosodic and/or syntactic environments where high edge 
tones appear, e.g., "high edge tones mark phonological phrase edges" or "high edge tones mark XP edges, which in turn are mapped to phonological phrase edges."

Secondly, this paper points out that relations between syntactic and prosodic domains are not the whole of the syntax-phonology interface. A classic divide between theories of syntax-prosody mapping is between 'direct reference' and 'indirect reference' theories. The key point of contention is whether prosodic structure mediates the effect of syntactic structure on phonological processes; the key point of consensus is that category-specific information is not passed from syntax to phonology. But the question of how Samoan high edge tones fit in the syntax-phonology interface is not limited to deciding whether they can be accounted for by a 'direct reference' or 'indirect reference' theory. There are other aspects to the interface. As stated in Selkirk (2011:435): “Two further core aspects... [are] the phonological realization (spell-out) of the morphosyntactic feature bundles of morphemes and lexical items that form part of syntactic representation and the linearization of syntactic representation which produces the surface word order of the sentence as actually pronounced."

My current analysis of syntactically determined high edge tones in Samoan situates them in these "further core aspects" of the syntax-phonology interface. The point that there are multiple places in the syntax-phonology interface where the high edge tones might be situated leads to the most general point I make in this paper: if there are different factors that underlie high edge tones in Samoan, then these need to be recognized to further understanding of the phenomenon. I show that a fine-grained analysis fits the current data. Syntactically determined high edge tones in Samoan are inserted in the spellout of specific, distinct configurations (absolutive case marking $\left(\mathrm{H}_{\mathrm{abs}}\right)$, coordination $\left(\mathrm{H}_{\text {coord }}\right)$, and fronting $\left.\left(\mathrm{H}_{\text {front }}\right)\right)$. Crucially, these are not inserted by the phonological grammar as tones marking prosodic domains, and therefore, their presence and placement are completely determined by syntactic factors and not conditioned by prosodic factors.

There is also evidence of sentence-medial prosodic boundary tones in Samoan. Calhoun (2017) and Yu and Stabler (2017) uncovered that there are high (and low) edge tones that variably appear in variable syntactic environments, and that typically co-occur with pauses. I hypothesize that these tones, annotated here as $\mathrm{H} \%$ and $\mathrm{L} \%$, come into the syntax-phonology interface not in spellout, but in marking prosodic constituent domains. Note that to keep the different kinds of high edge tones in my proposal straight, I don't use 'H-' as a unified annotation for all high edge tones in this paper, unlike previous literature on Samoan prosody, although I retain ' $\mathrm{H}$-' notation when citing previous literature. Instead, I use a bare ' $\mathrm{H}$ ' as an annotation for a high edge tone, i.e., 'Hs' refers to high edge tones, with the syntactic configuration proposed to be conditioning the tone subscripted, if relevant, e.g., $\mathrm{H}_{\mathrm{abs}}$. Prosodic boundary tones typically occurring with pauses are annotated with ' $\%$ ' diacritics, which are commonly used in prosody to denote intonational phrase tones.

The rest of this paper is organized as follows: Sect. 2 presents background on the Samoan language and Samoan prosody; Sect. 3 describes the design and procedure in elicitations and data analysis. Then, Sect. 4 presents distributional data showing that an $\mathrm{H}_{\mathrm{abs}}$ co-occurs with absolutive arguments in a variety of syntactic structures. These include transitive and intransitive sentence frames, with varying word orders, where absolutive arguments tested include singular and plural, specific and 
non-specific nominals, pronouns, and arguments internal to nominalizations. I also present evidence that the $\mathrm{H}_{\mathrm{abs}}, \mathrm{H}_{\text {coord }}$, and $\mathrm{H}_{\text {front }}$ are edge tones. Following this presentation of distributional data, I lay out and defend my proposal that $\mathrm{H}_{\mathrm{abs}}, \mathrm{H}_{\text {coord }}$, and $\mathrm{H}_{\text {front }}$ are inserted in the spellout of specific syntactic configurations in Sect. 5 and show that my proposal fits the current data. I then discuss alternative analyses of high edge tones in Samoan in Sect. 6 and show that they do not fit the current data as well as my analysis and conclude with Sect. 7. Supplementary materials for this paper can all be found at the OSF repository: https://osf.io/8cvg5/?view_only= e9be8cb15097493897b826f53487e345.

\section{Language background}

Samoan is an Austronesian language from the Independent State of Samoa and the (U.S.) Territory of American Samoa, with about 413,000 speakers in all countries (Lewis et al. 2014). It is in the Polynesian family in the Samoic-Outlier branch (Pawley 1966, 1967), which has a number of ergative-marking languages, including Samoan.

\subsection{Segmental phonology and word stress}

All Samoan examples in this paper are given using IPA symbols and appear in square brackets when in-line in the text. In-line in the text, I occasionally use Samoan orthography (always italicized), where [ $\mathrm{y}]$ is written as $g$, length as a macron, e.g., $\bar{a}$, and [?] as '.

The inventory of phonotactically licit syllable shapes in Samoan is limited to those in which every consonant is followed by a vowel: monomoraic $[(\mathrm{C}) \mathrm{V}]$, and bimoraic $[(\mathrm{C}) \mathrm{V}:]$ and $[(\mathrm{C}) \mathrm{VV}]$. The basic footing pattern, as observed in monomorphemes, consists of a moraic trochee at the right edge of the word (Zuraw et al. 2014). Primary stress is on the final vowel if it's long, and otherwise on the penultimate vowel. Further details on Samoan stress assignment are in Zuraw et al. (2014).

Primary stress is associated with a pitch accent, which is consistently phonetically realized with increased relative amplitude, longer duration, and a rise in fundamental frequency (f0). However, the presence of pitch accents associated with secondary stress is inconsistent. In this paper, I refer to both morae and syllables interchangeably; when I refer to syllables in the context of figures (where I often annotate syllables, e.g., 'S1' for first syllable), I always mean light syllables.

\subsection{Case-marking and word order}

Samoan has default VSO word order and marks ergative case on the subject of a verbinitial transitive sentence with the preposition [e], as exemplified in the transitive sentence in (2a). 'Absolutive' case on the direct object of a transitive sentence and the subject of an intransitive sentence has been said to be unmarked (Chung 1978:54-56; 
Ochs 1982:649; Collins 2014:94), but in (2), I indicate where the absolutive H appears. The intransitive sentence $(2 \mathrm{~b})^{3}$ also illustrates the prepositional element [i] as a marker of oblique case. This preposition marks stative agents (see Chung 1978:29), indirect objects, locatives, temporal expressions, sources, and goals (Mosel and Hovdhaugen 1992:144). Before pronouns and proper names, $i \bar{a}$ [ja:] rather than [i] marks oblique case. Figure 1 displays f0 contours for these sentences. The intonational annotations are explained in Sect. 2.3.1.

(2) Case-marking in transitive and intransitive sentences ${ }^{4}$

a. Transitive clause

na la'laya $*(e)$ le ma'lini $\mathbf{H}_{\mathbf{a b s}}$ le ma'manu.

PAST weave ERG DET marine ABS DET design

'The marine wove the design.'

b. Intransitive clause

na ya'lue $\mathbf{H}_{\text {abs }}$ le ma'lini (i le ma'manu). PAST work ABS DET marine OBL DET design

'The marine worked (on the design).'

Case-marking exponence in Samoan is affected by register and word order. Samoan is well-known for having two distinct registers: tautaula lelei 'good language' - used in literary contexts and Westernized institutional contexts like in church and school, as well as with foreigners, and tautaula leaga 'bad language'used in traditional ceremonies and meetings, as well as between family members and between friends (Shore 1977, 1980; Duranti 1981:165-168; Ochs 1988:196; Duranti 1990:4-5; Mosel and Hovdhaugen 1992:7-11). One of the most striking contrasts between the two registers is in the segmental phonology: $/ \mathrm{t} /$ and $/ \mathrm{k} / \rightarrow / \mathrm{k} /$ and $/ \mathrm{n} /$ and $/ \mathrm{y} / \rightarrow / \mathrm{y} /$ from tautaula lelei to tautala leaga.

The segmental ergative case marker $e$ is rarely used in tautala leaga (Mosel and Hovdhaugen 1992:9). Ochs (1982) found that the frequency of use of the ergative case marker $e$ is quite variable across social contexts: in utterances with postverbal agents, in a corpus of adult Samoan speech, the presence of $e$ ranged from $20 \%$ between family members to $75 \%$ in informal interactions between male non-family members and in discussion between titled men in formal village meetings (Ochs 1982: Table 1). Ochs (1982) also found substantial variability in word order choices in adult speech: $34.7 \%$ of the utterances were VSO order, $36.0 \%$ VOS order, $20.0 \%$ SVO order, and $9.3 \%$ OVS order (see Ochs 1982: Table 12). ${ }^{5}$

\footnotetext{
${ }^{3}$ While (2b) has VOS word order like (1b), it is a different kind of construction. In (2b), there is an ergative subject; in (1b), there is not. I will distinguish these two kinds of VOS constructions by using [VO]S bracketing for ones like (1b), but no bracketing for ones like (2b). [VO]S constructions are discussed in detail in Sect. 4.4.

${ }^{4}$ For brevity, the morpheme le is glossed as DET, a determiner marking specificity on singular nouns, except when specificity is relevant.

${ }^{5}$ Based on (1) in Ochs (1982), it appears that VOS order refers to a different kind of VOS construction than the [VO]S construction exemplified in (1b); see fn. 3 in this paper for more details. The two different kinds of constructions are not distinguished in the frequency counts.
} 
In non verb-initial word orders, no ergative, absolutive or oblique case-marking occurs on fronted nominals, as shown in (3), but fronted nominals are preceded by [?o], which I gloss as TOPIC. See Fig. 7 in Yu and Stabler (2017) for a representative f0 contour of (3a).

(3) No case marking on fronted DPs in non verb-initial word order 6

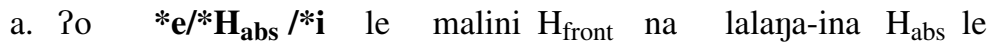
TOPIC ERG/ABS/OBL DET marine FRONT PAST weave-INA ABS DET mamanu. design

'It was the marine that wove the design.'

b. ?o $* \mathbf{e} / * \mathbf{H}_{\mathbf{a b s}} / * \mathbf{i}$ le malini $\mathrm{H}_{\text {front }}$ na jalue (i le TOPIC ERG/ABS/OBL DET marine FRONT PAST work (OBL DET mamanu). design)

'It was the marine that worked on the design.'

\subsection{Overview of intonational system}

In this section, I build on the background presented thus far on Samoan word-level prosody and morphosyntax to introduce the most relevant aspects of the intonational system of Samoan for this paper (see Orfitelli and Yu 2009, Zuraw et al. 2014, Calhoun 2015, 2017, Yu and Stabler 2017, Howard 2018 for more on other aspects of Samoan intonation not covered here). First, I explicate the intonation of the basic declarative in (2) in Sect. 2.3.1. Then I highlight the aspect of the intonational system that is the focus of this paper: the existence of sentence-medial high edge tones (Sect. 2.3.2).

\subsubsection{A first example}

Figure 1 is a side by side comparison of the f0 contours and intonational transcriptions for representative utterances of the transitive and intransitive declaratives in (2). There are three different types of intonational events annotated. There is an ' $\mathrm{LH}^{*}$,' which is realized over the verb [la'laya] 'weave' in Fig. 1a and [ya'lue] 'work' in Fig. 1b, as well as over [ma'lini] 'marine' and [ma'manu] 'design' in both figures. There is also an 'L\%' utterance-final fall that occurs at the end of both the declaratives. Finally, there is an $\mathrm{H}_{\mathrm{abs}}$ annotated at the right edge of [ma'lini] in Fig. 1a and [ya'lue] in Fig. $1 \mathrm{~b} . \mathrm{H}_{\mathrm{abs}}$ is discussed in detail in the following section.

I use ' $\mathrm{LH}^{*}{ }^{7}$ to annotate a rising pitch accent, where the '*' is a diacritic from autosegmental-metrical theory (see Ladd 2008 for an overview) that indicates pitch

\footnotetext{
${ }^{6}$ While I asked for acceptability judgments from consultants for the segmental case markers, I did not for the Hs: throughout this paper, the '* $\mathrm{H}$ ' is intended to indicate that no $\mathrm{H}$ ever occurred in productions of the sentence.

${ }^{7}$ I follow Orfitelli and $\mathrm{Yu}$ (2009), Zuraw et al. (2014) and remain agnostic about how the L and/or H is/are associated to the stressed syllable, and thus use the transcription $\mathrm{LH}^{*}$ instead of $\mathrm{L}^{*}+\mathrm{H}$ or $\mathrm{L}+\mathrm{H}^{*}$.
} 


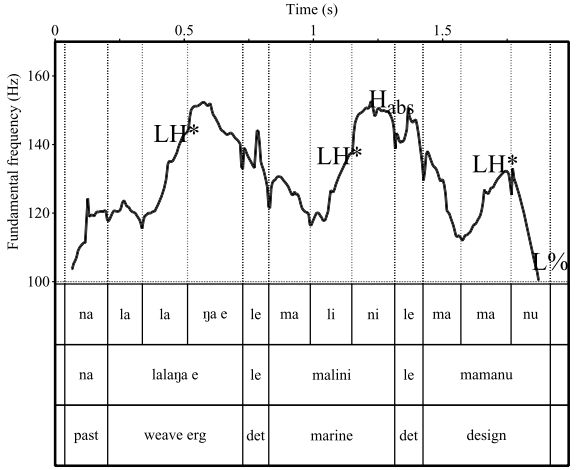

(a) Transitive declarative, (2a)

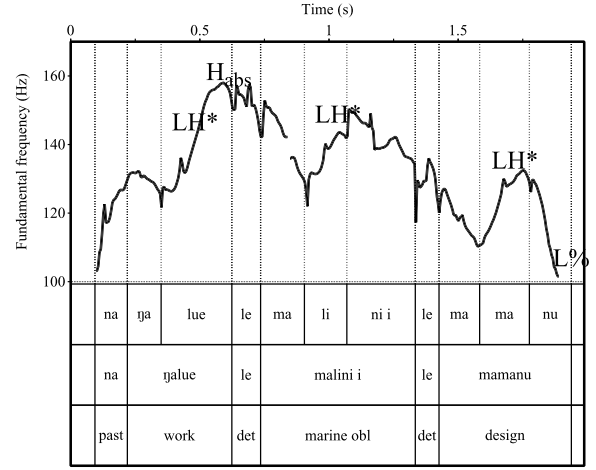

(b) Intransitive declarative, $(2 \mathrm{~b})$

Fig. 1 F0 contours in the basic declaratives from m01: transitive clause (2a) [na la'lana e le ma'lini le ma'manu] 'The marine wove the design' and intransitive clause ( $2 \mathrm{~b}$ ) [na ya'lue le ma'lini i le ma'manu] 'The marine worked on the design.' Pitch accent rises (LH*) occur over primary stressed syllables. An $\mathrm{H}_{\mathrm{abs}}$ occurs before the absolutive object in Fig. 1a and before the absolutive subject in Fig. 1b. As in all individual f0 contours shown in this paper, the dashed lines overlaying the fo contour mark syllable divisions given in the second tier of the textual transcriptions at the bottom of the figures

accents, and ' $\mathrm{L}$ ' stands for a low f0 target. $\mathrm{LH}^{*}$ pitch accents are associated to the primary stressed, penultimate syllables of [la'laya], [ya'lue], [ma'lini], and [ma'manu] (see Sect. 2.1 for a description of stress assignment in Samoan). ${ }^{8}$ The low target ' $L$ ' typically appears to be aligned to the beginning of the stressed mora. The high peak of the pitch accent is typically aligned at the right edge of the syllable it's associated with, or in the syllable following. This phenomena of PEAK DELAY is observed crosslinguistically (Silverman and Pierrehumbert 1990; Xu 1999, 2001; Myers 2003), and can also be observed in many other f0 contours in this paper, e.g., Figs. 10b, c; 7a, b, c.

The 'L\%' utterance final fall will not be of central importance for this paper.' I will, however, introduce and discuss sentence-medial falls to a low tone later in Sects. 5.2 and 6.3.1. I hold off introducing them until they can be put into context together with the sentence-medial high tones.

\subsubsection{A first encounter with sentence-medial high edge tones}

Looking at the f0 contours and their intonational transcriptions in Fig. 1, the reader may wonder how one could reliably and confidently transcribe $\mathrm{Hs}$ like $\mathrm{H}_{\mathrm{abs}}$ : the rises in the f0 contours for $\mathrm{LH}^{*} \mathrm{~s}$ and $\mathrm{H}_{\mathrm{abs}}$ look quite similar. This is an issue I address further in the discussion of methods of analysis in Sect. 3.3.1. For now, I'll point out that while the rises for $\mathrm{LH}^{*} \mathrm{~s}$ and Hs may look quite similar in Fig. 1, it turns out that they show systematic differences in phonetic realization. This is apparent

\footnotetext{
${ }^{8}$ Note also that f0 rises over the (stressless) tense-aspect marker (TAM) $n a$ 'PAST' even though it's followed by an unstressed syllable. The slope of utterance-initial f0 rises appears to vary quite freely, but a rise is typically present.

${ }^{9}$ See Calhoun (2015) for examples of f0 contours of declaratives that do not end in final falls. In Orfitelli and $\mathrm{Yu}$ (2009), Yu (2011), Yu and Stabler (2017), the utterance final fall was annotated as 'L-L\%'; here I use 'L\%', consistent with Calhoun $(2015,2017)$.
} 


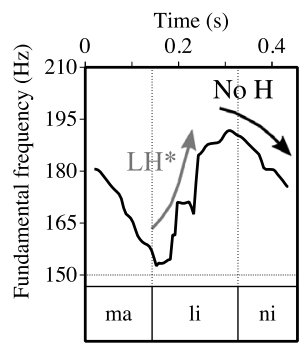

(a) LH* pitch accent only

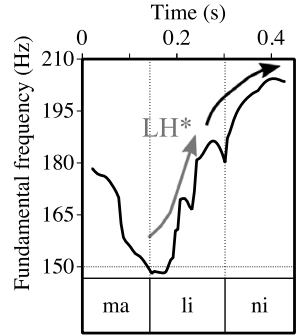

(b) $\mathrm{LH}^{*}$ pitch accent followed by $\mathrm{H}$

Fig. 2 Phonetic realization of a sentence-medial high edge tone (annotated $\mathrm{H}$ ) at the right edge of [ma'lini] 'marine' in the f0 contour, from $\mathrm{m} 01$. This is demonstrated by contrasting: (a) when an $\mathrm{H}$ is absent at the right edge of intransitive subject malini in VS-PP sentence (2b), vs. (b) when an $\mathrm{H}$ is present at the right edge of transitive subject malini in the VSO sentence (2a). In both figures, malini receives an $\mathrm{LH}^{*}$ pitch accent associated to the stressed penultimate mora

if we zoom in on the f0 contour just over [malini] 'marine' in Fig. 1, as shown in Fig. 2. Let me emphasize here that the $\mathrm{H}$ at the right edge of [malini] in Fig. $2 b$ is not triggered because [malini] is an absolutive argument. Rather, the $\mathrm{H}$ is triggered by the immediately following absolutive argument [le mamanu] 'DET design'. That is, the $\mathrm{H}_{\mathrm{abs}}$ is realized at the right edge of the word preceding the absolutive argument. This adds to the puzzles raised by the proposal of an absolutive tonal case marker in Sect. 1. While any reasonable syntactic theory would group the absolutive case head with the following DP, the $\mathrm{H}_{a b s}$ appears to be phrased to the left. I address this potential 'boundary paradox' between syntactic and prosodic constituency in Sect. 5.3.

Looking at Fig. 2, if the immediately following tonal event after the pitch accent on malini 'marine' is another pitch accent, e.g., an LH* on mamanu 'design' in (2b), then the f0 contour over malini falls after the high f0 peak over the last syllable towards the low target (L) of this next pitch accent, as in Fig. 2a. If however, an $\mathrm{H}_{\mathrm{abs}}$ is present, then the fo contour continues to rise over the last syllable of malini, e.g., in (2a), as in Fig. 2b. Throughout this paper, f0 contour data also shows that f0 often continues to stay high even into the following syllable in the presence of an $\mathrm{H}$ (e.g., the le 'DET' following malini in (2a)). ${ }^{10}$

It is this phonetic contrast in fo contour shape that I use to diagnose sentencemedial Hs in Samoan. Three syntactic configurations have been found that reliably trigger Hs: fronting (i.e., non verb-initial word orders), coordination, and absolutive case (Orfitelli and Yu 2009; Yu 2011; Calhoun 2015, 2017; Yu and Stabler 2017). These configurations are all exemplified in the $\mathrm{f} 0$ track of a representative utterance of (4) shown in Fig. 3. The Hs in (4) are bolded for clarity. The position of these Hs in the $\mathrm{f} 0$ contour is indicated in Fig. 3 by the time-alignment of the $\mathrm{H}$ annotations to the $\mathrm{f} 0$ contour. For example, the annotation ' $\mathrm{H}$ front' is time-aligned to the f0 contour at the right edge of the ' $o$-marked fronted argument [?o le malini] 'TOP DET marine'.

${ }^{10}$ As shown in Yu and Stabler (2017), the contrast between f0 contour shape when an H is present and when an $\mathrm{H}$ is absent remains even as speech rate increases. 
Fig. 3 An f0 contour demonstrating $\mathrm{Hs}$ appearing in three different syntactic configurations within the same sentence (4): at the right edge of a fronted argument $\left(\mathrm{H}_{\text {front }}\right)$, at the right edge of the first conjunct $\left(\mathrm{H}_{\text {coord }}\right)$ in verbal and nominal coordinated structures, and at the right edge of the word preceding an absolutive argument $\left(\mathrm{H}_{\mathrm{abs}}\right)$, from $\mathrm{m} 01$. As exemplified for the $\mathrm{H}_{\text {coord }}$ tones, f0 often continues to stay high even into the following syllable in the presence of an $\mathrm{H}$ (see also Sect. 2.3.2)

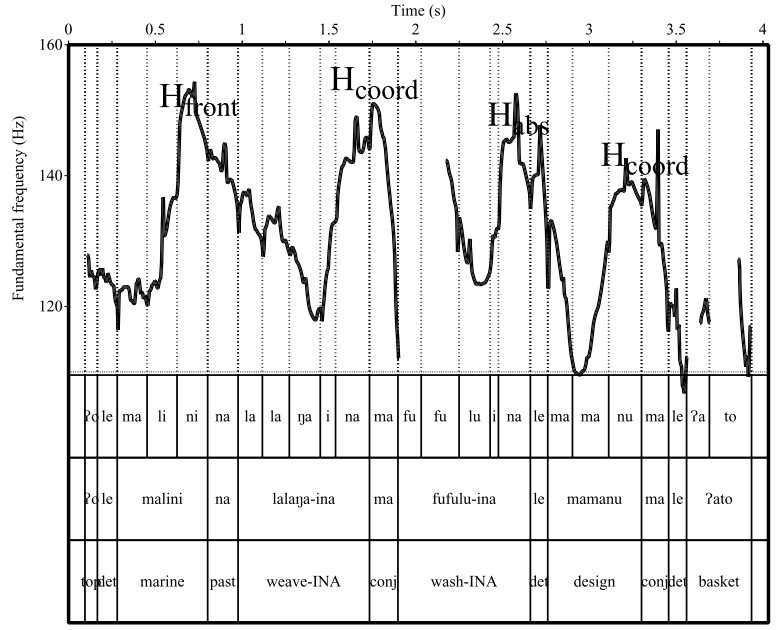

(4) ?o le malini $\mathbf{H}_{\text {front }}$ na lalaya-ina $\mathbf{H}_{\text {coord }}$ ma fufulu-ina $\mathbf{H}_{\mathbf{a b s}}$ TOPIC DET marine FRONT PAST weave-INA COORD CONJ wash-INA ABS

le mamanu $\mathbf{H}_{\text {coord }}$ ma le ?ato.

DET design COORD CONJ DET basket

'It was the marine that wove and washed the design and the basket.'

The three syntactic configurations that trigger Hs, as exemplified in (4) and Fig. 3, are summarized in (5). Where in a sentence each configuration triggers Hs never overlaps, e.g., an $\mathrm{H}_{\text {abs }}$ could never occur where an $\mathrm{H}_{\text {coord }}$ or $\mathrm{H}_{\text {front }}$ could. Representative f0 contours illustrating $\mathrm{Hs}$ in fronting and coordination can be found in $\mathrm{Yu}$ and Stabler (2017: Sect. 4).

(5) Syntactic configurations that trigger Hs, exemplified in (4) and Fig. 3

a. Fronting. An $\mathrm{H}_{\text {front }}$ occurs in non verb-initial sentences, e.g., SVO word order-in (4), at the right edge of the ' $o$-marked fronted argument [?o le malini] 'TOP DET marine' immediately preceding the predicate [na lalana-ina ...] 'PAST weave-INA ...'.

b. Coordination. An $\mathrm{H}_{\text {coord }}$ occurs at the right edge of the first conjunct in a coordinated structure, immediately preceding the conjunction [ma]. In (4), an $\mathrm{H}_{\text {coord }}$ occurs at the right edge of [lalana-ina] 'weave-INA', the first conjunct in a VP-coordination, as well as at the right edge of [le mamanu] 'DET design', the first conjunct in a nominal coordination.

c. Absolutive. In (4), an $\mathrm{H}_{\mathrm{abs}}$ occurs at the right edge of the verb [fufuluina] 'wash-INA', which immediately precedes the (coordinated, postverbal) absolutive argument [le mamanu ma le ato] 'DET design CONJ DET basket'.

Besides using Fig. 3 to introduce syntactic triggers of Hs in Samoan, I have also chosen it to demonstrate some challenges of intonational transcription and illustrate how transcription is analysis, not data. The reader may notice that the f0 contour 
is actually falling in the last mora of [malini], [ni], at the right edge of the fronted argument: this does not look like the f0 contour shape over [malini] in the presence of an $\mathrm{H}$ shown in Fig. 2b; it looks more like the $\mathrm{f0}$ contour shape when the $\mathrm{H}$ is absent, in Fig. 2a. Why then, am I transcribing an $\mathrm{H}$ ? One might have the same worry for the ' $\mathrm{H}$ abs' transcribed at the right edge of [fufulu-ina] 'wash-INA' in Fig. 3: there's a sharp dip in f0 in the last mora [na] right before the absolutive argument [le mamanu ma le ato] 'DET design CONJ DET basket'. It is perhaps not very satisfying for the reader if I say that I am nevertheless confident that there are Hs in these locations, based on experience from listening to and prosodically analyzing thousands of Samoan utterances: these sound like Hs to me. I can make an attempt to reconstruct from the acoustic signal why I perceive Hs here. One can see that the topline (the line connecting the peaks in the fo contour) stays high at these points (cf. the downtrend in f0 in Fig. 1), and also the f0 shoots very high and although it doesn't stay high over the last mora [ni] in [malini] and [na] in [fufulu-ina], it falls only towards the very end of it, not over the whole mora. ${ }^{11}$ At the right edge of [fufulu-ina], there also seems to be some segmental perturbation of the fo contour due to properties of the articulation of the lateral; in this particular utterance of le immediately following [fufulu-ina], the lateral in le is pronounced as an alveolar lateral tap or flap, [I] (an allophonic variant of /l/ I've observed in Samoan speakers), which could be contributing to the f0 dip seen in the realization of the $\mathrm{H}_{\mathrm{abs}}$. These kinds of observations and tricky (sometimes even ineffable) judgment calls underlie every single $\mathrm{H}$ (and any other tonal event) transcribed, and of course different transcribers might make different judgments. The way I set up phonetic analyses in this paper to support my claims about the distribution of $\mathrm{Hs}$ is designed to circumvent these transcriptional issues as much as possible, as I explain in Sect. 3.3.1.

\section{Materials and methods}

All data referred to in this paper were elicited and recorded from my consultants' speech. Information about the consultants is given in Sect. 3.1. Information about elicitation procedures is provided in Sect. 3.2, and the methods used for phonetic and phonological analysis of the data are explicated in Sect. 3.3. All data and analyses can be found at the OSF repository: https://osf.io/8cvg5/?view_only= e9be8cb15097493897b826f53487e345. The repository is structured with the same organization as the paper. For each data set discussed, the repository includes the full stimulus set, recordings, annotated TextGrid files, f0 estimations extracted, and $\mathrm{R}$ code to quantitatively analyze the f0 contours and produce the figures.

\subsection{Consultants}

Data were collected in the Los Angeles area in one- to two-hour sessions from September 2007 to December 2014 and July 2016 with one main consultant (m01),

\footnotetext{
${ }^{11} \mathrm{f} 0$ not staying high over the final mora in $\mathrm{H}$ realization as seen here is not an isolated occurrence; I have observed this in other recordings as well. Figure 4 and fn. 6 in Calhoun (2017) provide another example of a transcribed $\mathrm{H}(\mathrm{H}-)$ where f0 doesn't stay high over the final mora [na], in this case in the proper name Melina.
} 
aged 19 when I started working with him, who was born and raised in Upolu and had moved to the Los Angeles area four years previously. Data were also elicited and recorded from four consultants in Apia, Samoa in November 2011 (s13, s18, s19, s20), and an additional woman in her 50s in the Los Angeles area in January 2012 (s22). The additional consultant in Los Angeles had been in the United States for 27 years, but regularly spent an extended part of the year in Samoa. The consultants in Samoa included three men, aged 21 to 23 (s18-s20), and one woman aged 46 (s13) from the capital city of Apia and other areas of Upolu. ${ }^{12}$ Data were also elicited and recorded in Auckland, New Zealand in July 2015 from two additional women. One (f03) was 48 and had grown up in Apia and moved to New Zealand from there in 2009; the other (f05) was aged 19 and had grown up in Savai'i and been in New Zealand since age 10. All of them spoke primarily Samoan in daily life and were literate in Samoan, but also spoke English as a second language with some fluency. English was used as the contact language. For one consultant, s22, recordings were made both in the style of how one would speak in church (s22c) as well as to a sibling (s22s); since no detectable differences in prosodic patterns occurred between these two styles, the data from the two styles for this consultant were combined.

\subsection{Elicitation procedures}

Procedures for elicitations with the primary consultant are described below in Sect. 3.2.1, and procedures for the other consultants are described in Sect. 3.2.2. Technical details of recording are in Sect. 3.2.3.

\subsubsection{Primary consultant}

Elicitation sessions with the primary consultant m01 and also f03 in Auckland involved either (i) developing and/or checking words and sentences to be recorded, or (ii) recording sessions. In sessions involving the development of stimuli, the consultant was asked to help construct Samoan sentences either from some starting scenario or from an English sentence, to judge whether Samoan sentences from the literature or constructed by the author were licit, and to provide alternative ways to construct sentences, if any. During recording sessions, elicitation items were presented individually written on slides on a computer screen, and they were elicited in randomized order. Different constructions were included in each elicitation session, so that one construction served as a filler for another construction; this prevented minimally different sentences from being presented adjacently. The consultant was asked to read each sentence twice. All data in this paper from the primary consultant was elicited in tautala lelei. No systematic discourse context was provided for recording sessions: sentences were elicited "out-of-the-blue" unless pronouns or pro-drop was present, in which case a context was provided with a referent. ${ }^{13}$

\footnotetext{
${ }^{12}$ The work here all concerns Samoan as spoken in Samoa, and not Samoan spoken in American Samoa. Mosel and Hovdhaugen (1992:8) wrote: "Today we find a very marked difference in intonation between the two variants [from Samoa vs. American Samoa]."

${ }^{13}$ Data from systematic manipulation of discourse context in Yu and Stabler (2017) is briefly reviewed in Sect. 4.5.2; to preview, the presence of the $\mathrm{H}_{\mathrm{abs}}$ is insensitive to these manipulations.
} 


\subsubsection{Other consultants}

Since there was only a limited time to work with the other consultants, the elicitation procedure was necessarily different than for the primary consultant: these other consultants weren't used to the fieldwork elicitation context. The stimuli consisted of mostly sonorant sounds, sometimes at the expense of the plausibility of the sentences. Thus, recording sessions were preceded by an explanation that some of the sentences might be strange-like something out of a fairy tale-e.g., stories about different animals living together in a house. Consultants were also given the opportunity to skim through the sentences prior to recording for familiarization. The consultants were also told to flag any sentences that they thought didn't sound like Samoan, but like a foreigner trying to speak Samoan. Finally, consultants were asked to speak as if they were speaking to a friend to avoid heavily phrased, dictation-style reading (see Sect. 3.1 and OSF repository). One speaker responded to this instruction by speaking with segmental characteristics of tautala leaga, with $[\mathrm{t}] \rightarrow[\mathrm{k}]$ and $[\mathrm{n}] \rightarrow[\mathrm{y}]$. If the consultant flagged a sentence, then the consultant was reminded that some sentences might make sense only in a fairy tale, and sometimes a richer background context for the sentence was explicated. If the consultant still found the sentence problematic, then they were asked to repair it, and a note was made that the sentence wasn't licit for the consultant. This happened with verb-initial, non-VSO word order for one consultant in particular, who repaired the sentences by putting them in VSO word order. The consultants' understanding of the sentence meaning was also often checked as sentences were recorded, especially for more complex sentences. Otherwise, elicitation sessions were the same as for the primary consultant, i.e., different constructions serving as fillers for one another presented in randomized order, two fluent repetitions elicited per stimulus, etc.

\subsubsection{Recordings}

Recordings made in Samoa and Los Angeles before 2015 were made directly to a computer through a head-mounted microphone (Shure SM10A), whose signal ran through a Shure $\mathrm{X} 2 \mathrm{u}$ pre-amplifier and A-D device; recordings in Auckland and Los Angeles after 2015 were made to a Marantz PMD661 MKII. Recordings were made at a sampling rate of $22,050 \mathrm{~Hz}$ with 16-bit precision. Recording sessions in Los Angeles were made in either a sound-attenuated booth or a quiet room, and recordings in Auckland were made in a quiet room. Recordings in Apia, Samoa were also made in a quiet room insofar as possible; sometimes sudden torrential downpours produced substantial background noise.

\subsection{Analysis}

\subsubsection{Minimal comparisons as a strategy for diagnosing $\mathrm{Hs}$}

While I did intonational transcriptions for the data, my main strategy for diagnosing $\mathrm{Hs}$ in $\mathrm{fo}$ contours was to perform phonetic comparisons of f0 contours within 
minimal sets (Yu 2014), a classic methodological strategy exemplified by Bruce's (1977) foundational study of Swedish intonation (see also Yu and Stabler 2017 and Fig. 3 in Clemens and Coon 2016 for additional example of comparisons of this type). A minimal set was designed, as much as possible, to systematically vary only in a single factor of interest, while holding other factors constant. Hs were not diagnosed on an utterance-by-utterance basis, analyzing each utterance in isolation. An example of minimal comparison is how I explicated diagnosing the $\mathrm{H}$ in the f0 contour in Fig. 2b only in comparison with the f0 contour in Fig. 2a. Note that while I designed elicitations using minimal sets, I did not elicit minimal sets-as stated in Sect. 3.2, sentences were presented in randomized order in elicitation sessions.

An advantage of using minimal comparisons to diagnose $\mathrm{Hs}$ is that the comparisons help control for allophonic variation in the realization of Hs. As an example, one phonetic factor conditioning allophonic variation is tonal crowding, which occurs when there is close spacing between neighboring tonal events (Bruce 1977; Pierrehumbert 1980; Gordon 2000; Arvaniti et al. 2006; Gordon 2014, et seq.). In some cases, tonal crowding can even result in the neutralization of tonal distinctions which would be present if there were more segmental material available between the crowded tones (Pierrehumbert 1980:112-113). With minimal comparisons, even for sentences with substantial tonal crowding around the site of the $\mathrm{H}$, one still might be able to diagnose an $\mathrm{H}_{\mathrm{abs}}$ if there is a distinct contrast in f0 contour shape between different sentences where case is systematically varied. However, in the examination of the f0 contour for just a single utterance at a time, judging the presence or absence of an $\mathrm{H}$ might be quite difficult and subjective, as demonstrated in the discussion of Fig. 3 in Sect. 2.3.2.

In addition, this approach comparing f0 contours is advantageous because it stays close to the raw phonetic data, and all the choices made in processing the f0 data are transparent and reproducible if the code written for the analysis is released. In contrast, transcriptional analysis is well-known to vary between transcribers, as measured in studies of intertranscriber reliability (Ostendorf et al. 1995; Gut and Bayerl 2004; Yoon et al. 2004; Cole et al. 2010; Breen et al. 2012). The comparative approach I take here precludes the transcriber from imposing any subjective biases in transcription, and it releases the transcriber from making difficult judgment calls for transcriptional labels.

But this comparative, phonetic approach is only possible when enough is known about the basic atoms of the intonational system and what conditions them so that the researcher can design structured, targeted elicitations to home in on how some particular factor conditions these basic atoms. And initial discovery of these basic atoms is facilitated by the challenge of labeling them in transcription. That is to say, the phonetic, comparative approach taken here doesn't replace intonational transcription, but complements it and relies on insights from it. In this paper, I focus on analyzing f0 data local to sites in the sentence where I am testing for potential Hs. The transcriptional analysis in Calhoun $(2015,2017)$ complements this local, phonetic approach by analyzing whole f0 contours over utterances with intonational transcription to study non-local intonational patterns. 


\subsubsection{Data processing and analysis}

All sound files were segmented and annotated using Praat (Boersma and Weenink 2012). Utterances were segmented by word and syllable and transcribed intonationally by the author. F0 extraction was performed using Praat's autocorrelation algorithm, as implemented in VoiceSauce v1.19 (Shue et al. 2011), software for automatic voice quality analysis, with the floor and ceiling values for candidate f0 set to $40 \mathrm{~Hz}$ and $300 \mathrm{~Hz}$, respectively, and default settings for other parameters. For the f0 contours plotted throughout the paper, f0 values were averaged over each of 10 time slices uniformly dividing each syllable for each utterance throughout the paper, e.g., the first f0 value was the average f0 over the first tenth of the syllable. Converting the time scale from absolute time in seconds to time in syllables allowed trends in the shape of fo contours to be captured without the noise introduced by variable speech rates.

All further data processing and analysis was performed in R (R Core Team 2014). For data sets from multiple speakers, f0 values were $\mathrm{z}$-score normalized so that values would be comparable across speakers with different f0 ranges. The result of this normalization is to have scaled f0 values within a speaker such that the speaker's f0 values have a mean of 0 and standard deviation of 1 . Trends in f0 contour shape were visualized by plotting computed means and standard error for f0 data aggregated across sentences and/or across speakers and computing means and standard error. As a representative example: in Fig. 4, the thick solid black lines show mean f0 contours computed over VOS sentences, and the gray ribbons flanking the lines visualize variability in the f0 contours over these sentences by showing \pm 1 SE ( 1 standard error). The wider the gray ribbons are over some time span, the greater the variability in f0 values about the mean in that time span.

All plots were created using the ggplot 2 package (Wickham 2009). In every plot showing fo contours over a string that includes segmental case markers, these case markers are included as part of the final syllable of the preceding word. The rationale for this is that these monomoraic, vocalic case markers were very difficult to segment from the preceding vowel. (One might then worry that $\mathrm{H}_{\mathrm{abs}}$ is some phenomenon that is a side effect of including segmental markers as part of the preceding word in plots of f0 contours. But Yu and Stabler (2017: Sect. 2.4) analyzed data from utterances elicited in tautala leaga with case markers dropped and found that the $\mathrm{H}_{\mathrm{abs}}$ was still present.)

\section{Evidence for the absolutive $H$}

This section presents distributional evidence that a high edge tone co-occurs with absolutive arguments. Section 4.1 shows that in verb-initial sentences, the high tone reliably occurs before the object in transitive sentences, and Sect. 4.2 shows that it reliably occurs before the subject in intransitive sentences. Section 4.3 shows that this distribution of the high tone also holds for a range of nominal phrases: specific or non-specific, common or proper, pronominals, and arguments within nominalizations. Section 4.4 shows that an $\mathrm{H}$ always occurs before the subject in pseudo noun 
incorporation; however, no $\mathrm{H}$ appears before the pseudo-incorporated object. Section 4.5 shows evidence that the presence of the $\mathrm{H}_{\mathrm{abs}}$ is insensitive to word order in ditransitives and under systematic manipulations of discourse context. Finally, I close the section by presenting evidence that the $\mathrm{H}_{\mathrm{abs}}, \mathrm{H}_{\text {coord }}$, and $\mathrm{H}_{\text {front }}$ are edge tones rather than pitch accents (Sect. 4.6).

\subsection{Transitive sentences}

In transitive sentences, an $\mathrm{H}_{\mathrm{abs}}$ reliably precedes the absolutive argument, whether word order is VSO or VOS. I present evidence for this distribution from manipulating word order (VSO, VOS) in a set of transitive sentences exemplified in (6a), shown with VSO order, recorded with m01. An example of VOS order for (6a) is given in (6b). In VSO order, the first argument takes ergative case; in VOS order, it takes absolutive case.

(6) a. na tatala-(ina) e le tama $\mathbf{H}_{\mathbf{a b s}}$ le faitoto?a. PAST open-(INA) ERG DET boy ABS DET door

'The boy opened the door.'

b. na tatala-(ina) $\mathbf{H}_{\text {abs }}$ le faitoto?a e le tama. PAST open-(INA) ABS DET door ERG DET boy

'The boy opened the door.'

One other factor I varied was whether or not the "transitive" -Cia suffix form -ina was present on the verb. Cook (1999) states that this suffix may be present if word order in a transitive sentence is inverted, with the absolutive object first, while Chung (1978:55) states that VOS and VSO order are about equally common in frequency when the -Cia suffix is present. My primary consultant was happy to suffix a transitive verb with -ina regardless of the word order in the transitive sentence. The purpose of including the -ina suffix was to add additional (sonorant) segmental material before the first argument and thus make the phonetic contrast between the presence and absence of an $\mathrm{H}_{\mathrm{abs}}$ there easier to discern.

Figure 4 summarizes the effect of word order on the f0 contour over the verb and the first argument for the sentences in (6a). ${ }^{14}$ These f0 contour data show that an $\mathrm{H}$ always appears before the absolutive object and never before the ergative subjectregardless of word order, and regardless of whether or not -ina is present. ${ }^{15}$ Fig. $4 \mathrm{a}$ and $4 \mathrm{~b}$ show the contrast in f0 contours over the verb induced by the case of the first argument. Figure $4 \mathrm{a}$ shows the f0 contour over the last two syllables in the (unsuffixed) verb and ergative case marker if present, e.g., tala (e) for tatala 'open', and the determiner $l e$ in the first argument. Figure $4 \mathrm{~b}$ shows the f0 contour over the stem-final

\footnotetext{
${ }^{14}$ The large jumps in the fo contour in the penult in Figs. $4 \mathrm{a}$ and $4 \mathrm{c}$ are due to segmental perturbations from the obstruents in (6a), i.e., ([t,p,?]). The f0 jump in Fig. 4a is particularly dramatic when the first argument is absolutive because of the subsequent f0 rise to the $\mathrm{H}_{\mathrm{abs}}$. These f0 perturbations illustrate why sonorants are favored in intonational fieldwork.

${ }^{15}$ The number of syllables in the arguments and verbs in this stimulus set wasn't constant. But differences in prosodic length cannot account for the f0 patterns in Fig. 4-the same pattern of contrast between VSO and VOS orders was observed individually for each item.
} 

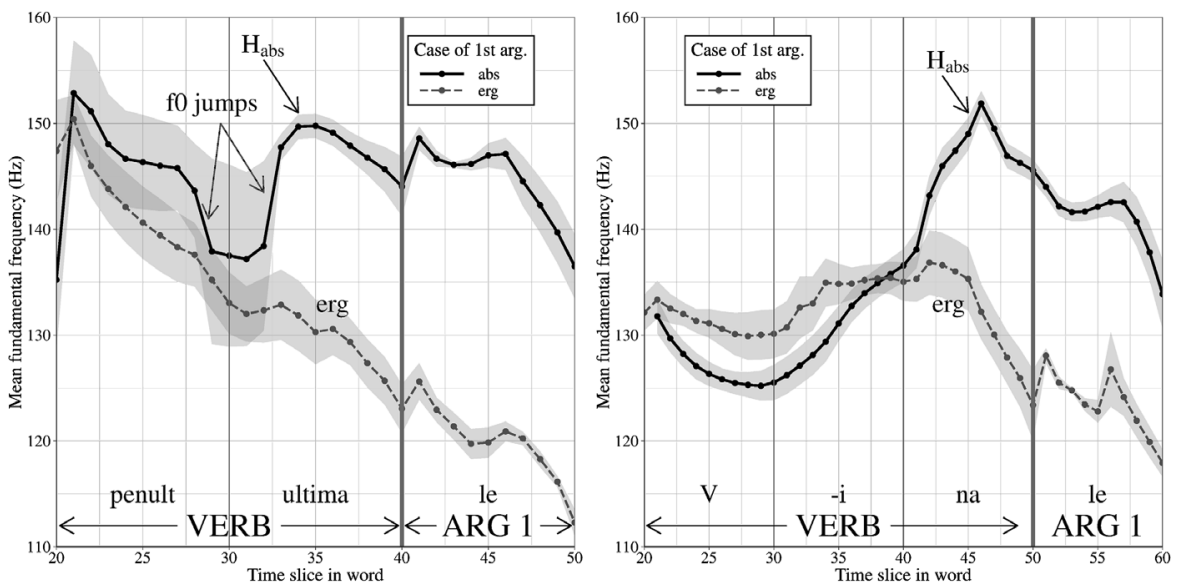

(a) Verb not suffixed with -ina and following le

(b) Verb suffixed with -ina and following le

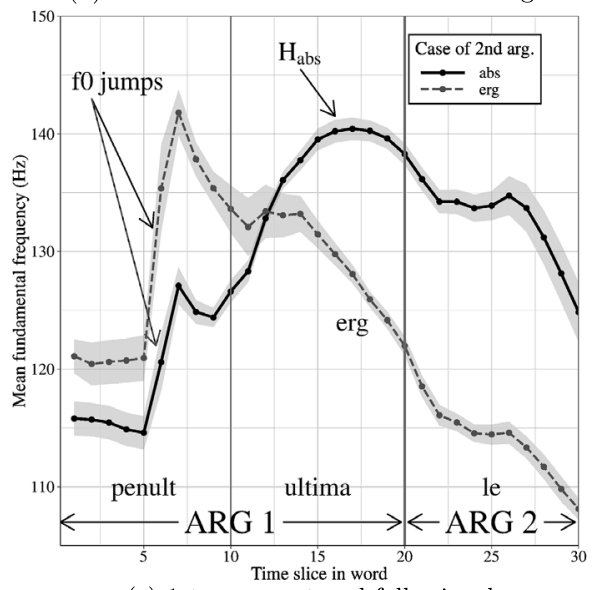

(c) 1st argument and following le

Fig. 4 Comparison of m01's mean f0 contours (37 tokens) for words in transitive sentences for VSO order (ergative subject first, (6a)) vs. VOS order (absolutive object first, (6b)). The large jumps in the f0 contour over the labeled penultimate syllables are due to segmental perturbations from obstruents

vowel of the verb and the -ina suffix (and the ergative case marker, if present), e.g., a-ina (e) for tatala-ina, and the determiner le in the first argument. Whether or not the verb stem was suffixed with -ina, f0 over the final syllable of the verb was $20-30 \mathrm{~Hz}$ higher if the case of the first argument was absolutive (VOS order). This f0 difference persisted into the determiner $l e$ in the first argument following the verb. Figure 4c shows how the case of the second argument affects the f0 contours over the last two syllables of the first argument and the determiner in the second argument, e.g., tama le 'boy DET' for (6a). F0 on the ultima of the 1st argument was also about $20 \mathrm{~Hz}$ higher when the case of the second argument was absolutive (VSO) rather than ergative (VOS); this f0 difference persisted into the determiner le of the second argument as well. 
Fig. 5 A comparison of mean f0 contours over the verb for intransitive sentences from $\mathrm{m} 01$ (54 tokens), like [manoni] 'smelly' in (8) vs. their transitive counterparts, like [layona] 'hear' in (9). When the subject immediately following the verb is absolutive, the f0 contour rises in the 3rd syllable 'S3' to the absolutive high. When the subject immediately following the verb is ergative, the fo contour falls in the $3 \mathrm{rd}$ syllable ' $\mathrm{S} 3$ '

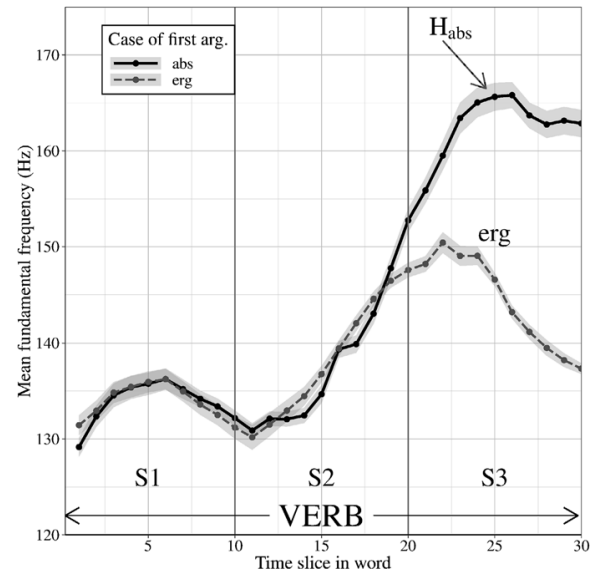

\subsection{Intransitive sentences}

In intransitive sentences, an $\mathrm{H}$ reliably precedes the absolutive subject, as I demonstrate below with data from m01. Section 4.1 already demonstrated that an $\mathrm{H}$ does not occur between the verb and an immediately following ergative subject in a transitive sentence. Thus, the f0 contour over the verb in a VSO transitive sentence can serve as a baseline for how the $\mathrm{f} 0$ contour looks without an $\mathrm{H}$ present, compared to when the $\mathrm{H}$ is present in an intransitive sentence (7).

(7) Is there an $\mathrm{H}$ between the verb and the immediately following argument?

a. Transitive baseline: Verb [ERG Subject] [H Object]

b. Intransitive : Verb [ H? Subject] [OBL DP]

I compared the f0 contours on the verb between intransitive sentences like those in (8) and their nearly string-identical transitive baseline counterparts. These transitive counterparts replaced the intransitive verb [manoni] 'to be smelly/fragrant' with the transitive verb [layona] 'to hear', changed the absolutive subject to an ergative subject, and changed the oblique object to an absolutive object, e.g., (9) is the transitive counterpart to (8).

(8) na manoni $\mathbf{H}_{\text {abs }}$ le manu i le maile i le afiafi. PAST smelly ABS DET bird OBL DET dog OBL DET evening 'The bird was smelly to the dog in the evening.'

(9) na lanona e le manu $\mathbf{H}_{\text {abs }}$ le maile i le afiafi. PAST hear ERG DET bird ABS DET dog OBL DET evening 'The bird heard the dog in the evening.'

Figure 5 shows a clear difference between the mean f0 contour over transitive verb [layona] 'hear' and the mean f0 contour over intransitive verb [manoni] 'smelly/fragrant'. The f0 contour rises over the stressed second syllable (labeled S2) of both verbs. However, the f0 contour over [lajona] drops in the third syllable (labeled S3), while the f0 contour over [manoni] continues to rise and stay high. Thus, 
Fig. 5 shows that, unlike verbs before ergative subjects, verbs before absolutive subjects have an $\mathrm{H}$ realized over the last syllable. In Sect. 4.5.1, I show that $\mathrm{H}_{\mathrm{abs}}$ shows up on oblique PPs before absolutive arguments, too.

\subsection{Other types of nominal phrases}

Thus far, I have only presented distributional data for the $\mathrm{H}_{\mathrm{abs}}$ with specific and common nominal phrases that are singular or plural, such as le manu 'DET.SPEC.SG bird' or manu 'DET.SPEC.PL birds' (DET.SPEC.PL is $\varnothing$ ). If the $\mathrm{H}$ under discussion really is marking absolutive case, then it should appear under all different kinds of absolutive nominal phrases. Not showing that the $\mathrm{H}_{a b s}$ is insensitive to nominal phrase types leaves open the possibility that the $\mathrm{H}$ is marking something more restricted than absolutives. As a case in point, Niuean, a Polynesian language related to Samoan, case-marks different types of nominal phrases differently (Massam 2001:156, (2)):

(10) Niuean case marking (Massam 2001:156, (2))

$\begin{array}{lcc} & \text { ERG } & \text { ABS } \\ \text { Proper/pronoun } & e & a \\ \text { Common } & h e & e\end{array}$

In this section, I provide data on the distribution of the $\mathrm{H}_{\mathrm{abs}}$ in a variety of nominal phrases from Mosel and Hovdhaugen (1992: Ch. 6). I show that the presence of the $\mathrm{H}_{\mathrm{abs}}$ is insensitive to whether the nominal phrase is specific or non-specific or proper or common (Sect. 4.3.1), pronominal or non-pronominal, (Sect. 4.3.2), or internal to nominalizations (Sect. 4.3.3).

\subsubsection{Specificity}

I found that the absolutive high appears before both specific $(11,12)$ and nonspecific nominals $(13,14)$ in data from $\mathrm{f} 03$ and f05. I established the presence of the $\mathrm{H}_{\mathrm{abs}}$ by comparing pitch tracks between sentences where I systematically varied specificity of objects in transitives and PP objects in intransitives. The reason I compared absolutive objects to PP objects is so that I would have controlled prosodic position in the sentence for the minimal comparisons of f0 contours (Sect. 3.3.1). The data set was recorded from two consultants in Auckland, who were provided a context for each sentence (shown below; contexts for the intransitive sentences are analogous and given in the OSF repository). In the examples given below, (11-14), the object is always underlined and $\mathrm{H}_{\mathrm{abs}}$ tones preceding the object are bolded. The presence of an $\mathrm{H}_{\mathrm{abs}}$ before proper names in the intransitive sentences also shows that $\mathrm{H}_{\mathrm{abs}}$ tones occur before proper as well as common nouns.

(11) Specific, singular le

a. Context: Moana asked Manogi to pick the ripest melon at the market and bring it home.

e lePi momoli e Manoni $\mathbf{H}_{\text {abs }} \underline{\text { le }} \underline{\text { meleni i }}$

PRES NEG deliver ERG Manogi ABS DET.SPEC.SG melon OBL

le fale.

DET.SPEC.SG home 
'Manogi didn't bring the melon home yet.'

b. cf. intransitive

e le?i jalue $\mathrm{H}_{\mathrm{abs}}$ Melani $\mathrm{i} \quad \underline{\text { le }} \underline{\text { mamanu }} \mathrm{i}$

PRES NEG work ABS Melani OBL DET.SPEC.SG design OBL

le fale.

DET.SPEC.SG home'

'Melani didn't work on the design at home yet.'

(12) Specific, plural $\varnothing$

a. Context: Moana asked Manogi to pick the biggest three melons at the market and bring them home.

e le?i momoli e Manoni $\mathbf{H}_{\mathbf{a b s}}$ meleni i le fale.

'Manogi didn't bring the melons home yet.'

b. cf. intransitive e le?i yalue $\mathrm{H}_{\mathrm{abs}}$ Melani i mamanu i le fale.

'Melani didn't work on the designs at home yet.'

(13) Nonspecific, singular se

a. Context: Moana asked Manogi to pick any melon at the market and bring it home.

e le?i momoli e Manoni $\mathbf{H}_{\mathbf{a b s}}$ se meleni i le fale.

'Manogi didn't bring any melon home yet.'

b. cf. intransitive e le?i yalue $\mathrm{H}_{\mathrm{abs}}$ Melani i se mamanu i le fale.

'Melani didn't work on any design at home yet.'

(14) Nonspecific, plural $n i$

a. Context: Moana asked Manogi to pick some melons at the market and bring them home.

e le?i momoli e Manoni $\mathbf{H}_{\mathbf{a b s}}$ ni meleni i le fale.

'Manogi didn't bring any melons home yet.'

b. cf. intransitive e le?i yalue $\mathrm{H}_{\mathrm{abs}}$ Melani i ni mamanu i le fale.

'Melani didn't work on any designs at home yet.'

\subsubsection{Pronouns}

In this section, I show that postverbal pronouns (which are free-standing) that are absolutive must be preceded by an $\mathrm{H}_{\mathrm{abs}}$, e.g, (15c). In addition, I show that a postverbal pronoun can host an $\mathrm{H}_{\mathrm{abs}}$ marking an immediately following absolutive argument, e.g., (15a). ${ }^{16}$

\footnotetext{
${ }^{16}$ As for preverbal pronouns, Mosel and Hovdhaugen (1992:374) write that they are unmarked. It's difficult to collect empirical evidence on whether or not an $\mathrm{H}_{\mathrm{abs}}$ precedes preverbal pronominal clitics, though. They immediately follow TAM markers, e.g. na ia 'PAST 3.SG', with one exceptional TAM particle te that they immediately precede, e.g. 'ou te '1.SG GENR' (glosses from Mosel and Hovdhaugen 1992). Therefore, at most, preverbal pronouns are preceded in the sentence by a TAM marker. All singular and dual preverbal pronouns are monosyllabic and/or have initial primary stress, while all plural preverbal
} 
From s13, s18, s19, s20, m01, and s22c/22s, I elicited simple VSO and VOS declaratives with the pronominal form as the first argument (15) or the second, and with malini 'the marines' as the other argument. For both pronominal and nonpronominal DPs, I varied the case over all three possibilities for subject, direct object, and indirect object-ergative, absolutive, or oblique-resulting in 12 configurations: 3 cases (erg, abs, obl) $\times 2$ arguments (ma:?ua, malini) $\times 2$ orders (VSO, VOS). (While the verb momoli 'to take, deliver, drop off' is ditransitive and some of the sentences may involve pro drop, I show later in Sect. 5.1.1 that pro drop has no special effects on the distribution of $\mathrm{H}_{\mathrm{abs}}$ tones: only overt arguments affect the presence of $\mathrm{H}_{\mathrm{abs}}$ tones.) I used a ditransitive verb to be able to construct sentences contrasting ergative, absolutive, and oblique case for a given argument in a single, controlled data set. A scenario was introduced for each sentence to give a referent for pro drop, e.g. the scenario that 'we two delivered the fish to the marines' for eliciting 'We two delivered (pro) to the marines.'

(15) Examples: pronoun as first (overt) argument

a. na momoli e ma:?ua $\mathbf{H}_{\text {abs }}$ malini. PAST take ERG 1.DU.EXC ABS marine

'We two dropped off the marines.'

b. na momoli e ma:?ua i malini. PAST take ERG 1.DU.EXC OBL marine

'We two delivered (it) to the marines.'

c. na momoli $\mathbf{H}_{\text {abs ma:?ua }} \mathrm{i}$ malini. PAST take ABS 1.DU.EXC OBL marine '(pro) took us two to the marines.'

The elicitation of the described set of sentences resulted in data from 6 consultants in total. Only the subset of VSO sentences was included from the consultant who rejected VOS word order. One consultant produced many fluent utterances including prosodic junctures with silence, i.e., $\mathrm{H} \%$ and $\mathrm{L} \%$ tones. Since the presence of these larger prosodic junctures obscure the presence of $\mathrm{H}_{\mathrm{abs}}$ tones, the consultant was asked to repeat the sentences at a faster speech rate when this occurred (a faster speech rate did not result in $\mathrm{H}_{\mathrm{abs}}$ tones disappearing, consistent with data from manipulating speech rate in Yu and Stabler 2017). For the other 4 consultants, no more than a handful of items were discarded due to speech errors or obvious prosodic junctures, see (50) for details.

Figure 6 illustrates the effect of case on mean z-score normalized f0 contours over the verb and pronominal argument in the elicited set of sentences, including sentences

pronouns have initial secondary stress. Thus, if TAM markers do show an f0 rise over the final syllable, it cannot be determined if the rise is due to an $\mathrm{H}$ and/or due to a pitch accent on the initial syllable in the pronoun. Besides, as I mention in Sect. 2.3, a rise in f0 typically occurs over the TAM marker anyway, even if it's immediately followed by an unstressed syllable. And in many cases the f0 contour over the TAM could be perturbed due to glottal stops: 8 of the 11 TAM markers listed on (Mosel and Hovdhaugen 1992:140) have glottal stops. 


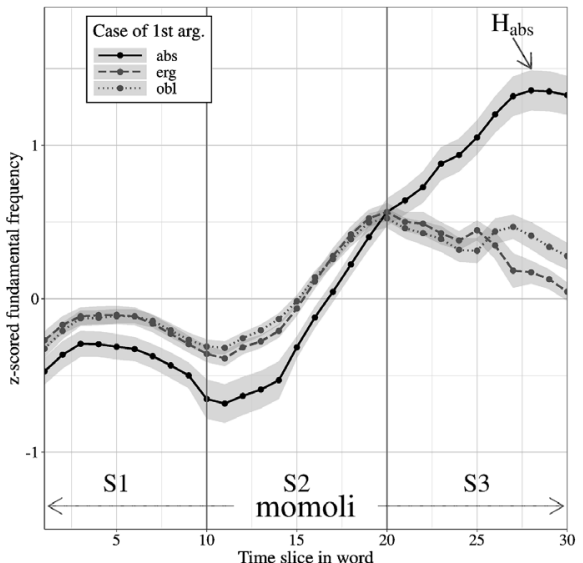

(a) fo contour on [momoli] 'deliver' when followed by [ma:?ua] '1.Du.ExC'

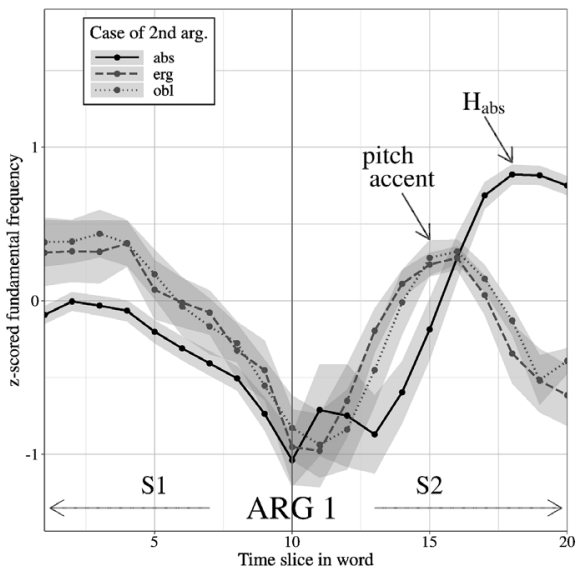

(c) f0 contour on 1st argument [ma:?ua] '1.DU.ExC'

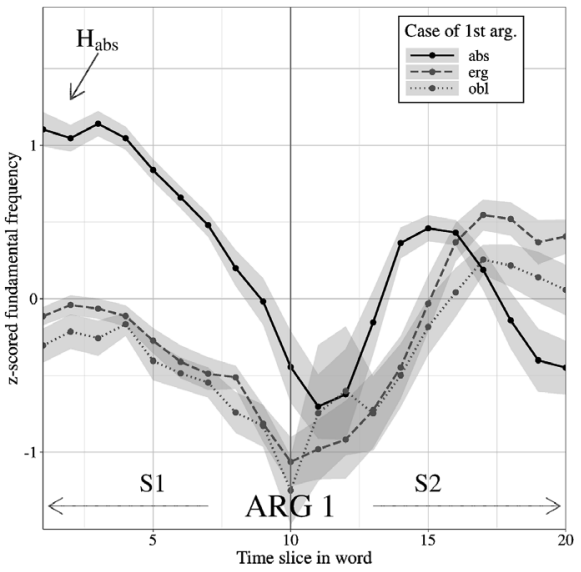

(b) fo contour on 1st argument [ma:?ua] '1.DU.ExC'

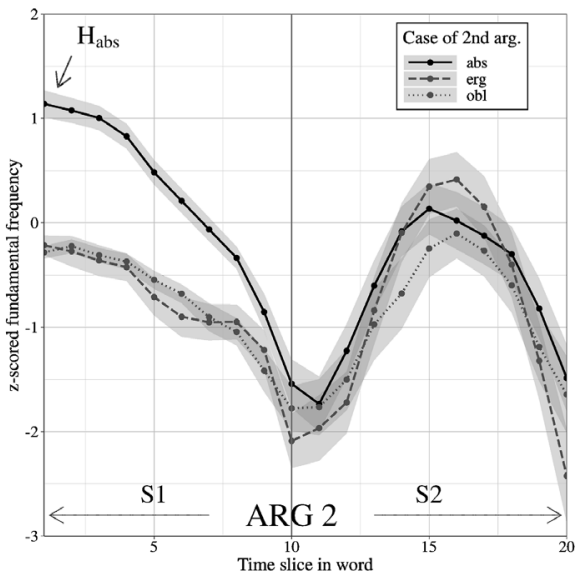

(d) fo contour on 2nd argument [ma:?ua] '1.DU.EXC'

Fig. 6 Mean z-score standardized f0 contours for [momoli] 'deliver' and [ma:?ua] '1.DU.EXC' in sentences with postverbal pronouns, e.g., (15), from s13, s18, s19, s20, m01, and s22c/22s (6 speakers, 94 tokens for (a)-(c), 89 tokens for (d)). The large dips in the f0 contour at the boundary between the first and second syllables in the pronoun [ma:?ua] (b,c,d) are due to the glottal stop, which was typically realized as some laryngealization rather than a full glottal stop. In Figs. 6b, c, and d, [ma:?ua] is partitioned into intervals as [ma:] in ' $\mathrm{S} 1$ ' and [ua] in 'S2'

in (15), and shows that the presence of an $\mathrm{H}$ occurred only before (overt) absolutive pronouns. Figure 6a shows that an $\mathrm{H}_{\mathrm{abs}}$ occurred at the right edge of the verb [momoli] 'deliver' when it was immediately followed by absolutive pronoun [ma:?ua] '1.DU.EXC', but not an ergative or oblique one. Note that the final rise in the f0 contour before absolutive [ma:?ua] cannot be attributed to a pitch accent due to secondary stress on [ma:]. If there were a pitch accent on [ma:?], then we'd expect to see f0 rises into [ma:?ua], regardless of case. Figure $6 \mathrm{~b}$ shows that this $\mathrm{H}$ persisted into the first syllable of the absolutive-case marked pronoun [ma:?ua] '1.DU.EXC'. Figure 6c shows that an $\mathrm{H}$ only occurred at the right edge of [ma:?ua] when it was immediately 


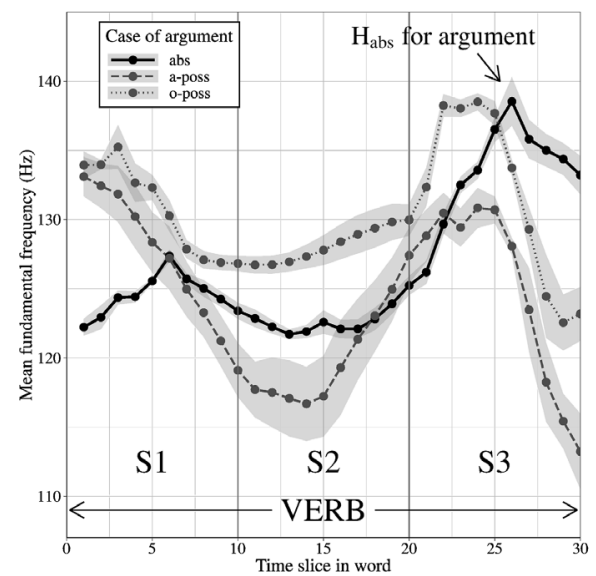

(a) fo contour on last 3 syllables of word, preceding arg. internal to nominalization, e.g., [mamanu] 'design' in (16a)

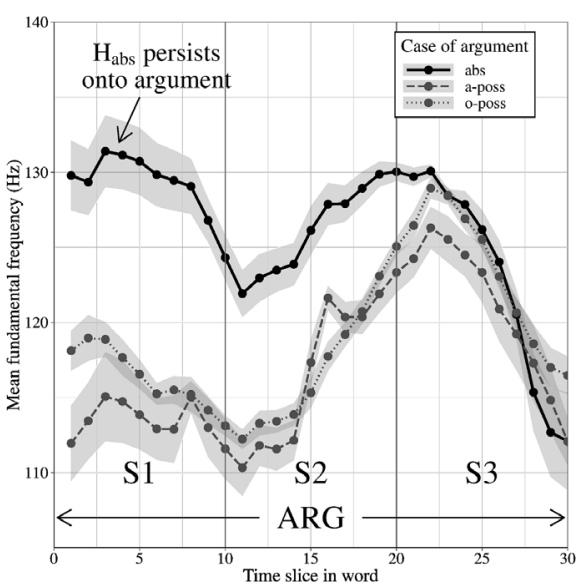

(b) fo contour on arg. internal to nominalization e.g., [malini] 'marine' in (16a)

Fig. 7 Mean f0 contours from m01 (56 tokens) for nominalizations in (16) and in (17). Figures 7a, b show that a $\mathrm{H}$ precedes the argument internal to the nominalization only when it's segmentally unmarked (absolutive) and not if it's an $a$-marked agent or $o$-marked patient

followed by an absolutive argument. Note that the f0 rise to the $\mathrm{H}_{\mathrm{abs}}$ clearly occurred later than the f0 rise due to the pitch accent on the stressed penultimate mora $[\mathrm{u}]$ in [ma:Pua]. Figure 6d shows that the high fo from this $\mathrm{H}_{\mathrm{abs}}$ persisted from the first argument into the first syllable of the second argument, absolutive [ma:?ua]. All together, Figs. $6 \mathrm{a}, \mathrm{b}$, and d show that absolutive postverbal pronouns are preceded by an $\mathrm{H}$; non-absolutive postverbal pronouns are not. Figure $6 \mathrm{c}$ shows that the postverbal pronoun itself can also bear an $\mathrm{H}_{\mathrm{abs}}$ when it precedes an absolutive argument.

\subsubsection{Case internal to nominalizations}

This section shows using data from $\mathrm{m} 01$ that the distribution of segmental case marking and Hs for arguments internal to nominalizations is also consistent with the existence of an $\mathrm{H}_{\mathrm{abs}}$. Examples of nominalizations are given in (16) and (17). ${ }^{17}$ Bracketed syntactic schema are given, where [N V] stands for the nominalized verb. The agent in a nominalized transitive predicate may either maintain ergative marking (16c) or be marked with the alienable genitive $a$ (16a) (Mosel and Hovdhaugen 1992:545). The patient in a nominalized transitive predicate may either be marked with the inalienable genitive marker $o$ (16b) or (appear to be) unmarked (16c) (Mosel and Hovdhaugen 1992:546; Collins 2014).

Figure 7 a shows the mean f0 contour over the final three syllables of the word preceding: (i) the $a$-marked agent, e.g., mamanu 'design' preceding a malini 'GEN marine' in (16a), (ii) the $o$-marked patient, e.g., momoli-ina 'deliver-INA' preceding o le malala 'GEN DET charcoal' in (16b), or (iii) the unmarked patient, e.g., liona 'lion' preceding le manini 'DET fish' in (16c); this word is annotated in the figure

${ }^{17}$ It's not clear whether the obliques are inside or outside the nominals. 
as "verb" for short. Figure 7b shows the mean f0 contours over the unmarked or $o$ marked patient, or the $a$-marked agent, not including the determiner $l e$, if present in the sentence. Together, the figures show that when an argument internal to a nominalization is $a$ - or $o$-marked, e.g., malini 'marine' in (16a) or mamanu 'design' in (17), it isn't preceded by an $\mathrm{H}$; however, if the argument is not preceded by a segmental case marker, e.g., le manini 'DET fish' in (16c), it is preceded by an $\mathrm{H}$.

In Fig. 7a, the contrast between mean fo contours may be hard to discern at first glance. In the last syllable, the dotted $o$-poss f0 contour is as high as the solid absolutive one, and the absolutive f0 contour also falls slightly at the end. However, a closer look shows that: (i) the $o$-poss f0 contour peak in syllable 3 is relatively lower than the absolutive one, since the $o$-poss f0 contour starts close to $10 \mathrm{~Hz}$ higher than the absolutive one in syllable 2, and (ii) the fall over syllable 3 for the $a$ - and $o$-poss contours is clearly sharper than for the absolutive, and Fig. $7 b$ shows that the absolutive high at the right edge of the word in Fig. $7 \mathrm{~b}$ is maintained into the absolutive patient in the nominalization, while the f0 contours over the $a$ - and $o$-marked arguments are clearly lower. This is an example of where minimal comparisons between f0 contours is important (Sect. 3.3.1).

(16) Arguments internal to absolutive nominalizations

a. With $a$-possessive ${ }^{18} \mathrm{~V}\left[\mathrm{H}_{\mathrm{abs}}\right.$ DET [N V] Obj PNI $\left._{\text {Agt }_{\mathrm{GEN}}}\right] \mathrm{PP}$

e $\quad\left\{\right.$ faPa-le:-lelei / leana $\mathrm{H}_{\mathrm{abs}}$ [le lalaya ${ }^{*} \mathrm{H}$ mamanu a malini] PRES $\{$ do-NEG-good / bad $\}$ ABS DET weave $* H$ design GEN marine i le afiafi.

OBL DET afternoon

'The marine's weaving of the design is not good in the afternoon (fa?ale:-lelei: poorly done, leaya: superstition).' (based on Mosel and Hovdhaugen 1992:545, (13.100))

b. With $o$-possessive, V Agt $\mathrm{ARG}_{\mathrm{ER}}\left[\mathrm{H}_{\mathrm{abs}} \mathrm{DET}[\mathrm{N} \mathrm{V}] \mathrm{Obj}_{\mathrm{GEN}}\right] \mathrm{PP}$

e iloa-atu e le malini $\mathrm{H}_{\text {abs }}$ [le momoli-ina o le

PRES spot ERG DET marine ABS DET deliver-INA GEN DET

malala $]_{a b s}$ i le ala.

charcoal OBL DET street

'The marine spots the delivering of the charcoal in the street.'

c. Without $a$ or $o$-possessive, V Agt $\operatorname{ARR}_{\text {ER }}\left[\mathrm{H}_{\mathrm{abs}}\right.$ DET [N V] $\operatorname{Agt}_{\mathrm{ERG}} \mathrm{H}_{\mathrm{abs}}$ $\left.\mathrm{Obj}_{\mathrm{ABS}}\right] \mathrm{PP}$

e iloa-atu e le malini $\mathbf{H}_{\text {abs }}$ [le momoli-ina e le liona PRES spot ERG DET marine ABS DET deliver-INA ERG DET lion

$\mathbf{H}_{\text {abs }}$ le manini $]_{a b s}$ i le ala.

ABS DET fish OBL DET street

'The marine spots the delivering of the fish by the lion in the street.'

\footnotetext{
${ }^{18}$ The lack of an H before the PNI object mamanu 'design' is consistent with a pseudo noun incorporation analysis of mamanu, where bare NPs are genuinely unmarked, see Sect. 4.4. I also found that the absolutive particle $i a$ is illicit before the PNI object mamanu, see Sect. 5.3 for more on ia.
} 
(17) Example of argument internal to oblique nominalization, $\mathrm{V} \mathrm{H}_{\mathrm{abs}} \mathrm{Agt}_{\mathrm{ABS}}$ [OBL DET [N V] Obj GEN $_{\text {PP }}$

e matamata $\mathrm{H}_{\mathrm{abs}}$ le malini [i le lalana o le mamanu] $\mathrm{i}$ PRES watch ABS DET marine OBL DET weave GEN DET design OBL le fale.

DET house

'The marine watches the weaving of the design at home.'

In summary, within a nominalization, arguments that are segmentally case-marked as genitive are not preceded by an $\mathrm{H}$, but arguments that are not segmentally casemarked, i.e., absolutive arguments, do.

\subsection{Pseudo noun incorporation}

I complete the description of the distribution of the $\mathrm{H}_{\mathrm{abs}}$ with pseudo noun incorporation (PNI) (Massam 2001). I show an example of [VO]S/VSO alternation in (18). With PNI (18a), the order is Verb-Object-Adverb-Subject, cf. default Verb-AdverbSubject-Object transitive order in (18b). The placement of the adverb shows whether a construction is PNI or not (Collins 2014, 2016). In addition, PNI objects must be non-specific. Also, the agent Manogi is unmarked (segmentally) in PNI (18a), but marked with ergative case in (18b). Using minimal comparisons between non-PNI and PNI sentences with $\mathrm{m01}$, I found that the $\mathrm{H}_{\mathrm{abs}}$ always appears before postverbal subjects in PNI constructions, and never before the pseudo-incorporated object. I used two sets of minimal comparisons: (i) one set contrasting the members of the [VO]S / VSO alternation, as shown in Fig. 8, and (ii) one set contrasting [VO]S / VOS, as shown in Fig. 9. The reason I include both is because, while [VO]S / VOS provides a better minimal comparison in some ways, VOS acceptability has been highly variable among my consultants and also consultants in Calhoun $(2015,2017)$. (My primary consultant, whose data is used in this section, is happy to produce VOS word order under a wide variety of contexts.) Thus, I also include comparisons within the [VO]S / VSO alternation.

(18) PNI [VO]S / VSO alternation example, with adverb placement diagnosing PNI

a. [V *H $\left.\mathrm{O}_{\mathrm{PNI}} \mathrm{Adv}\right] \mathrm{H}_{\mathrm{abs}} \mathrm{S}_{\mathrm{ABS}} \mathrm{PP}$ (PNI): unmarked non-specific bare NPI object

na fufulu *H meleni leaya $\mathrm{H}_{\text {abs }}$ Manoni i le ala.

PAST wash melon bad ABS Manogi OBL DET street

'Manogi melon-washed badly in the street.'

b. cf. [V Adv] $\mathrm{S}_{\mathrm{ERG}} \mathbf{H}_{\text {abs }} \mathrm{O}_{\mathrm{ABS}} \mathrm{PP}$ (non-PNI): ABS-marked specific plural object

na fufulu leana e Manoni $\mathbf{H}_{\mathbf{a b s}}$ meleni i le ala.

PAST wash bad ERG Manogi ABS melon OBL DET street

'Manogi washed the melons badly in the street.' 


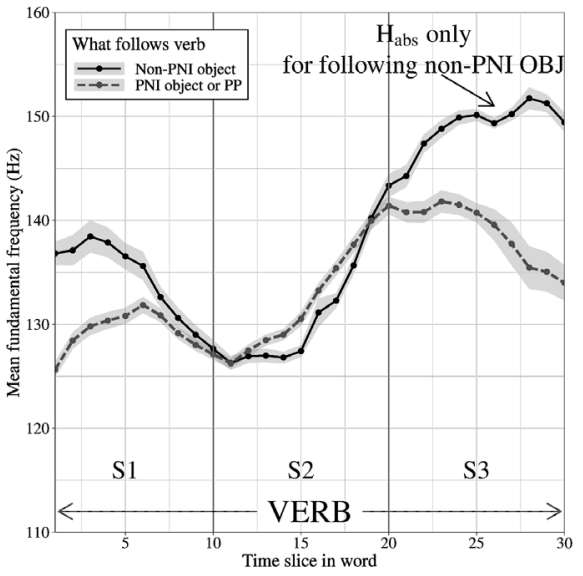

(a) No $\mathrm{H}$ on verb in $\left[\underline{\mathrm{V}} \mathrm{O}_{\mathrm{PNI}}\right] \mathrm{S}_{\mathrm{ABS}} \mathrm{PP}(\mathrm{PNI})$ or $\underline{\mathrm{V}} \mathrm{S}_{\mathrm{ERG}} \mathrm{O}_{\mathrm{ABS}} \mathrm{PP}$ (non-PNI)

$\mathrm{H}$ on $\mathrm{S}_{\text {PRONOUN }} \underline{\mathrm{V}} \mathrm{H} \mathrm{O}_{\mathrm{ABS}} \mathrm{PP}$ (non-PNI)

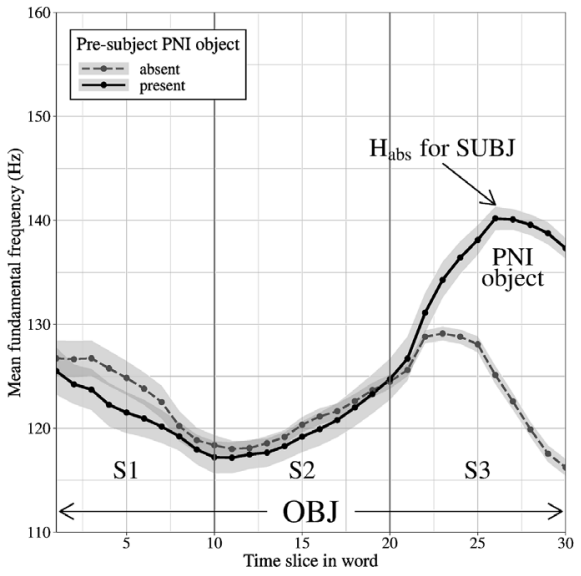

(b) $\mathrm{H}$ on obj. in $\left[\mathrm{V} \mathrm{O}_{\mathrm{PNI}}\right] \mathrm{H} \mathrm{S}_{\mathrm{ABS}} \mathrm{PP}$ (PNI), but no $\mathrm{H}$ on obj. in $\mathrm{V} \mathrm{S}_{\mathrm{ERG}}$ ABS $\mathrm{O}_{\mathrm{ABS}} \mathrm{PP}$ (non-PNI) or $\mathrm{S}_{\mathrm{PRONOUN}} \mathrm{V} \mathrm{O}_{\mathrm{ABS}} \mathrm{PP}$ (non-PNI)

Fig. 8 The effect of pseudo noun incorporation on the presence of the $H$ at the right edge of the verb and the object in sentences from m01, 26 tokens for (a), 34 tokens for (b). The comparison is between [V $\mathrm{O}_{\mathrm{PNI}}$ ] $\mathrm{S}_{\mathrm{ABS}} \mathrm{PP}$ (PNI), e.g., (18a) and $\mathrm{V} \mathrm{S}_{\mathrm{ERG}} \mathrm{O}_{\mathrm{ABS}} \mathrm{PP}$ (non-PNI) e.g., (18b) plus [ $\left.\mathrm{S}_{\text {PrOnOUN }} \mathrm{V} \mathrm{O}_{\mathrm{ABS}}\right] \mathrm{PP}$ (non-PNI object, pre-verbal pronominal subject)

For the [VO]S / VSO alternation comparison, I elicited four minimal sets of sentences like (18) with and without PNI from my primary consultant, m01. ${ }^{19} \mathrm{I}$ did not include adverbs in the sentences, but elicited the sentences in contexts where object specificity was clear, and checked the contexts with adverbial placement.

Mean f0 contours over the verb (e.g., fufulu 'wash' in (18)) ${ }^{20}$ and the last word in the object (e.g. [leana] 'bad' in (18)) are shown in Fig. 8. Figure 8a shows that the f0 contours over the verb in PNI and non-PNI constructions with postverbal subjects both do not rise up to a high peak. In these constructions, the verb is immediately

\footnotetext{
${ }^{19}$ I also elicited sentences with postverbal pronominal subjects, which behaved as expected, like postverbal non-pronominal subjects. It is also possible to have preverbal pronominal subjects in PNI constructions, which I additionally tested with $\mathrm{f03}$ and $\mathrm{f05}$ in Auckland. For these sentences, an adverb must be present to distinguish between non-PNI and PNI constructions, since there is no agent contrasting in case-marking between ergative in non-PNI and absolutive in PNI. Examples are given in (ii), the answer to (i). Whether PNI was absent or present in the sentence, no H appeared before the object татапи 'design'.
}

(i) ?o le a: na fai loa e janana $i$ le fale? TOP DET wh PAST do then ERG Gagana OBL DET home 'And then what did Gagana do at home?'

(ii) a. na ia lalaya loa mamanu i le fale. (no PNI) PAST 3.SG weave then design OBL DET home

'Then he wove designs at home.'

b. na ia lalaya $* \mathrm{H}$ mamanu loa $\mathrm{i}$ le fale. (PNI) PAST 3.SG weave ABS design then OBL DET home 'Then he design-wove at home.'

${ }^{20}$ I excluded non-sonorant verbs like fufulu in plotting. 


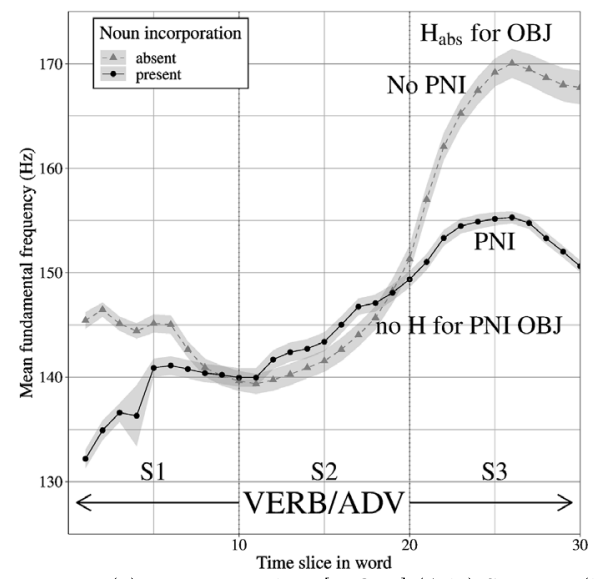

(a) No $\mathrm{H}$ on verb in $\left[\underline{\mathrm{V}} \mathrm{O}_{\mathrm{PNI}}\right]$ (Adv) $\mathrm{S}_{\mathrm{ABS}}$ but $\mathrm{H}$ on verb/adv. in $\mathrm{V}(\mathrm{Adv}) \mathrm{H} \mathrm{O}_{\mathrm{ABS}} \mathrm{S}_{\mathrm{ERG}}$

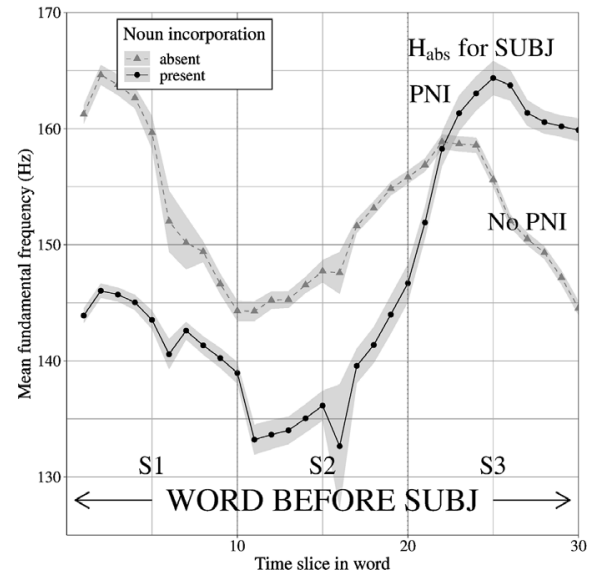

(b) $\mathrm{H}$ on obj./adv. in $\left[\mathrm{V} \mathrm{O}_{\mathrm{PNI}}\right](\mathrm{Adv}) \mathrm{H} \mathrm{S}_{\mathrm{ABS}}$, but no $\mathrm{H}$ on obj. in $\mathrm{V}(\overline{\mathrm{Adv}}) \mathrm{H} \mathrm{O}_{\mathrm{ABS}} \mathrm{S}_{\mathrm{ERG}}$

Fig. 9 The effect of (pseudo) noun incorporation on the presence of the $\mathrm{H}$ at the right edge of the word preceding the object and the word preceding the subject in the sentences in (19), from m01 (58 tokens). The comparison is between the PNI construction [V $\mathrm{O}_{\mathrm{PNI}}$ ] (Adv) $\mathrm{H} \mathrm{S}_{\mathrm{ABS}}$, e.g., (19a), and the non-PNI construction V (Adv) $\mathrm{H} \mathrm{O}_{\mathrm{ABS}} \mathrm{S}_{\mathrm{ERG}}$, e.g., (19b)

followed by either the PNI object or ergative subject. However, an $\mathrm{H}$ does appear at the end of the verb when it is followed by a non-PNI, absolutive object in constructions with preverbal pronominal subjects. This contrasts suggests that the PNI object is not absolutive. Figure $8 \mathrm{~b}$ is consistent with Fig. 8a in demonstrating an absence of an $\mathrm{H}$ before the PNI object: as the f0 contour continues through the first syllable of the object immediately after the verb, it continues to drop to the L valley of the pitch accent on S2 in the PNI and non-PNI object. However, Fig. $8 \mathrm{~b}$ shows that an $\mathrm{H}$ appears at the end of the PNI object immediately followed by a subject, while no $\mathrm{H}$ appears at the end of an object immediately followed by an oblique PP. This contrast suggests that the subject in PNI constructions is absolutive.

For the [VO]S / VOS comparison, I elicited a set of sentences varying contexts for specificity of the object in "design-weaving" from m01, as shown in (19) and Fig. 9. While the object in VOS could take specific and non-specific singular and plural determiners, the PNI object in [V O] S could not take any determiners. With a specific plural object, VOS word order can be string-identical to [VO]S word order. My primary consultant describes a meaning contrast between VOS and [VO]S, as the [VO]S being a context where the marine's job is to weave designs, whereas the VOS word order could refer to a single event of weaving the designs.

[VO]S / VOS alternation comparison

a. e [lalaya $* \mathrm{H}$ mamanu (pea / leana)] $\mathbf{H}_{\mathbf{a b s}}$ le

PRES weave ABS design (continually/badly) ABS DET.SPEC.SG malini.

marine

'The marine design-weaves (continually/badly).' 
b. e lalaya (pea / leaya) $\mathbf{H}_{\text {abs }}\{$ le / se /

PRES weave (continually / badly) ABS \{SPEC.SG / NSPEC.SG /

$\varnothing \quad /$ ni $\} \quad$ mamanu e le malini.

SPEC.PL / NSPEC.PL \} design ERG DET marine

'The marine weaves the/any/the/some design(s).'

Mean f0 contours over the word preceding the object (the verb [lalana] 'weave' in (19a) and the verb [lalaya] or adverb [leaya] 'badly' in (19b)) and the word preceding the subject (the object [mamanu] 'design' or the adverb [leaya] 'badly' in (19a) and the object [mamanu] 'design' in (19b)) are given in Fig. 9. Figure 9a shows that an H appears before the absolutive object in VOS, but not before the PNI object in [V O] $\mathrm{S}$. Figure $9 \mathrm{~b}$ shows than an $\mathrm{H}$ appears before the subject in [V O] $\mathrm{S}$, but not before the ergative subject in VOS. Figure $9 \mathrm{~b}$ also shows the $\mathrm{H}$ on the absolutive object in VOS, at the left edge in syllable 1 (S1).

In summary, in PNI constructions, an $\mathrm{H}$ appears before postverbal subjects. However, no $\mathrm{H}$ appears before the pseudo-incorporated object-whether the subject is pronominal, or whether the subject is postverbal or preverbal.

\subsection{Other word orders}

In this section, I present evidence that the presence of the $\mathrm{H}_{\mathrm{abs}}$ is insensitive to argument order in ditransitives (Sect. 4.5.1) and changes in word order in different discourse contexts (Sect. 4.5.2).

\subsubsection{The presence of segmental case markers and $H_{a b s}$ is insensitive to argument order in ditransitives}

There is no reason to expect segmental case markers to fail to surface in ditransitives. Suppose, though, that the $\mathrm{H}_{\mathrm{abs}}$ marked the right edge of a constituent preceding the absolutive under some syntax-prosody mapping. Then the presence of the $\mathrm{H}_{\mathrm{abs}}$ might depend on argument order in the ditransitive, since syntactic constituency would certainly be sensitive to argument order. But in fact, the presence of the $\mathrm{H}_{\mathrm{abs}}$, as well as the presence of the segmental case markers, is insensitive to argument order in ditransitives. I show this using f0 data from a set of ditransitive sentences derived from (20), where I permuted the location of the case markers in all $3 !=6$ ways, producing the argument orders schematized in Table 1. For instance, the first column in the table shows word orders where the absolutive object occurs first, i.e., na momoli le liona $e$ le nunua i le toloa (ABS ERG OBL) and na momoli le liona i le nunua e le toloa (ABS OBL ERG), and the first row in the second column has the order given in (20), (ERG ABS OBL). The consultants that provided the data were: s13, s18, s19, s20, m01, and s22c/s. ${ }^{21}$ I found that an $\mathrm{H}$ occurred immediately preceding the absolutive argument, regardless of the word order, as indicated in Table 1.

${ }^{21}$ One of the six consultants, s20, rejected both word orders with an initial oblique argument, as well as the abs-erg-obl order (s20's data wasn't included for the f0 plots). 
Table 1 Permutations of word order among arguments in a ditransitive sentence, grouped by the location of the absolutive argument

\begin{tabular}{|c|c|c|}
\hline $\mathrm{V}$ ABS & $\mathrm{V} \_\mathrm{ABS}$ & ABS \\
\hline $\mathrm{V} \mathbf{H}_{\mathbf{a b s}}$ ABS ERG OBL & V ERG $\mathbf{H}_{\mathbf{a b s}}$ ABS OBL & V ERG OBL $\mathbf{H}_{\text {abs }}$ ABS \\
\hline $\mathrm{V} \mathbf{H}_{\mathrm{abs}}$ ABS OBL ERG & V OBL $\mathbf{H}_{\mathbf{a b s}}$ ABS ERG & V OBL ERG $\mathbf{H}_{\text {abs }}$ ABS \\
\hline
\end{tabular}

(20) na momoli e le liona $\mathbf{H}_{\text {abs }}$ le nunua i le toloa. $^{22}$ PAST take ERG DET lion ABS DET dolphin obl DET duck

'The lion took the dolphin to the duck.'

Figure 10 shows the mean $\mathrm{f} 0$ contours over the verb and the first two arguments in the ditransitive sentence. (The third argument is shown in the OSF repository.) Each plot shows three mean $\mathrm{f} 0$ contours: one for each position of the absolutive argumentthe 1 st argument, 2 nd, or $3 \mathrm{rd}$. In each plot, the only f0 contour shape that shows a final rise is the fo contour when the absolutive argument immediately follows the word shown in the plot. For instance, the only f0 contour shape with a word-final rise over the verb momoli 'deliver' (Fig. 10a), occurs when the first argument liona 'lion' is absolutive. Figures $10 \mathrm{~b}$, $\mathrm{c}$ also show that high fo from the $\mathrm{H}_{\mathrm{abs}}$ carries over into the beginning of the absolutive argument. For example, the fo contour over the 2 nd argument пипиа "dolphin" (Fig. 10c) begins almost $20 \mathrm{~Hz}$ on average higher when it is absolutive compared to when it is ergative or oblique.

In summary, an $\mathrm{H}_{\mathrm{abs}}$ appears before the absolutive direct object in verb-initial ditransitive sentences, regardless of how the arguments in the sentence are ordered. Likewise, the ergative $e$ appears before the ergative subject, and oblique $i$ before the indirect object in ditransitives, irrespective of argument order. In this sense, the distribution of the $\mathrm{H}_{\mathrm{abs}}$ patterns like that of the segmental case markers. But I treat these ditransitive results with caution, since discourse context was not explicitly controlled. Nevertheless, the distributional patterns are consistent with $\mathrm{H}_{\mathrm{abs}}$ behaving as an absolutive tonal case marker.

\subsection{2 $H_{a b s}$ is not sensitive to discourse context}

In the corpus of data for this paper, elicitations were typically done under out-of-theblue focus, with the exception of specifying referents for sentences with pronouns and pro-drop. This raises the potential concern that $\mathrm{H}_{\mathrm{abs}}$ might actually be marking some systematic information structural property not identical with absolutive case. (If there is some informational structural property that exactly coincides with absolutive case marking in syntax, we would never be able to distinguish them.) It has been observed cross-linguistically, independent of case-alignment, that new information

\footnotetext{
${ }^{22}$ In the midst of fieldwork, I discovered that пипиа 'dolphin' which I found in a Samoan wordbook was either an extremely rare word or possibly a typo for титиа. Although one of my older consultants accepted it, for most consultants, it was effectively a nonce word since I showed consultants the picture of the dolphin in the word book labeled as пипиа. Since пипиа was in every single sentence in this ditransitive data set, the results described here cannot be attributed to something about пипиа-there are no asymmetries in f0 patterns that I can observe from пипиа compared to the other two arguments.
} 


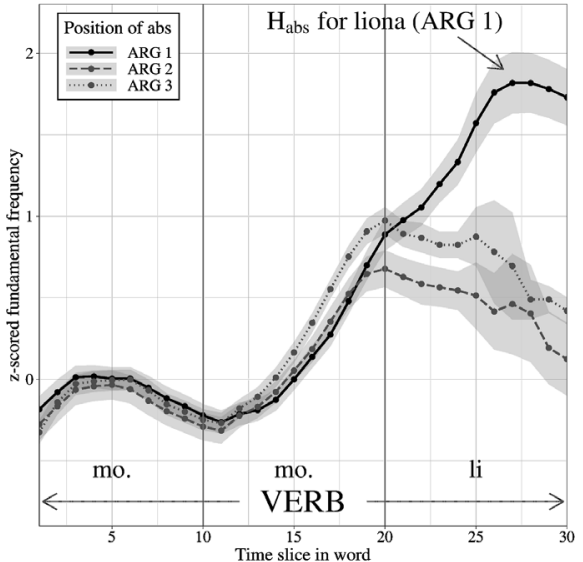

(a) momoli 'deliver' (verb)

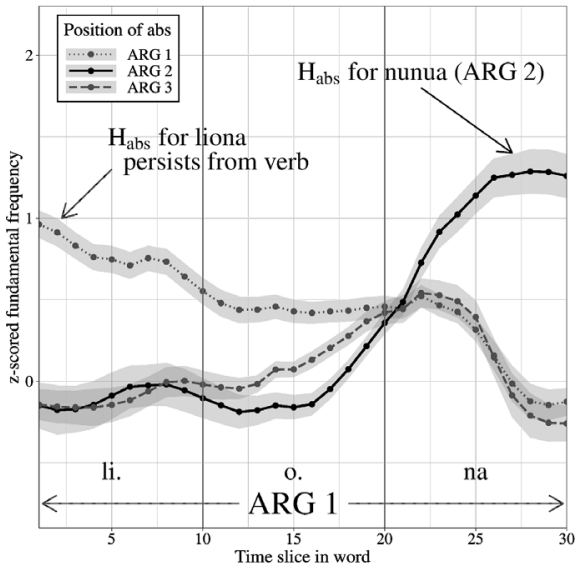

(b) liona 'lion' (1st argument)

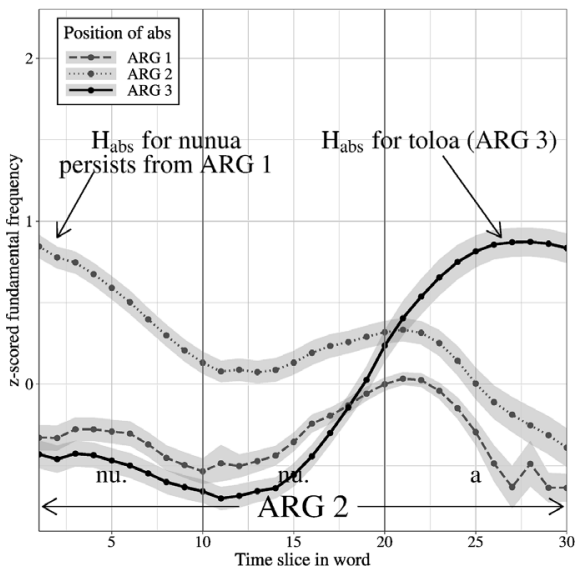

(c) nunua "dolphin" (2nd argument)

Fig. 10 Mean z-score standardized f0 contours for the verb momoli 'deliver' and the first two arguments liona 'lion' and пипиа "dolphin" in the ditransitive sentence set based on permuting the location of the case markers in (20). Data from s13, s18, s19, m01, and s22c/s (5 speakers, 71 tokens)

preferentially appears in the $\mathrm{S}$ (subject) or $\mathrm{O}$ (object) roles, but not in the A (agent) role, e.g., DuBois (1987). Thus, if no context is given to a speaker in sentences elicited 'out-of-the-blue', it's possible that speakers could be creating a context in their head, and opting for one that aligns with typical frequencies, i.e., where the absolutive argument happens to also to be introducing new information. However, the tautala lelei and tautala leaga data sets in Yu and Stabler (2017) provide evidence from systematic manipulation of discourse contexts that suggests that $\mathrm{H}_{\mathrm{abs}}$ is not in fact marking new information or information under focus or given material. Four sets of question-answer pairs manipulating discourse conditions were elicited: two with transitive verbs ([lalana] 'weave', taking an inanimate object; [lanona] 'hear', taking an animate object), and two with intransitive verbs ([malana] 'journey', taking an inanimate PP object; [leana] 'be bad', taking an animate PP object). 
Whether an argument was given, new, or under contrastive focus in the answers to the questions had no effect on the appearance of an $\mathrm{H}_{\mathrm{abs}}$ (H- in intonational transcriptions): an $\mathrm{H}$ always appeared before the absolutive argument, and never before the ergative argument or oblique object. This result is consistent with Calhoun's (2015) results from intonational transcriptions for sentences elicited under broad focus ('What happened earlier'), question focus on the agent or direct object, and contrastive focus on the agent or direct object. That study also showed no evidence that the $\mathrm{H}$ preceding the absolutive was sensitive to discourse structure.

\subsection{Evidence that Hs are edge tones}

Having shown that a high tone appears before the absolutive argument, I now turn to the question of whether the position of the high tone alignment is determined by the positioning of heads (prominent, stress-bearing units) and/or edges (Ladd 2008: Ch. 2-4). What's the evidence that the Hs discussed thus far track with edges? Or is there evidence that the Hs track with prominent, stress-bearing morae? For instance, could the absolutive high be a trailing upstepped high in the pitch accent?

A classic method to diagnose if a tone might track with a stress-bearing unit or if it might track with an edge is to vary the position of stress and the number of syllables/morae in words, and to observe if the alignment of the tone correlates with stress position (the signature of a pitch accent) (and)/or with word length (the signature of a edge tone) (Jun and Fletcher 2014). However, the penultimate mora is the furthest mora from the left edge of a prosodic word that native Samoan words can bear primary stress on (Zuraw et al. 2014). Thus, the position of primary stress cannot be shifted far away enough from the right word edge in Samoan to clearly determine if Hs track with stress or edges. One way to circumvent the closeness of stress to the right edge in Samoan is to turn to code-switching. Codeswitching between Samoan and English is a common everyday occurrence for the speakers I've worked with, especially in California and New Zealand, and in English, there can be antepenultimate primary stress in a word, e.g., Melanie ['meləni]. If the $\mathrm{H}$ tracks with the pitch accent, then the $\mathrm{H}$ peak should occur earlier with antepenultimate stress than penultimate stress. If the $\mathrm{H}$ tracks with the right edge, then the $\mathrm{H}$ peak should stay at the right edge even when stress is antepenultimate rather than penultimate. (It's also possible that the $\mathrm{H}$ might track with both the pitch accent and the edge.)

Like in Yu and Stabler (2017), I performed a Bach test (Halle 1978:301), using English proper names with stress patterns non-native to Samoan. I performed a production experiment with $\mathrm{m} 01$ where I manipulated stress position in proper names to be penultimate (Lorena, Marina, Melani) or antepenultimate (Emily, Helena, Melanie) ${ }^{23}$ in different syntactic configurations where I had previously found that an $\mathrm{H}$ would be reliably present or absent at the right edge of the proper name (fronting, coordination, default word order and VOS/V-PP-S transitives and intransitives). Some example question-answer pairs elicited for antepenultimate stress in Melanie are given in (21) - constructions where an $\mathrm{H}$ is reliably present at the right edge of the first

${ }^{23}$ While Melanie and Emily have final secondary stress, which could possibly trigger some associated f0 movement, Helena does not. F0 contour shape did not differ between the individual names. 
name - and (22) - constructions where an $\mathrm{H}$ is reliably absent at the right edge of the first name. All of these Q/A pairs were set up to provide a context for polarity focus, so the questions and answers were string-identical, except for the affirmative 'yes' initiating the answer. For example, the question for the fronted expression in (21a) [?o liona a Melanie na tayi i mauya?] meant 'Was it Melanie's lions that cried on the mountain?'. Sentences were constructed to have the same number of morae (8) up to the $\mathrm{H}$ testing site and after the $\mathrm{H}$ testing site (6) to control for prosodic length.

(21) Example question/answer pairs for Bach test with proper names, $\mathrm{H}$ site present at right edge of first name

a. Fronted expression (Context: ?o liona a Melanie na tayi i mauya?)

('Was it Melanie's lions that cried on the mountains?')

Ioe, ?o liona a Melanie $\mathbf{H}_{\text {front }}$ na taji i mauya.

yes, TOPIC lion GEN Melanie FRONT PAST cry OBL mountain

'Yes, it was Melanie's lions that cried on the mountains.'

b. Transitive VSO (Context: na lalaya e Melanie mamanu leana?)

('Was it Melanie that wove the designs badly?')

Ioe, na lalaga e Melanie $\mathbf{H}_{\mathbf{a b s}}$ mamanu leaga.

yes, PAST weave ERG Melanie ABS design bad

'Yes, Melanie wove the designs badly.'

c. Coordination (Context: na momoli e Melanie ma Lana meleni?)

('Was it Melanie and Lana that dropped off the melons?')

Ioe, na momoli e Melanie $\mathbf{H}_{\text {coord }}$ ma Lana $\mathrm{H}_{\mathrm{abs}}$ meleni.

yes, PAST deliver ERG Melanie COORD CONJ Lana ABS meleni

'Yes, Melanie and Lana dropped off the melons.'

(22) Example question/answer pairs for Bach test with proper names, $\mathrm{H}$ site absent at right edge of first name

a. Intransitive VS-PP (Context: na yalue Melanie mamanu leana?)

('Was it Melanie that worked on the designs badly?')

Ioe, na jalue $\mathbf{H}_{\text {abs }}$ Melanie i mamanu leaga.

yes, PAST work ABS Melanie OBL design bad

'Yes, Melanie worked on the designs badly.'

b. Name (Context: na malaya Melanie Mamanu i mauya?)

('Was it Melanie Mamalu that travelled to the mountains?')

Ioe, na malana $\mathbf{H}_{\mathbf{a b s}}$ Melanie Mamanu i mauya.

yes, PAST travel ABS Melanie Mamanu OBL mountain

'Yes, Melanie Mamanu travelled to the mountains.'

Figure 11 shows the effect of primary stress position on mean f0 contours over the first name and surrounding words when an $\mathrm{H}$ is present at the right edge. The $\mathrm{L}$ valley for names with penultimate stress aligns with the onset of the penultimate mora of the name, while the L valley for names with antepenultimate stress aligns with 
Fig. 11 The effect of primary stress position on the f0 realization of an $\mathrm{H}$ at the right edge of the first name in sentences like those given in (21) and (22). When the first name has antepenultimate stress, e.g., in Melanie, there is still a high fo peak at the right edge of the first name, indicating that the Hs track with the right edge rather than with stress position. Data from m01, 208 tokens

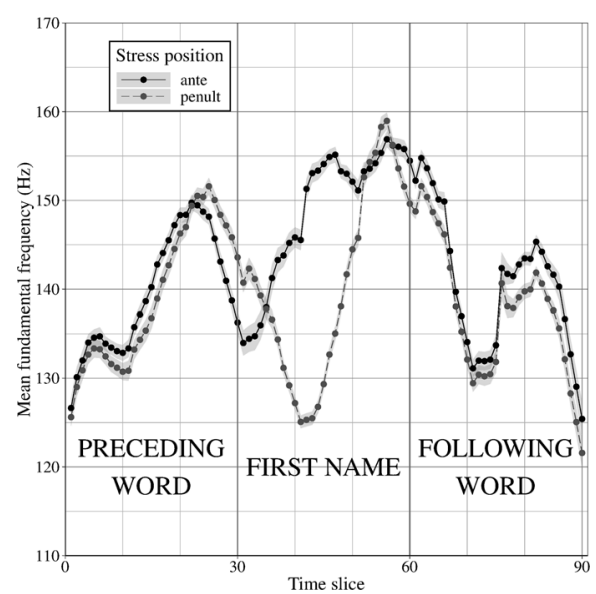

the onset of the antepenultimate (i.e., initial) mora. This shift in L valley alignment is expected, and shows that the L valley is tracking with stress position. How the high f0 peak tracks is less clear. While the high peak in penultimate stress is clearly in the final mora, there appears to be either two high peaks or a high plateau in antepenultimate stress that starts in the antepenultimate mora and extends through the final mora. This f0 contour behavior is consistent with there being two distinct high tonal targets: one high peak tracking with antepenultimate stress (the high target for the $\left.\mathrm{LH}^{*}\right)$ and another high tone tracking the right edge $(\mathrm{an} \mathrm{H})$. It is not the case that the f0 contour begins to fall after reaching the high peak in the penultimate mora of the first name, as we would expect if there were only high tones tracking with stress and none tracking the right edge. Instead, the maintenance of high f0 at the right edge even with antepenultimate stress suggests that the three syntactically conditioned Hs are aligned to the right edge.

Together, these observations support the hypothesis that $\mathrm{H}_{\mathrm{abs}}, \mathrm{H}_{\text {coord }}$, and $\mathrm{H}_{\text {front }}$ are edge tones and not (part of) pitch accents. ${ }^{24}$ This raises another question. Taking the $\mathrm{H}_{\mathrm{abs}}$ as an example $\mathrm{H}$ : if the $\mathrm{H}_{\mathrm{abs}}$ is an edge tone, though, what's the evidence that it tracks with the right edge of the phonological material preceding the absolutive argument, rather than with the left edge of the absolutive argument? After all, the realization of the absolutive high persists into the syllable preceding the first primary stress in the absolutive argument. But if the absolutive high tracked with the left edge of the absolutive argument, it would be strange to have the fo peak realized in anticipation of the segmental material of the absolutive argument. If anything, one would expect the fo peak to be realized after the syllable that the tone is associated to due to peak delay.

\footnotetext{
${ }^{24} \mathrm{~A}$ point of interest is that the low valley in the pitch accent preceding $\mathrm{Hs}$ is noticeably lower than when no $\mathrm{H}$ is present; this could be an accident of the stimuli/elicitation design, or high tone anticipation; more investigation is needed.
} 


\section{What is $\mathbf{H}_{a b s}$ ? $H_{a b s}$ as the spellout of absolutive case}

I've reviewed in Sect. 2.3.2 and shown in Sect. 4 that a sentence-medial high edge tone surfaces with the following three distinct syntactic constructions: absolutive arguments, coordination, and fronted expressions. One further point to emphasize is that $\mathrm{H}_{\mathrm{abs}}, \mathrm{H}_{\text {coord }}$, and $\mathrm{H}_{\text {front }}$ are reliably triggered by their respective syntactic configurations: up to some small degree of noise, Hs always appear when expected and never appear when unexpected. In the plots of mean f0 contours in this paper, the gray ribbons visualizing variability across uttered tokens (see Sect. 3.3.2) all have the same shape as the mean f0 contours. This reflects that the distribution of $\mathrm{Hs}$ in each utterance that contributed to the phonetic data in this paper was consistent across repetitions, items, and speakers, as the reader can verify in the OSF repository. The frequency count data of transcribed Hs in Yu and Stabler (2017, Sect. 6) also show the same degree of reliability, modulo the appearance of "overriding" prosodic boundary tones that can be attributed to separate and unrelated factors discussed in Sect. 5.2. With this frequency data unambiguously showing that the distribution of Hs is entirely predictable from the three different syntactic configurations, no statistics are needed to quantify the degree of reliability. Moreover, Yu and Stabler (2017, Sect. 2) also provides evidence that the appearance of $\mathrm{H}_{\mathrm{abs}}$ is insensitive to prosodic length, speech rate, and register.

Given this reliability, I propose that $\mathrm{H}_{\text {abs }}$, as well as $\mathrm{H}_{\text {coord }}$ and $\mathrm{H}_{\text {front }}$, are syntactically triggered. For the purposes of having a concrete proposal to refer to in grappling with the syntax-prosody interface, I assume that $\mathrm{H}_{\mathrm{abs}}$ is introduced postsyntactically as a pronounced reflex of the structural configuration of absolutive case (see e.g., Marantz 1991, Bobaljik 2008) following Yu and Stabler (2017), which assumes a syntactic analysis of Samoan inspired by Collins (2016, 2015, to appear, 2014); see also the derived tree in (30). But whether $\mathrm{H}_{\mathrm{abs}}$ might be (part of) a pronounced morpheme that is in the lexicon, which is then concatenated with other lexical items in syntactic derivation, or if it is inserted postsyntactically as a reflex of a syntactic configuration stated over bundles of abstract features (see Yu and Stabler 2017: Sect. 7.2) doesn't matter for the basic claim I defend here: $\mathrm{H}_{\mathrm{abs}}, \mathrm{H}_{\text {coord }}$, and $\mathrm{H}_{\text {front }}$ are introduced in the spellout of syntactic structure. I remain agnostic, too, as to whether $\mathrm{H}_{\text {coord }}$ and $\mathrm{H}_{\text {front }}$ might be (part of) lexical items, or inserted postsyntactically, but see Yu and Stabler (2017) for one proposal about how postsyntactic tonal insertion of $\mathrm{H}_{\text {coord }}$ and $\mathrm{H}_{\text {front }}$ might be formalized. When I use the term 'morpheme' in this paper, it is a descriptive term that refers to something spelled out in syntactic structure, without reference to whether it might happen in lexical insertion or postsyntactically.

An immediate puzzle raised by this proposal is: why would these particular syntactic configurations trigger Hs? A natural step might be to propose some shared property underlying the three syntactic configurations is in fact what triggers Hs. In this section, I present empirical evidence that shows that such a move towards unification is not supported. Rather, the evidence demonstrates that if there is anything more general underlying absolutive case that triggers an $\mathrm{H}$, it is case: the distribution of $\mathrm{H}_{\mathrm{abs}}$ patterns with the distribution of segmental case markers. (Sect. 6 continues the argument that $\mathrm{H}_{\mathrm{abs}}$ is a case marker in terms of theories of the syntax-prosody interface.) First, I show that the distribution of $\mathrm{H}_{\mathrm{abs}}$ shares properties with the distribution of segmental case markers: $\mathrm{H}_{\mathrm{abs}}$ is illicit when other segmental case markers 
are illicit (Sect. 5.1). This section also addresses Calhoun's (2014, 2017) apparent challenge to the $\mathrm{H}_{\mathrm{abs}}$ case marking proposal that $\mathrm{Hs}$ are absent before post-verbal absolutives under focus-sensitive $n a^{\prime} \mathrm{o}$ 'only'. I show that in fact, no case markerswhether segmental or tonal-can surface under $n a^{\prime} o$. Then in Sect. 5.2, I show that high (and low) edge tones that variably appear across variable syntactic environments (Calhoun 2017; Yu and Stabler 2017) can be attributed to factors other than syntax, namely, prosodic phonology. This addresses Calhoun's (2017) apparent challenge to the $\mathrm{H}_{\mathrm{abs}}$ case-marking proposal that $\mathrm{H}_{\mathrm{abs}}$ does not in fact occur reliably with absolutives or fronting and also occurs in disparate, additional syntactic environments. Finally, in Sect. 5.3, I provide an explanation for why the absolutive case marker is tonal and not segmental like other case markers in Samoan and summarize my overall proposal.

\section{1 $\mathrm{H}_{\mathrm{abs}}$ is illicit where the segmental case markers are illicit}

This section demonstrates that $\mathrm{H}_{\mathrm{abs}}$ is illicit when segmental case markers are illicit: that is, the distributional behavior of $\mathrm{H}_{a b s}$ patterns like that of segmental case markers. Section 5.1.1 shows that ergative and absolutive case makers both fail to surface with argument traces in pro-drop and extraction out of relative clauses. Section 5.1.2 points out several constructions where not only $\mathrm{H}_{\mathrm{abs}}$, but also segmental case markers are illicit: in fronted arguments, on preverbal pronominal clitics, and in focussensitive $n a^{\prime} o$ constructions.

\subsubsection{Case markers do not surface with argument traces}

Under pro-drop of an ergative argument or the extraction of an ergative argument, it would not be expected for the ergative case marker to remain behind with the trace. But suppose that $\mathrm{H}_{\mathrm{abs}}$ was not inserted in spellout, but marked the right edge of a constituent preceding the absolutive, under some syntax-prosody mapping. As Calhoun (2015:21) points out, "prosodic phrasing is standardly held to align only with overt syntactic structure," e.g., see Elfner (2012: Ch. 5) for a recent argument that this is true based on empirical evidence from Connemara Irish as well as Selkirk and Lee (2015:9). And so if $\mathrm{H}_{\mathrm{abs}}$ marked the left edge of some phonological constituent corresponding to a syntactic constituent initiated by the absolutive, it might be expected for an $\mathrm{H}_{\mathrm{abs}}$ to fail to surface under pro-drop or extraction of an absolutive. But if the $\mathrm{H}_{\mathrm{abs}}$ marked a right prosodic edge, although the absolutive argument itself wouldn't be overt under pro-drop or extraction, the phonological material in the immediately preceding prosodic phrase marked by the $\mathrm{H}_{\mathrm{abs}}$ would be-predicting that the $\mathrm{H}_{\mathrm{abs}}$ might remain behind. In this section, I show this is not the case: like the ergative case marker $e$, an $\mathrm{H}_{\mathrm{abs}}$ does not surface with traces.

pro-drop In the sentences in (23) and (24) from four speakers (m01, s13, s18, s22c/s), I found that an $\mathrm{H}_{\mathrm{abs}}$ was absent under pro-drop of the absolutive. However, an $\mathrm{H}_{\text {abs }}$ was present under pro-drop of the ergative, as long as an overt absolutive argument was present. That is, for the pro-drop sentences in (23) and (24), as long as [malini] was absolutive, $\mathrm{H}_{\mathrm{abs}}$ appeared. Figure 12a shows the mean f0 contours 


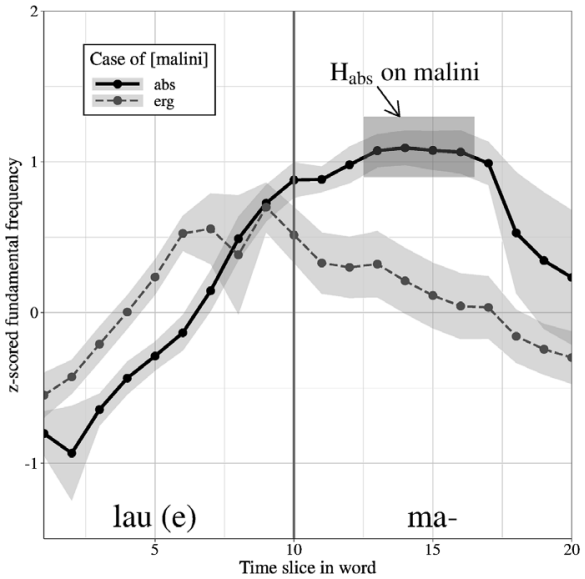

(a) na lau (e) malini (23)

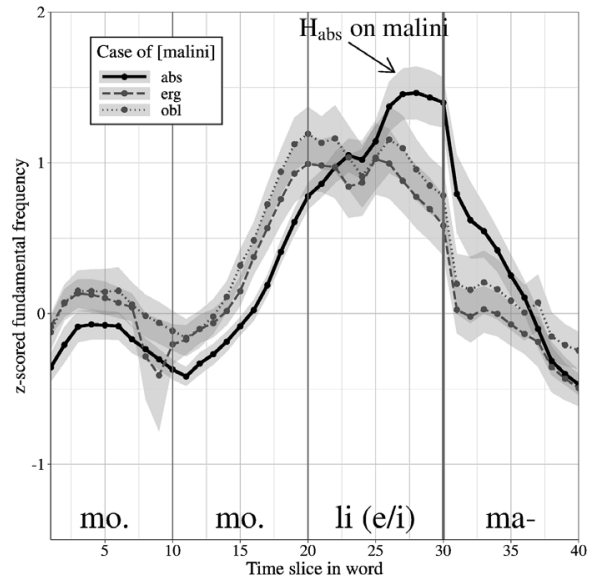

(b) na momoli (e/i) malini (24)

Fig. 12 Mean z-score standardized f0 contours for pro drop sentences in (23) and (24) from m01, s13, s18, and s22c/s (4 speakers, 15 tokens for (a), 24 for (b)). $\mathrm{H}_{\mathrm{abs}}$ isn't present if the absolutive pronoun is pro-dropped, but is present under ergative pro-drop as long as the overt argument [malini] is absolutive

over [lau] 'make.fun' and the first syllable of [malini] for the sentences in (23). Even though the realization of the $\mathrm{H}$ on [lau] is difficult to discern because of final stress on [lau], the realization of the $\mathrm{H}$ is quite clear at the onset of the absolutive argument [malini] in the f0 contour. This is another example of how minimal comparisons is useful (Sect. 3.3.1). Figure 12b shows the same results for pro-drop in (24): $\mathrm{H}_{\mathrm{abs}}$ is absent if the absolutive pronoun has been pro-dropped, but it is present otherwise, as long as the absolutive argument is overt.

a. na lau e malini.

PAST make.fun ERG marine

'The marines made fun of pro.' (pro drop of ABS)

b. na lau $\mathbf{H}_{\text {abs malini. }}$

PAST make.fun ABS marine

'pro made fun of the marines.' (pro drop of ERG)

(24) na momoli $\left\{\mathrm{e} / \mathbf{H}_{\mathbf{a b s}} / \mathrm{i}\right\}$ malini.

past drop.off $\{$ ERG / ABS / OBL $\}$ marine

'The marines dropped off pro / pro dropped off the marines / pro dropped off pro with the marines.'

Syntactic extraction in relative clauses $H_{a b s}$ also does not appear in a relative clause when an absolutive argument has been extracted out of it. I show this with two data sets: one comparing extraction of the ergative subject vs. the absolutive object out of transitive embedded clauses (from s13, s18, m01, s22) and one comparing extraction of ergative subjects out of transitive clauses vs. extraction of absolutive subjects out of intransitive clauses (from m01). 
I elicited (25) as a minimal pair for comparing extraction of the ergative subject vs. the absolutive object out of a relative clause; see Sect. A.7 for a minimal pair with a transitive matrix clause also elicited. The embedded verb is underlined.

(25) Extraction of ergative subject vs. absolutive object, intransitive matrix clause $^{25}$

a. Extraction of ergative subject

na manoji i le liona $\mathbf{H}_{\text {abs }}$ [le malini $]_{i}$ [na lalaja-ina $t_{i}$

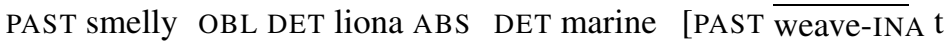

$\mathbf{H}_{\text {abs }}$ le mamanu].

ABS DET design]

'The marine that wove the design was smelly to the lion.'

b. Extraction of absolutive object

na manoni i le liona $\mathbf{H}_{\text {abs }}$ [le mamanu $]_{i}$ [na lalaya-ina PAST smelly OBL DET liona ABS DET design [PAST weave-INA

e le malini $\left.t_{i}\right]$.

ERG DET marine $\mathrm{t}$ ]

'The design that the marine wove was smelly to the lion.'

I show mean f0 contours over the last three syllables of the embedded verbs (e.g., [ya-i.na] from [la.laya-i.na]) in (25) from four speakers in Fig. 13a. Figure 13a shows that $\mathrm{H}_{\mathrm{abs}}$ does not appear at the right edge of the embedded verb if the absolutive object has been extracted. However, $\mathrm{H}_{\mathrm{abs}}$ does appear on the embedded verb if the ergative subject has been extracted, with the absolutive object remaining in the embedded clause.

To confirm that the H distribution shown in Fig. 13a isn't the effect of subject vs. object extraction, I also elicited six additional sentences from my primary consultant with only subject extraction out of a relative clause, where the ergative or absolutive subject was extracted to object position in the matrix clause. Two examples are given in (26). These sentences were also "easier" extractions: subject extraction out of the final constituent in the matrix clause. Figure $13 \mathrm{~b}$ shows that with these extractions, too, $\mathrm{H}_{\mathrm{abs}}$ did not appear on the embedded verb if the absolutive subject was extracted, but did appear if the ergative subject was extracted and the absolutive object was still present in the embedded clause. For this set of sentences, f0 on the embedded verb happened to be globally higher when the absolutive subject was extracted, compared to when the ergative subject was extracted. However, the contrast in the presence vs. the absence of $\mathrm{H}_{\mathrm{abs}}$ is still clear: the fo contour is falling in the final syllable of the verb when the absolutive subject is extracted, but rising when the ergative subject is extracted.

(26) Examples of ergative vs. absolutive subject extraction

a. Extraction of ergative subject

\footnotetext{
${ }^{25}$ The sentences in (25) have oblique object - absolutive subject word order because this order was volunteered by two consultants.
} 


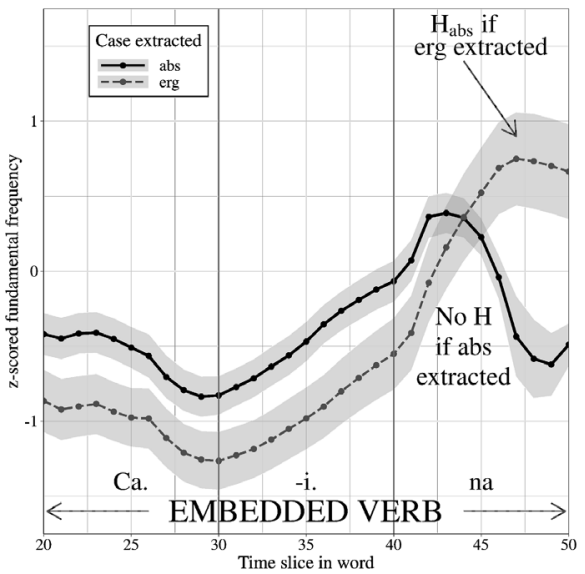

(a) ERG subject vs. ABS object extraction (25)

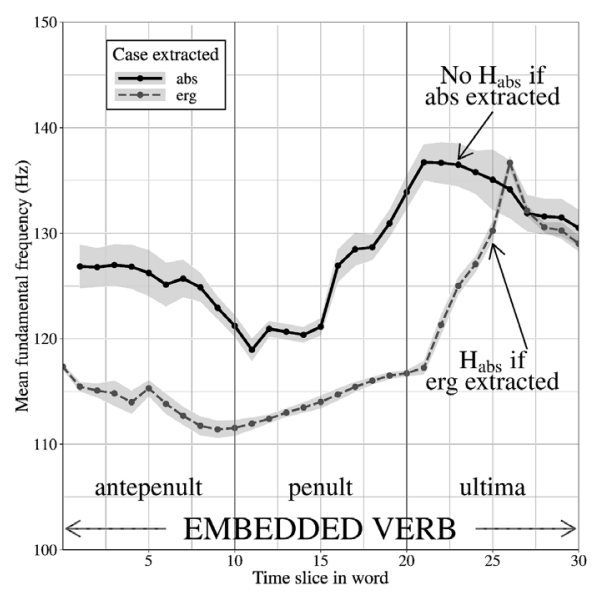

(b) ERG vs. ABS subject extraction (26)

Fig. 13 Mean contours over embedded verb in relative clause. (a) z-scored f0 contours for ergative subject vs. absolutive object extraction, e.g., (25) from m01, s13, s18, s22c/s (4 speakers, 36 tokens); (b) f0 contours for ergative vs. absolutive subject extraction e.g., (26) from m01, 13 tokens. $\mathrm{H}_{\mathrm{abs}}$ appears only if the ergative, rather than the absolutive argument, is extracted

e lajona e le liona $\mathbf{H}_{\text {abs }}$ [le malini $]_{i}$ na momoli-ina $t_{i}$ PRES hear ERG DET lion ABS DET marine PAST deliver-INA $t$

$\mathbf{H}_{\text {abs }}$ le manini.

ABS DET.GS fish

'The lion hears the marine that delivered the fish.'

b. Extraction of absolutive subject

e lajona e le malini $\mathbf{H}_{\text {abs }}[\text { le manini }]_{i}$ na manoni $t_{i}$ i PRES hear ERG DET marine ABS DET fish PAST smelly $\mathrm{t}$ OBL le liona.

DET lion

'The marine hears the fish that was smelly to the lion.'

\subsubsection{Genuinely unmarked bare NPs: $H_{a b s}$ is illicit where other case markers are also illicit}

Up to this point in the paper, I have documented cases where Hs are not observed before bare NPs that are independently expected not to be case-marked, i.e., before pseudo-incorporated objects (Sect. 4.4). Yu and Özyıldız (2016:399, Sect. 3.4.2) shows other constructions. I have also shown syntactic environments where not only $\mathrm{H}_{\mathrm{abs}}$, but also other case markers are illicit: preceding fronted arguments (3), preceding preverbal pronominal clitics (Sect. 4.3.2), and preceding argument traces (Sect. 5.1.1). 
Additionally, we show here that no case markers - including $\mathrm{H}_{\mathrm{abs}}$ - can co-occur with focus-sensitive na 'o 'only'. ${ }^{26}$ Calhoun $(2014,2017)$ first noted that an $\mathrm{H}_{\mathrm{abs}}$ does not co-occur with absolutive arguments under $n a^{\prime} \circ$ and argued that this data challenges the claim that there is a tonal absolutive case marker. ${ }^{27}$ But Calhoun (2017:15) did not elicit ergative or oblique nominals under $n a^{\prime} o$ and reported eliciting constructions with " $n a^{\prime}$ o modifying a noun phrase in all of the syntactic positions in which it is known to be grammatical in Samoan": preceding the verb phrase, a fronted noun phrase, or a postverbal absolutive argument (Calhoun 2017:11, (16)-(18)).

Mosel and Hovdhaugen (1992:272-273) says that "noun phrases combined with $n a^{\prime} \mathrm{o}$ are always unmarked for case:... They occur in the function of fronted noun phrases, absolutive arguments in verbal clauses, predicates in nominal clauses, and predicative noun phrases in semi-verbal clauses" and Mosel and Hovdhaugen (1992:526) refers to "the absolutive noun phrase of $n a$ ' $o$." I suspect that either some language change has occurred since Mosel and Hovdhaugen's (1992) work that may have admitted non-absolutive arguments under $\mathrm{na}^{\prime} \mathrm{o}$ (although the Auckland consultants I elicited $n a^{\prime} \circ$ constructions from had a wide age range- 19,23 , and 48 years old), or perhaps Mosel and Hovdhaugen's (1992) work conflated segmentally unmarked case with absolutive case.

I show here that case-marking data in $n a^{\prime} \mathrm{o}$ constructions collected from my Auckland consultants (f03, f05) in fact supports the analysis of $\mathrm{H}_{\mathrm{abs}}$ as a tonal case marker. The examples in (27) show na' $o$ combining with nominals bearing different cases. Case markers are shown to be ungrammatical in positions preceding and following $n a^{\prime} o{ }^{28}$ Plots are given in the OSF repository.

\section{Case marking cannot co-occur with na $^{\prime} \mathrm{o}$}

a. Na' $O$ in ABS subject. Context: Were Melina and Melani bad to the lion?

na leaya $* \mathbf{H}_{\text {abs }}$ na?o $* \mathbf{H}_{\text {abs }}$ Melina $\mathrm{i}$ le liona.

PAST bad ABS only ABS Melina OBL DET.SPEC lion

'Only Melina was bad to the lion.'

b. Na' $o$ in ABS object. Context: Did Melina hear the lion and the bird?

na lajona e Melina $* \mathbf{H}_{\mathbf{a b s}}$ na?o $* \mathbf{H}_{\mathbf{a b s}}$ le liona.

PAST hear ERG Melina *ABS only *ABS DET.SPEC lion

'Melina heard only the lion.'

c. $N a^{\prime} o$ in ERG subject. Context: Did Melina and Melani hear the lion?

$$
\begin{aligned}
& \text { na layona *e na?o *e Melina } \mathrm{H}_{\mathrm{abs}} \text { le liona. } \\
& \text { PAST hear *ERG only *ERG Melina ABS DET.SPEC lion }
\end{aligned}
$$

\footnotetext{
${ }^{26}$ For a semantic analysis of $n a^{\prime} o$ and related material, see Hohaus and Howell (2015).

${ }^{27}$ There were some cases where Calhoun (2017) reported that an $\mathrm{H}$ did appear before the absolutive under $n a^{\prime} o$. I leave those cases aside in this section and address them in the following section, Sect. 5.2, where I argue that these high edge tones, which typically co-occur with pauses, are prosodic boundary tones, distinct from the three syntactically-conditioned Hs in Samoan.

${ }^{28}$ While I asked for acceptability judgments from consultants for the segmental case markers, I did not for the Hs. Yu and Özyıldız (2016, Sect. 3.4.1) showed that absolutive particle ia is not licit under na'o, see also Sect. 5.3.
} 
'Only Melina heard the lion.'

d. Na' $O$ in OBL PP. Context: Was Melina bad to the lion and the bird?

na leaya $\mathrm{H}_{\mathrm{abs}}$ Melina *i na?o *i le liona.

PAST bad ABS Melina* OBL only * OBL DET.SPEC lion

'Melina was bad to only the lion.'

The same is true if the argument under $n a^{\prime} o$ is fronted, e.g., in na'o le liona na lagona e Melina. 'only DET lion PAST hear ERG Melina', the fronted counterpart of (27b): the only $\mathrm{H}$ that appears is the expected $\mathrm{H}_{\text {front }}$ at the right edge of fronted $n a^{\prime} \mathrm{o}$ le liona 'only the lion'. Thus, the $\mathrm{H}_{\mathrm{abs}}$ patterns together with segmental case markers in being illicit under $n a^{\prime}$ o, supporting a unified analysis of $\mathrm{H}_{\mathrm{abs}}$ and segmental case markers in Samoan. That case marking is illicit under $n a^{\circ} \mathrm{o}$ is intriguing considering Hohaus and Howell's (2015) analysis that $n a$ ' $o$ is a special case of ' $O$-marked' constructions. More generally, Brown and Koch (2016: §4.1) analyzes focus-sensitive 'only' expressions in Polynesian such as $n \bar{a} k o$ in Tokelauan as association between a focus-sensitive $n a$ particle and *ko-marked nominals. Perhaps there is a connection between the apparent absence of case-marking under $n a^{\prime} \circ$ and in fronted DPs; recall that fronted DPs are preceded by ' $o$. Together, this data raises the hypothesis that ' $o$ interacts with case-marking and might block case assignment_-possibly even because it itself assigns case.

\subsection{High prosodic boundary tones are distinct from Hs inserted in spellout}

In the course of demonstrating that the $\mathrm{H}_{\mathrm{abs}}$ is illicit where other (segmental) case markers are also illicit in the preceding section, I showed that Calhoun's (2017) transcriptional data that H- (almost) never appears before post-verbal absolutives under $n a^{\prime} \mathrm{o}$ is not problematic for analyzing the $\mathrm{H}_{\mathrm{abs}}$ as the spellout of absolutive case. In this section, I address another challenge Calhoun (2017) raises for the analysis of $\mathrm{H}_{\mathrm{abs}}$ as a tonal case marker: variability in the appearance of high edge tones before post-verbal absolutives under $n a^{\prime} \mathrm{o}$ and between nominals in equative copular clauses (Mosel and Hovdhaugen 1992: Sect. 11.3).

$\mathrm{Yu}$ and Stabler (2017) hypothesizes that there are high edge tones in Samoan which are not inserted in spellout like $\mathrm{H}_{\mathrm{abs}}, \mathrm{H}_{\text {coord }}$ or $\mathrm{H}_{\text {front }}$. Yu and Stabler (2017) found that there were positions where none of these three would be expected, but where both high and low edge tones occurred, often alongside a pause. It was hypothesized that these sporadically appearing tones were high and low prosodic boundary tones. Recall that by 'prosodic boundary tone,' I mean a tone that marks the edge of prosodic constituents above the level of the prosodic word. Such tones are, by definition, subject to the vagaries of prosodic phrasing choices of the speaker. While prosodic boundary tones can be indirectly conditioned by syntax, crucially, they are also conditioned by non-syntactic, prosodic factors, e.g., 'prosodic markedness' restrictions on size and eurhythmy and speech rate (see Yu and Stabler (2017: Sect. 2.2)). Based on the work presented in Yu and Stabler (2017) and in Calhoun (2017), I raise the possibility that the $\mathrm{H}$-s Calhoun (2017) transcribed as preceding absolutives under $n a^{\prime} \mathrm{o}$ are prosodic boundary tones rather than $\mathrm{H}_{\mathrm{abs}}$ tones, and that positions where Calhoun (2017) transcribed both L-s and H-s are positions where low and high prosodic boundary tones ( $\mathrm{L} \%$ and $\mathrm{H} \%$ ) variably occur. 


\subsubsection{Prosodic boundary tones in na'o constructions in Calhoun (2017)}

In the discussion of the absence of $\mathrm{H}_{\mathrm{abs}}$ under $\mathrm{na}^{\prime} \mathrm{o}$ in the immediately preceding section (Sect. 5.1.2), I noted that Calhoun (2017) actually did report the appearance of some high edge tones before absolutives under na' $o$, but I was abstracting away from this. I address this observation here. There are three $n a^{\prime} o$ construction types in Calhoun (2017) with post-verbal absolutives under na'o (Calhoun 2017, (41), (42), (44)). Among these three, Calhoun (2017:22, (41)) reports transcribing an H- preceding $n a^{\prime} \mathrm{o}$ absolutive objects only in sentences with V $n a^{\prime} \mathrm{o}$ OS order, and then, only $25 \%$ of the time.

If no case-marking occurs under $n a^{\prime} \mathrm{o}$, as I hypothesized in Sect. 5.1.2, then how can these apparent sporadic H-s be accounted for? Fig. 6 in Calhoun (2017) compares f0 tracks for two renditions of the same V na' $o$ OS sentence, one in which an $\mathrm{H}$ - is transcribed before $n a^{\prime} \circ$ and one in which there isn't. Calhoun's (2017) transcriptional data doesn't distinguish between edge tones which occur with pauses and those that not. But as Calhoun (2017:22) notes, a pause (longer than the duration of $n a^{\prime} \circ$ in the utterance) occurs following the rise in fo to the high edge tone at the right edge of the verb in Fig. 6. If it is typical for a pause to co-occur with the $\mathrm{H}$ - here, then it may be that the H-s under $n a$ ' $o$ reported $25 \%$ of the time are not absolutive H-'s, and not H-s marking the right edge of a phonological phrase (as proposed by Calhoun), but high prosodic boundary tones marking the right edges of higher-level prosodic constituents such as intonational phrases, i.e., what would often be intonationally transcribed as $\mathrm{H} \%$ rather than $\mathrm{H}$ - in the conventions used in Orfitelli and $\mathrm{Yu}$ (2009), Yu (2011), Calhoun (2015), Yu and Stabler (2017), Calhoun (2017).

There are other places that Calhoun (2017) reports H-s in $\mathrm{na}^{\prime} \mathrm{o}$ constructions. These all occur following a fronted argument (which may be under na' $o$ or not), and variably occur alongside low edge tones transcribed as L-s. Some of the H-s could be $\mathrm{H}_{\text {front }}$ tones, but others could be prosodic boundary tones. Figures 3 and 5 , which are described as typical realizations, show pauses as long as two syllables following the transcribed L-, suggesting that sentence-medial low edge tones, too, might be prosodic boundary tones marking the right edge of a higher-level domain like an intonational phrase, e.g., an L\%.

\subsubsection{Prosodic boundary tones in equative copular constructions in Calhoun (2017)}

Like in the $n a^{\prime} o$ constructions, Calhoun (2017) finds many instances of high edge tones in places where an $\mathrm{H}_{\mathrm{abs}}$ would not be expected, as well as low edge tones. In all cases, the transcribed edge tones occur at the left or right edges of ' $O$-marked nominals and/or at the left edges of PPs or clausal conjuncts. Some of the transcribed H-'s might be tones syntactically conditioned by fronting; see Collins (2016:8, Sect. 2.2) for an XP-fronting account of predicate initial ordering. But all representative f0 contours for copular constructions shown in Calhoun (2017) exhibit phonetic signatures of higher-level prosodic phrase breaks. Figures 7,8, and 10 in Calhoun (2017) show pauses following every transcribed $\mathrm{H}$ - and L- - some pauses as long as a 3-syllable word in the utterance, and Fig. 9 shows a stretch of glottalization spanning three syllables at the right edge of the transcribed L-. (Glottalization at domain edges has been 
found to be more frequent at the edges of higher-level prosodic domains, e.g., see Dilley and Shattuck-Hufnagel 1996).

In summary, the copular and the $n a^{\prime} \mathrm{o}$ construction data in Calhoun (2017) is not problematic for the analysis of the absolutive high as a tonal case marker, if the low and high edge tones that reliably co-occurred with pauses are in fact boundary tones marking a high-level prosodic constituent such as the intonational phrase.

The presence of an audible pause is often taken to be a phonetic signature of a prosodic domain edge high up in the prosodic hierarchy, e.g., the intonational phrase. Pauses indicate strong prosodic boundaries and are due to a slowdown in the speed of articulators (see Krivokapić (2014) for a review); in this sense, (fluent) pauses at the end of intonational phrases can be seen as extreme lengthening. As a rule of thumb, pauses have been used to diagnose intonational phrase boundaries, see e.g., Selkirk (1978/1981:135), Pierrehumbert (1980:19), Ladd (1986:315-317), Nespor and Vogel (1986:188), Krivokapić (2007:163), Jun and Fletcher (2014:501-502). (For instance: "It is between intonational phrases (and only between them, we would claim) that one finds potential pauses." (Selkirk 1978/1981:135)) The convention that (fluent) pauses are used to diagnose intonational phrase boundaries-plus the fact that sentencemedial low edge tones in Calhoun (2017), Yu and Stabler (2017) co-occur reliably with a following pause - raises the possibility that low edge tones are licit only at the end of intonational phrases.

An analysis of edge tones with pauses as intonational phrase boundary tones provides a unified analysis for both the variability in the appearance of an edge tone, as well as the alternation between low and high edge tones- these properties are typical for prosodic boundary tones across languages, e.g., see Jun (1998, 2005, 2014). In Sect. 6.3.2, I further discuss the hypothesis that there are high (and low) edge tones that are prosodic boundary tones, and that these tones are distinct from $\mathrm{H}_{\mathrm{abs}}, \mathrm{H}_{\text {coord }}$, and $\mathrm{H}_{\text {front }}$.

\subsection{On the improbability of a tonal morpheme in a "non-tonal" language}

This section (Sect. 5) has explicated my proposal about what $\mathrm{H}_{\mathrm{abs}}$ is. I close the section by addressing perhaps the most surprising ${ }^{29}$ aspect of it: positing high tones inserted in the spellout of three disparate syntactic configurations in a "non-tonal" language in a "non-tonal" language family. ${ }^{30}$ I address two issues: (i) if such a language where tone appears in so few and such disparate syntactic configurations could

\footnotetext{
${ }^{29} \mathrm{~A}$ reviewer states that the claim that tones can be associated with specific syntactic configurations in Samoan is not surprising because vocative constructions have particular tunes in various languages. Although vocative is often informally referred to as "case," it is in fact different in character than ergative or absolutive case. Case interacts with the morphosyntactic content of the rest of the sentence. That is not true in vocatives.

${ }^{30}$ Prior to Yu (2011), pitch patterns in Samoan had never been described as either distinguishing word meaning or morphosyntactic relations, other than the contrast in force between declaratives and interrogatives (e.g., Mosel and Hovdhaugen 1992:40-43). In fact, only 15/1236 (1.2\%) of Austronesian languages are reported to have lexical tone (Remijsen 2001:474). A number of these lexical tonal languages are in contact with non-Austronesian languages, and none of them are in the Polynesian family like Samoan. No Austronesian languages (to my knowledge) have been described as having pitch patterns that signal a particular morphosyntactic relationship such as tense, number, or case. It may be that such phenomena have not yet been discovered because prosodic fieldwork on Austronesian languages has only recently become
} 
plausibly exist, and (ii) if there is any plausible explanation for a tonal case marker alongside segmental ones.

Languages where tone appears in few and disparate syntactic configurations do exist. Hyman (2018: (1), 2011a: (1.17), 2011b, et seq.) (the wording varies slightly in different papers) defines a tone language as follows: "A language with tone is one in which an indication of pitch is lexically affiliated with at least some morphemes." The motivation for this definition is illustrated with Chimwiini. Chimwiini is described by Kisseberth and Abasheikh (2011) as having an obligatory high tone ("accent") in the final word of every phonological phrase. The high tone is phrase-penultimate by default, but phrase-final for some syntactic configurations. Tone placement is the only thing that carries the contrast between first and second vs. third person in past and present when there is no overt subject. By his definition, Hyman (2011a:130, 135) points out that this single tonal contrast qualifies Chimwiini to be a tone language (i) even if "very sparsely so," and (ii) even if the high tones demarcate phonological phrases (they are still "lexically affiliated": they carry morphemic contrast). Similarly, an $\mathrm{H}_{\mathrm{abs}}$ carries morphemic contrast between absolutive vs. other cases in Samoan and if segmental case markers are dropped, can be the only signal of this contrast. Thus, Samoan is a tone language, even if very sparsely so.

There are other, disparate syntactic configurations that reliably trigger phrase-final rather than phrase-penultimate high tones in Chimwiini. A phrase-final high tone has also been found to be triggered by: relative clauses, negative imperatives, the $k a$ conditional tense, and the conjunction na (Kisseberth and Abasheikh 2011: Sect. 4.1). In all other cases besides first and second vs. third person, the syntactic configuration also triggers segmental changes. For example, a relative verb is marked by a final high tone, but it is also marked by a final -a or -o vowel (Kisseberth and Abasheikh 2011: Sect. 4.1.2). And a conjunction triggers not only final high tone on the coordinated phrase, but also the appearance of the conjunction na. Samoan looks like this, too. Disparate syntactic configurations are spelled out with segmental as well as tonal material. Coordination is spelled out not only with $\mathrm{H}_{\text {coord }}$, but also a coordinator like the conjunct ma. Fronting is spelled out not only with $\mathrm{H}_{\text {front }}$, but also with a change in word order and the appearance of ' $o$. But one particular configuration, absolutive, may be spelled out only with tonal material.

Some other languages where tone-morphology interactions are very sparse include Chickasaw (Gordon 2005: Sect. 11.2.3) and Uspanteko (Bennett and Henderson 2013: Sect. 2.3). Both are described as accentual systems. In Chickasaw, some verbs appear with a high tone (and possibly segmental changes) to express aspectual contrast. In Uspanteko, a plural marker, VP focus clitic, possessive prefixes and a "phrase final status suffix" are associated with the introduction of a high tone. Other languages where particular tones reliably appear under collections of specific syntactic constructions include Dogon languages (Heath and McPherson 2013; McPherson and Heath 2016) and Naxi. In Naxi, the distribution of rising tones is restricted. Synchronic reduction and deletion of a small set of high frequency H-toned enclitics in connected speech/less formal speech can result in a rising contour on the previous syllable when the "orphaned" tone reassociates (Michaud 2006). These enclitics

more prevalent. Richards's (2017) recent work on Tagalog documents an interaction of word order with pitch peak scaling. 
include topicalizers, focus markers, classifiers, exclamative particles, and 'or.' Moreover, Michaud (2006, Sect. 1) traces the diachronic source of a small set of lexical items and constructions that always appear with rising tones to be the orphaned $\mathrm{H}$ tone from an "earlier H-toned possessive."

The Naxi example of tonal reassociation under reduction/deletion of segmental material bears similarities to a possible explanation of why the absolutive case marker might be tonal rather than segmental. Yu and Özyıld1z (2016) discusses the existence of a segmental absolutive particle $i a$ (denoted here as $i a_{\mathrm{abs}}$ ) which appears to be a possible source of $\mathrm{H}_{\mathrm{abs}}$. Whether similar processes might be in play for $\mathrm{H}_{\text {coord }}$ or $\mathrm{H}_{\text {front }}$ remains an open question. Empirical data on $i a_{\mathrm{abs}}$ and a proposal about the emergence of $\mathrm{H}_{\mathrm{abs}}$ from $i a_{\mathrm{abs}}$ are presented in Yu and Özyıldız (2016); I sketch the outline here and refer the reader to Yu and Özyıldız (2016) for details.

Only a few sources in the literature remark that absolutive arguments are preceded by $i a_{\mathrm{abs}}$ (Hovdhaugen 1987:154-155; Mosel and Hovdhaugen 1992:51, 143; Vonen 1988:38-39). Mosel and Hovdhaugen (1992:143) states that $i a_{\mathrm{abs}}$ is always optional and is mostly used before proper nouns and seldom in literary texts. Vonen (1988:3839) also states that $i a_{\mathrm{abs}}$ is always optional and that it can be followed by an article, especially after hesitation. No actual examples of elicited utterances of $i a_{\mathrm{abs}}$ have appeared in the literature other than a few in Hovdhaugen (1987). Yu and Özylldız (2016) reports that speakers never spontaneously produced $i a_{\mathrm{abs}}$ in elicitation, but were meta-linguistically aware of it (if, for one younger speaker, prescriptively from grammar exercises in school) and had systematic intuitions about its distribution. In other words, $i a_{\mathrm{abs}}$ appears to be moribund. Yu and Özyıldız (2016) describes the distribution of absolutive $i a_{\mathrm{abs}}$ in the same set of syntactic structures as those included in this paper. Yu and Özyıldız (2016) shows that $i a_{\mathrm{abs}}$ is licit before absolutives, but not before ergatives or obliques. Moreover, like the segmental case markers, and patterning with the distribution of $\mathrm{H}_{\mathrm{abs}}, i a_{\mathrm{abs}}$ is illicit under fronted expressions and $n a^{\prime} o$ (Yu and Özyıldız 2016: Sect. 3.4.1). And $i a_{\text {abs }}$ is illicit before $\mathrm{H}_{\text {coord }}$ and $\mathrm{H}_{\text {front }}$.

The distribution of $i a_{\mathrm{abs}}$ thus provides additional evidence that $\mathrm{H}_{\mathrm{abs}}$ is a case marker. In addition, the coinciding distribution of $\mathrm{H}_{\mathrm{abs}}$ and $i a_{\mathrm{abs}}$ offers an explanation for why the absolutive case marker in contemporary Samoan is tonal. Namely, the origin of the absolutive high could be leftward tonal reassociation of the high tone from the pitch accent on absolutive $i a_{\mathrm{abs}}$, upon deletion of the segmental material of $i a_{\mathrm{abs}}$, following Yu and Özyıldız (2016, Sect. 4.1). At a high-level, the process of segmental deletion and tonal re-linking that would be involved in this proposed origin of $\mathrm{H}_{\mathrm{abs}}$ is typical of tonal behavior in natural language, e.g., in the formation of Naxi rising tones. A characteristic property of tone, both synchronically and diachronically, is its "stability": even if the segmental material hosting a tone deletes, a tone will remain and be re-associated to remaining segmental material (Yip 2002:67; Hyman $2011 \mathrm{~b}: 210)$. In the case of Samoan, the tone on $i a_{\mathrm{abs}}$ arises from stress, so this is in fact an example of "stress stability" (Kaisse 1982, Sect. 2.1), as discussed in Kaisse's $(1982,1977)$ analysis of hiatus resolution in varieties of Modern Greek. For example, under fast speech rate, $\gamma$ rí $\gamma$ ora érxome 'quickly I come' $\rightarrow$ rrì $\gamma$ orá 'rxome. The bolded $e ́$ is deleted, but its stress appears on the previously unstressed, immediately preceding $a$ (also bolded) (Kaisse 1982, (13a)). The difference in Samoan is that the $\mathrm{H}_{\mathrm{abs}}$ doesn't appear to be associated with stress (Sect. 4.6). 


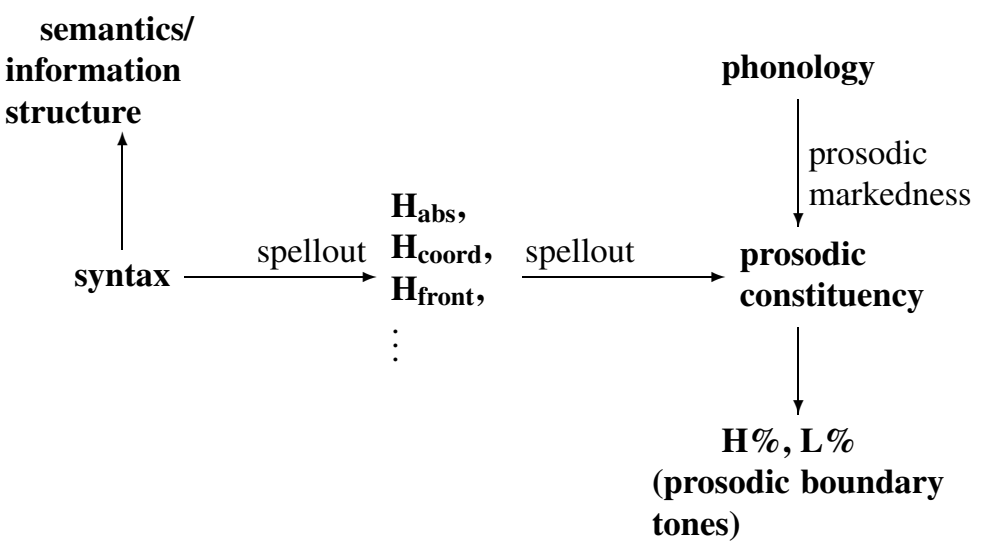

Fig. 14 Diagram schematizing my proposal about two kinds of Samoan edge tones, cf., diagram in Fig. 16 schematizing Calhoun (2017) proposal

One last thing I'll mention here is that the origin of $\mathrm{H}_{\mathrm{abs}}$ from $i a_{\mathrm{abs}}$ also potentially offers another way in which absolutive case marking patterns with ergative and oblique case marking. One puzzling property of $\mathrm{H}_{\mathrm{abs}}$ is that it appears to be realized on phonological material preceding the absolutive argument, rather than on it. (Yu and Özyıldız 2016, Sect. 4.1 provides additional reasons based on typological generalizations about tonal association for why leftward rather than rightward tonal association from the $\mathrm{H}$ of $i a_{\mathrm{abs}}$ to phonological material preceding the absolutive would be expected.) This property is less puzzling, if we assume that all case markers in Samoan are phonologically left-leaning, e.g., enclitic-even if they are syntactically right-leaning. Then absolutive $i a_{\mathrm{abs}}$, too, might be phonologically phrased to the left, resulting in leftward association of its high tone. This type of syntax-prosody "mismatch" is exceedingly common cross-linguistically (Klavans 1985; Himmelmann 2014). Moreover, contemporary utterances with absolutive $i a_{\text {abs }}$ that I have elicited include renditions where the segments of $i a_{\text {abs }}$ are highly reduced (and possibly stressless), but an $\mathrm{H}_{\mathrm{abs}}$ is still easily detected.

The next section, Sect. 6, shows that alternative analyses do not fit the current empirical data as well as my proposal. For ease of comparison, I give a high-level summary of my proposal and how it fits the current data below.

As shown in Fig. 14, I assume that semantic and information structure are encoded in syntactic structure (Kiss 1995). I propose that there are two distinct components of the grammar that trigger high edge tones in Samoan: (i) spellout, where Hs appear as phonological reflexes of structural configurations in syntax, and (ii) phonological grammar, in processes conditioned on prosodic domains. Hs inserted in spellout $\left(\mathrm{H}_{\mathrm{abs}}, \mathrm{H}_{\mathrm{coord}}, \mathrm{H}_{\text {front }}\right.$, and perhaps more to be uncovered) have no access to prosodic domains. There is also no general property underlying absolutive case, coordination, and fronting that triggers Hs. Hs (and Ls) inserted in the phonological grammar (H\% - and L\%, too), i.e., 'prosodic boundary tones,' have no direct access to syntactic domains. They are conditioned on prosodic domains, which, in turn, are conditioned jointly on the basis of syntactic structure and prosodic markedness restrictions (see Sect. 5.2). 
The two types of Hs-from spellout, and from phonological grammar-can be distinguished by the following:

1. Distributional facts

- Hs inserted in spellout reliably appear in a small, restricted set of distinct syntactic configurations (absolutive case, coordination, fronting; more may be found with additional fieldwork). Moreover, the distribution of $\mathrm{H}_{\mathrm{abs}}$ patterns with the distribution of segmental case markers rather than with the distribution of $\mathrm{H}_{\text {coord }}$ and $\mathrm{H}_{\text {front }}$.

- Hs (and Ls) inserted by the phonological grammar, denoted as $\mathrm{H} \%$ and L\%, don't reliably appear in particular syntactic configurations. Instead, they are triggered by prosodic domains, which are sensitive to both syntactic structure and prosodic factors. Thus these Hs variably and sporadically appear in variable syntactic configurations. These syntactic configurations do include those that trigger the spellout of an $\mathrm{H}$, but also others, e.g., ergative case and oblique modifiers and objects.

2. Phonetic realization

- Hs inserted in spellout do not co-occur with a pause.

- $\mathrm{H} \% \mathrm{~s}$ (and L\%s) inserted in the phonological grammar reliably co-occur with a pause.

3. Sensitivity to prosodic factors

- The presence/absence of Hs inserted in spellout is insensitive to prosodic factors, e.g., speech rate and prosodic length.

- $\mathrm{H} \% \mathrm{~s}$ (and L\%s) inserted in the phonological grammar are sensitive to prosodic factors.

To facilitate future work, I state the criteria for distinguishing the different kinds of Hs as strongly as possible to make my proposal easily testable and falsifiable. For example, I would be surprised if the distinction in phonetic realization is as stark as stated. Tonal and rhythmic signatures of prosodic domains can be "mismatched" (as in Break Index 2 in ToBI transcription Beckman et al. 2005), e.g., so a rushed H\% might not co-occur with a pause.

\section{Alternative analyses of high edge tones in Samoan: Syntax-prosody mapping and information structure}

In this section, I present possible alternative analyses of high edges in Samoan, including the ones proposed in Calhoun $(2015,2017)$, and show that they do not fit the current data as well as mine. Given that it appears that syntactic structure conditions at least some of the high edge tones in some way and that the pronounced elements at hand are tones, considering an analysis of the Hs based on what is known about the syntax-prosody interface is only natural. All but one of the alternative analyses, including Calhoun (2015) discussed here fall within the syntax-prosody interface. 
The exception is Calhoun's (2017) proposal of a syntax-less information structureprosody interface, which I discuss in Sect. 6.4. Unlike my proposal, both Calhoun $(2015,2017)$ pursue analyses where all high edge tones in Samoan are unified as having a single, shared source. It may be worth reiterating from Sect. 1 that my proposal in Sect. 5 falls within the syntax-prosody interface: some high edge tones in Samoan are introduced in spellout, and some are conditioned by prosodic domains, which may in turn be conditioned by syntactic domains.

The rest of this section discusses alternative analyses of high edge tones in Samoan within the syntax-prosody interface. First, I give derived syntactic tree structures after the spellout of the absolutive, coordination, and fronting Hs. The purpose of providing these trees is not to argue that these trees must be the "right" ones for Samoan, but to allow me to engage concretely with alternative analyses of $\mathrm{Hs}$ that fall within the syntax-prosody interface. I begin by considering analyses within the bounds of 'direct reference' theories, e.g., Kaisse (1985), Odden (1987), Pak (2008). These theories allow the domain of a phonological process to be defined directly in terms of syntactic relations (Sect. 6.2). In Sect. 6.3, I discuss analyses that fall within 'indirect reference' theories, e.g., Nespor and Vogel (1986), Selkirk (1986), Hayes (1989), Inkelas (1989), Truckenbrodt (1999), Selkirk (2011). These assume that the domain of phonological processes are defined in terms of prosodic constituents rather than directly in terms of syntactic relations and structures: phonological processes may reference syntactic structure only indirectly via systematic (but not necessarily transparent) relations between prosodic and syntactic constituents. I close the section by briefly considering some other recent ideas about the syntax-prosody interfaces, including analyses that refer to syntactic phases, e.g., Ishihara (2004), Kratzer and Selkirk (2007), Dobashi (2009), Downing (2010), Cheng and Downing (2016).

\subsection{A working proposal for the spellout of $\mathbf{H}_{\mathbf{a b s}}$}

The proper syntactic treatment of case in Samoan and other ergative languages remains controversial, e.g., Chung (1978), Legate (2008), Koopman (2012), Collins (2014, 2016), but those structural issues were largely orthogonal for the presentation of empirical data in Sect. 4. However, grappling with any theory of the syntax-prosody interface demands as a prerequisite some syntactic analysis and some prosodic analysis of the phenomenon at hand. Here, we provide a working proposal for syntactic structure and spellout in Samoan for $\mathrm{H}_{\mathrm{abs}}$. We adopt the proposals of $\mathrm{Yu}$ and Stabler (2017), which follows a syntactic analysis of Samoan based on Collins (2016, 2015, 2014, to appear). This syntactic analysis includes a VP-fronting account of [VO]S/VSO order, as schematized in $(28,29)$. Due to space constraints, we show only a derived tree for the transitive clause (2a). See Yu and Stabler (2017) for syntactic analyses and derived trees for coordination and fronting. ${ }^{31}$

\footnotetext{
${ }^{31}$ Like Yu and Stabler (2017), it is not the goal of this paper to argue that these particular trees are the "correct" ones for Samoan. The structures proposed are in the spirit of syntactic analyses well-supported by careful consideration of extensive data in Collins (2016, 2015, 2014, to appear). I invite the reader to consider and contribute their own independently motivated, alternative analyses, too, and explore how the assessment of different syntax-prosody theories of Samoan high edge tones might change as a result.
} 
(28) [VO]S order: VP containing object fronts (Woolford 2015:495, (12))

a. Base order $\mathrm{S}[V P \mathrm{~V} O]$

b. Order after VP-fronting $[V P \mathrm{~V} \mathrm{O}] \mathrm{S}$

(29) VSO order: object moves out of VP before VP fronts (Woolford 2015:495, (13))

a. Base order $\mathrm{S}[V P \mathrm{~V}$ O]

b. Order after object shift $\mathrm{S} O[V P \mathrm{~V}$ t]

c. Order after VP-fronting $[V P \mathrm{~V} \mathrm{t}] \mathrm{S} \mathrm{O}$

(30) Derived tree for transitive declarative (2a)

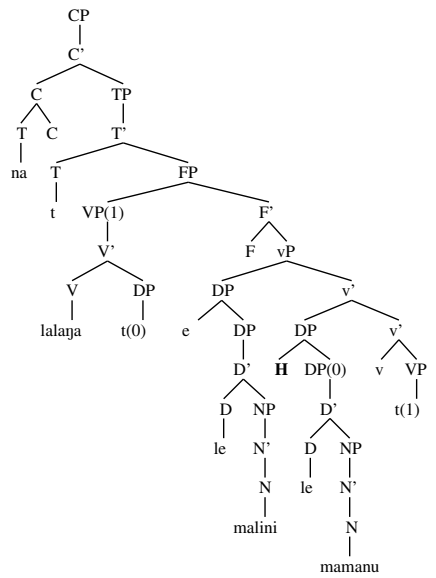

\subsection{Direct reference theories in syntax-prosody mapping}

Direct reference theories allow phonology to directly "see" syntax, but my proposal that $\mathrm{H}_{\mathrm{abs}}, \mathrm{H}_{\mathrm{coord}}$, and $\mathrm{H}_{\text {front }}$ are introduced by particular syntactic configurations does not fit within these theories. This is because direct reference theories allow phonological processes to access only "category-neutral, label-neutral, c-command relationships and edge conditions existing among syntactic terminal nodes, as determined by $\theta$-theoretic hierarchical structure" (Elordieta 2008:225). In fact, as pointed out in Kaisse and Zwicky (1987:7), the major point of agreement between direct and indirect reference theories (other than that syntax can influence phonological patterns) is that syntactic "category membership is generally irrelevant (cross-categorial behavior being the rule...". As far as I can tell, it does not seem that such cross-categorial syntactic relations can unify syntactic configurations for absolutive case, coordination and fronting; see the OSF repository for more details.

\subsection{Indirect reference theories in syntax-prosody mapping}

Proposing an indirect reference theory demands an additional kind of analysis not required for proposing a direct reference theory: an analysis of prosodic constituency 
for the phenomenon at hand. This is true of course, for any theory of the Samoan Hs that relies on prosodic constituency, whether it falls under the category of indirect reference or not.

The necessary motivation for the introduction of prosodic constituency for describing a phenomenon is the same as for syntactic constituency: positing constituents captures generalizations in the observed patterns of natural language, e.g., see Nespor and Vogel (1986:58-59). When constellations of phonological processes consistently target or refer to a particular chunk of phonological material, that is reason to identify that chunk as a prosodic domain in the grammar (Selkirk 1978/1981; McCarthy and Prince 1986/1996; Nespor and Vogel 1986; Pierrehumbert and Beckman 1988; Hayes 1995; Jun 1996, 1998; Selkirk 2011; Myrberg and Riad 2015). For instance, Jun's (1996, 1998) evidence from a constellation of phonological processes for a prosodic domain termed the 'accentual phrase' in Korean includes post-obstruent tensing, vowel shortening, lenis stop voicing, and tonal insertion. Identifying prosodic domains as categories and referring to them in a prosodic grammar (Selkirk 1978/1981) then presumably allows the grammar to be more succinct than if prosodic domains are not recognized.

A common finite, ordered set of categories in a prosodic grammar is the enumeration in (31) (Selkirk 2011, (1)); given such an enumeration, prosodic trees are derived using these categories, and the category names are used as node labels. I will assume this enumeration for the discussion of prosodic trees and constituency in this paper.

(31) Enumeration of categories in a prosodic grammar (Selkirk 2011, (1))
a. Intonational phrase ( $\iota)$
b. Phonological phrase $(\phi)$
c. Prosodic word $(\omega)$
d. Foot $(\mathrm{Ft})$
e. Syllable $(\sigma)$

Comparing a syntactic tree from an independently motivated syntactic analysis of the phenomenon at hand-call this $S$ - to a prosodic tree motivated by generalizations over the domains of phonological processes-call this $P$, one might then discover that there are systematic relations between constituents in the trees. For instance, in Match theory (Selkirk 2009, 2011), the following correspondence relations are predicted to hold between syntactic and prosodic constituents (stated as violable constraints):

(32) Definition of syntax-prosody MATCH constraints (Bennett et al. 2016:187, (34))

a. MATCH-WoRD: Prosodic words correspond to the heads from which phrases are projected in the syntax (heads that will often have a complex internal structure determined by head movement).

b. MAtCh-Phrase: Phonological phrases correspond to maximal projections in the syntax. 
c. MATCH-Clause: Intonational phrases correspond to those clausal projections that have the potential to express illocutionary force (assertoric or interrogative force, for instance).

A syntactic tree $S$ can be transduced into a predicted prosodic tree $P_{S}$ respecting these constraints. Following Elfner (2012) and Bennett et al. (2016), I assume that in this transduction, $S$ is first transduced to a flattened syntactic tree $S^{\prime}$, where any phonologically empty terminals are deleted, and then any two syntactic nodes are merged if they both exhaustively dominate the same set of remaining terminals; $S^{\prime}$ is then transduced into $P_{S}$ following the constraints in (32). For instance, consider the transduction of (30a) into a prosodic tree respecting the constraints in (32), shown in (33). The prosodic tree in (33b) is the predicted prosodic tree if prosodic and syntactic constituency "match" in the sense of MATCH-PHRASE in (32). ${ }^{32}$ See Yu (2019) for details.

a. the syntactic tree $S$ for (2a)

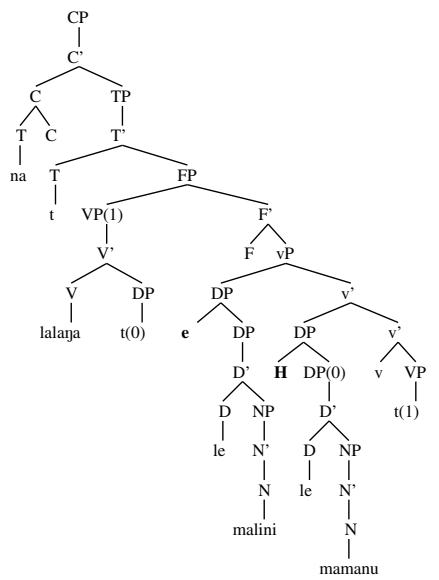

b. the predicted prosodic tree $P_{S}$ for $S$

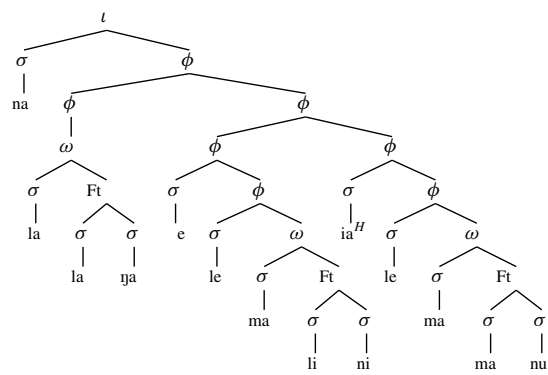

We can then compare the prosodic tree $P$, as determined by generalizations over domains of phonological processes, to the predicted prosodic tree transduced from

\footnotetext{
${ }^{32}$ For the purposes of having a working proposal, I assume that $i a_{\mathrm{abs}}{ }^{H}$ (or $\mathrm{H}_{\mathrm{abs}}$ ) comes in alongside segmental material in a single prosodic tree. Of course, alternative treatments of $\mathrm{H}_{\mathrm{abs}}$ are available, e.g., having it come in a separate structure together with other tones, e.g., Liberman (1975a, Sect. 2.4.3) or Pierrehumbert and Beckman (1988, Ch. 5).
} 
the syntactic tree, $P_{S}$. Note crucially, that the prosodic trees $P$ and $P_{S}$ are arrived at independently, one from a hypothesis about how syntactic trees map to prosodic ones $\left(P_{S}\right)$, and one from a hypothesis about generalizations over phonological processes ( $P$ ) (Ladd 2008:288-290). Even if these two prosodic trees are not identical, there might still be a systematic — though not immediately apparent—relation between syntactic and prosodic trees. One option to reveal this systematic relation is the approach taken in Match theory: any deviations between $P$ and $P_{S}$ are explained away as the result of the adherence of the prosodic tree to phonological well-formedness constraints ranked above the interface constraints in (32) (Selkirk 2011). ${ }^{33}$

Using this approach, I explicate alternative analyses that fall within indirect reference theories. In Sect. 6.3.1, I point out there is little evidence from the domain of phonological processes to help diagnose prosodic constituency in Samoan. Perhaps the main evidence available is the positioning of edge tones, so in Sect. 6.3.2, I take an in-depth look at what evidence there is that edge tones in Samoan are prosodic boundary tones. My conclusion from these two sections is that there is in fact not particularly strong evidence that sentence medial Hs in absolutive, coordination, and fronting constructions mark the right edges of phonological phrases, as assumed in Calhoun $(2015,2017)$. Thus, any theory of Hs in Samoan that relies on the assumption of a particular analysis of prosodic constituency has the challenge of finding additional phonetic and phonological evidence for the assumptions made. Finally, Sect. 6.3.3 shows that even considering the different options for approaching mismatches, no systematic relation between syntactic and prosodic trees is at all apparent because the syntactic configurations in which Hs occur defy generalization (as we have already seen from one perspective, in the discussion of direct reference theory in Sect. 6.2). This is a point also made in Calhoun (2017), contra Calhoun (2015). In summary, the current evidence for an indirect reference theory of Hs in Samoan is not strong.

\subsubsection{Lack of evidence bearing on prosodic constituency in Samoan}

An attractive possibility for unifying the configurations where Hs occur is to posit that all Hs are tones that demarcate the edges of a particular kind of prosodic constituent. This is the approach that Calhoun $(2015,2017)$ takes: sentence-medial high (and low) edge tones mark the right edge of phonological phrases ( $\phi$-phrases). As reviewed in Sect. 6.3, we have reason to posit a phonological constituent when we can show that a constellation of phonological processes consistently target or refer to it. What phonological processes refer to the putative $\phi$-phrase?

\footnotetext{
${ }^{33}$ Another option is to take the $P$ as the ground truth for the "right" syntactic tree and assert that the original syntactic analysis has been revealed by the prosodic tree to be incorrect (Liberman 1975b; Wagner 2005, 2010; Hirsch and Wagner 2015). A similar option is to take $P$ as the ground truth for the "right" syntactic analysis and assert that it's not syntactic constituents that correspond to prosodic ones, but a different kind of syntactic unit—syntactic phases e.g., Ishihara (2004), Kratzer and Selkirk (2007), Dobashi (2009), Downing (2010), Cheng and Downing (2016). (Another option would be to take $P_{S}$ as the ground truth for the "right" prosodic tree and assert that the original phonological analysis has been revealed by the syntactic tree to be incorrect: this might characterize the approach taken by linguists who take prosodic constituents to be defined by hypotheses about how syntactic trees are transduced to prosodic ones.)
} 
One phonological process that is commonly bounded to be internal to a particular prosodic domain is f0 range scaling. Calhoun (2015:219) found evidence that " $\mathrm{H}$ tones trigger 'accent suppression'," but Calhoun (2017:26) found counter-evidence to this. Another phonological process that commonly occurs at prosodic domain edges is pre-boundary lengthening (Sect. 5.2). However, Yu (2011), Calhoun (2015:216), and Calhoun (2017:20) all state that if there is any (non-pausal) pre-boundary lengthening where sentence-medial Hs occur at all, it is subtle. Moreover, there is a pre-boundary lengthening process that targets a subset of the putative $\phi$-phrases-the $\phi$-phrases that co-occur with pauses, as discussed in Sect. 5.2. There, I raised the possibility that high and low edge tones that co-occur with pauses are prosodic boundary tones, perhaps intonational phrase tones, and distinct from the absolutive, coordination, and fronting Hs.

Thus, it appears that the only phonological process we know of that targets a putative $\phi$-phrase in Samoan is tonal insertion of an edge tone. In the next section, I point out that tonal insertion alone is not necessarily strong evidence for proposing a particular prosodic constituent.

\subsubsection{Not all edge tones are triggered by prosodic boundaries}

In this paper, I have been using the term 'edge tone' descriptively to refer to a tone that seems to track with a (morphosyntactic) word edge. In intonational analysis, it is common practice to assume that a tone with this behavior marks a prosodic constituent edge, see e.g., Jun (1998:221) and Jun and Fletcher (2014). (This doesn't necessarily preclude it from also being associated to a stress-bearing unit, e.g., Prieto et al. 2005, Grice et al. 2015.) But a tonally marked domain does not necessarily imply a particular prosodic constituent category, nor vice versa (Gussenhoven 1990). First, it is not the case that a prosodic constituent must be marked by a tone (Bennett 2015:346); it might instead be marked by f0 scaling, or by the application of segmental phonological processes, e.g., devoicing (Hyman and Monaka 2011). More generally, it is not necessarily the case that prosodic constituency determined by the placement of tones is the same as prosodic constituency determined by the application of other phonological processes (Jun 1998, Sect. 4.2). For example, Gussenhoven (1990) illustrates how the prosodic structure of English reporting clauses, vocatives, and constant polarity tags challenges the assumption that tonal association domains are the same as domains defined by durational properties such as pausing.

Second, it is not the case that a tone that tracks with word edges is invariably triggered by phonological constituency. Himmelmann and Ladd (2008:255) points out: “... not all lexical tone languages use intonational boundary tones; for example, some West African tone languages appear not to have them, so that in these languages the pitch contour of an utterance is almost completely determined by the string of lexical tones." That is, an edge tone might be lexically specified. For instance, in Bole, a Chadic language of Nigeria, an example of a completely tonally specified utterance is: ànín lálá méngò 'the owners of the spider came back', where acute accents mark high tones and grave accents mark low tones. Of course some of the lexically specified tones will fall at word edges. An interesting example of lexical edge tones comes from Pittayaporn's (2007) description and analysis of final particles in Thai. 
Pittayaporn (2007) defines final particles to be grammatical morphemes that occur at the end of (intonational) phrases; some are specified for tone and others are not, and intonational boundary tones surface when there is a toneless final particle. But if the intonational phrase ends in a tonally specified lexical word or final particle, then the boundary tone does not surface: lexical words and tonally-specified particles "override" boundary tones. Pittayaporn (2007) thus shows cases where edge tones might be either tones that come in in lexical insertion (in lexical words), or tones that come in in spellout of some syntactic configuration (in particles). Note that the latter case-edge tones that come in in spellout of some syntactic configuration-is exactly the case that I am proposing for Samoan Hs.

Finally, there are recent case studies of variably aligned tones that again highlight a dissociation between edge tones and prosodic boundary tones. Maskikit-Essed and Gussenhoven (2016) analyzes Intonational Phrase-final high boundary tones in Ambonese Malay as "boundary tones that remain floating" because the alignment of the $\mathrm{H}$ peak does not systematically correlate with some segmental anchor within the word. This is an example of prosodic boundary tones that are not aligned to edges, and indeed, perhaps not even associated to any prosodic structure. Bruggeman et al. (2017) finds variable alignment of a $\mathrm{H}$ tonal target within focused question words 'qwords,' e.g., 'what' and phrases, e.g., 'which pineapple' in Tashlhiyt Berber. The qword tones in question phrases are consequently analyzed as being associated directly to the focused qword/phrase rather than some specified prosodic constituent, see Bruggeman et al. (2017, Fig. 13) — even though the L tone is often aligned at/near the right edge of the qword. This qword example could be seen as another case of tones reliably appearing in some syntactic configuration, analyzed as coming in the spellout of that syntactic configuration. Additional examples of variable alignment will likely be discovered as coverage of the world's prosodic systems in fieldwork continues to grow.

In summary, the fact that a tone appears at/tracks with a word edge does not imply that it was inserted by the grammar as the consequence of phonological constituency. I have presented examples from a variety of languages in which an edge tone instead can be analyzed as coming in in lexical insertion or spellout. In this case, the fact that a tone aligns to an edge is because spellout placed it there. I have also shown that there is precedence for positing that tonally-marked domains are not necessarily particular constituents in the prosodic hierarchy. Thus, the presence of high edge tones alone is not enough to warrant the assumption that some or all of them mark a particular category in the prosodic hierarchy, such as a phonological phrase, as assumed in Calhoun $(2015,2017)$.

\subsubsection{Lack of unified syntactic environments where Hs appear}

Any alternative analysis for Hs that falls within indirect reference theories assumes that there is evidence to support that the Hs mark prosodic domain edges. In Sect. 6.3.1 and Sect. 6.3.2, I have cautioned that it is far from clear that $\mathrm{Hs}$ in Samoan are prosodic boundary tones, or that we understand how to parse Samoan utterances into phonological phrases: that is, the key assumption underlying any indirect reference theory of Samoan Hs is not well supported. Coming from the viewpoint 
Fig. 15 The mapping from $S$ in (33a) to this prosodic tree $P$ violates MATCH-PHRASE to satisfy higher-ranked prosodic markedness constraints

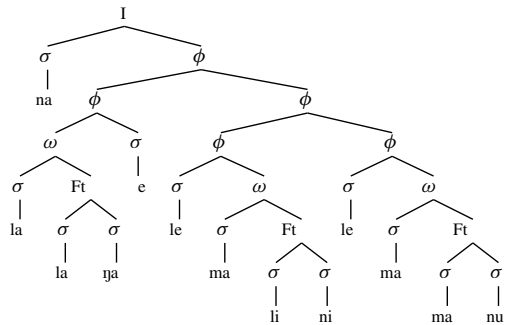

of syntactic structure, the support for an indirect reference theory fares no better, as also pointed out in Calhoun (2017). In Sect. 6.2, I already showed that no reasonable category-free, general syntactic configuration can unify the absolutive, fronting, and coordination configurations where Hs reliably appear. Thus, there is no impetus to unify a collection of syntactic configurations via prosodic constituency. I reinforce this point here by showing that assuming that Hs mark $\phi$-phrases does not fit either the prosodic tree $P_{S}$ predicted by MATCH PHRASE operating on the syntactic tree $S$ shown in (33), or the $[V P \mathrm{Vt}] \mathrm{S} \mathrm{O}$ and $[V P \mathrm{~V} \mathrm{O}]$ syntactic constituency implied by a VP-fronting account of Samoan syntax (Collins 2016).

Let us assume that Hs mark the right edge of $\phi$-phrases. (If Hs marked prosodic words, we'd expect to see many more of them, coinciding with the domain of footing; if Hs marked intonational phrases, we'd expect to see much fewer of them sentencemedially.) Consider the syntactic/prosodic tree pair shown in (33), for a VSO transitive sentence (with the terminal $\left[\mathrm{ia}^{H}\right]$ deleted in $P_{S}$ ). The predicted prosodic tree $P_{S}$ incurs no violation of MATCH-PHRASE. If Hs marked the right edge of $\phi$-phrases, we'd expect to see Hs not only immediately preceding the absolutive object, but also the ergative subject. This does not fit with the data: Hs do not reliably appear before the ergative subject in VSO sentences. But in the beginning of Sect. 6.3, I offered a number of approaches to rescue an analysis involving prosodic constituency. Here, we might allow for 'mismatch': suppose that some prosodic markedness constraints are ranked higher than MATCH PHRASE. Then a reasonable prosodic tree $P$ might be the one shown in Fig. 15. Here, I have assumed that the ergative case marker $e$ is phrased to the left to satisfy STRONGSTART (Selkirk 2011:470, (38)), which militates against weak prosodic elements at left edges. This rephrasing of $e$ also removes the violation of a BINARITY-MINIMUM constraint (see Elfner 2012:153, (4), and refs. within) in the prosodic tree $P_{S}$ in $(33 \mathrm{~b})$ due to the unary branching leading to the terminal [lalaya] 'weave'. But even allowing for the mismatch in Fig. 15, assuming that Hs mark the right edge of $\phi$-phrases would still imply the presence of an $\mathrm{H}$ before the ergative DP, which does not fit the data.

More generally, consider the constituency in the VP-fronting account of Samoan assumed here (Collins 2016): the default word order in a transitive clause, ${ }_{V} P \mathrm{~V}$ t] $\mathrm{S} \mathrm{O}$, and the word order in pseudo noun incorporation $[V P \mathrm{~V} \mathrm{O}] \mathrm{S}$. In Sect. 4.4, I showed that an $\mathrm{H}$ precedes the subject in $\left[V_{P} \mathrm{~V}\right.$ O] S, i.e., $\left[V_{P} \mathrm{~V} \mathrm{O}\right] \mathbf{H ~ S}$. But again, it is not the case that an $\mathrm{H}$ reliably appears before the ergative subject, i.e., $\left[V_{P} \mathrm{~V}\right.$ t] H S O. This basic asymmetry in the distribution of syntactically-conditioned Hs in Samoan does not fit the predictions of an indirect theory where Hs are associated to $\phi$-phrases, given the working proposal of the syntax-prosody interface assumed 
here. ${ }^{34}$ To rescue an indirect theory in which Hs mark $\phi$-phrases, we could abandon the well-established VP-fronting account for some syntactic analysis that would place a major syntactic constituency boundary preceding the subject in pseudo noun incorporation, but not preceding the subject in transitive clauses. I invite the reader to consider possible alternative, independently motivated syntactic analyses fitting this criteria. Another approach would be to refer to syntactic phases rather than constituents in syntax-prosody mapping; but doing so would still require meeting the challenge of fitting this asymmetry and would require stipulation of phases to fit this data and the distribution of other syntactically-conditioned $\mathrm{Hs}$ beside the absolutive high.

\subsection{Calhoun (2017) proposal: Hs and information structure}

Calhoun (2017: Sect. 2.2) argues that an indirect theory of Samoan edge tones is not well-supported because the current evidence is against Hs marking XPs. Instead, Calhoun (2017:36-37) proposes that sentence-medial high (and low) edge tones in Samoan are all phonological phrase boundary tones and states the following: the results "suggest it is important to consider information structure in tandem with syntactic influences on phrasing, so information structural effects are not mistaken for syntactic ones (cf. Schultze-Berndt and Simard 2012). The data presented here rather support the view that word ordering and prosodic structure in Samoan are strongly influenced by information structure." The proposal is quoted in (34) and a strong version of the proposal with a syntax-less mapping from information structure to prosodic structure is schematized in Fig. 16, cf. my proposal in Fig. 14.

(34) Summary of Calhoun's (2017) proposal (Calhoun 2017:37)

a. The default ordering of information in Samoan is rheme-theme. In this order, the rheme is normally phrased separately to the theme.

b. If the theme contains a focus, it should normally precede the rheme, a focused theme following the rheme is dispreferred. In theme-rheme order, a prosodic boundary between the constituents is optional.

c. H- phrase tones mark an information unit as incomplete. Typically, this marks the end of a rheme with a following theme. However, H- tones can also mark coordinated information units.

d. L- phrase tones mark a completed information unit.

e. A weak ((!) $\left.\mathrm{H}^{*}\right)$ or no accent on a constituent marks it as backgrounded.

In principle, this proposal can account for the data in this paper, i.e., where edge tones appear and don't appear. But the proposal-as currently stated-could reasonably account for an extremely wide range of distributions of edge tones because it isn't readily falsifiable. First, specific information structural configurations are only ever proposed to variably trigger the presence of edge tones, e.g., the proposal states

${ }^{34}$ Calhoun (2017: Sect. 2.2) makes a similar point, but for VSO and VOS transitive clauses, rather than for $\mathrm{VSO}$ and pseudo noun incorporation $[V P \mathrm{~V} \mathrm{O}] \mathrm{S}$ configurations as is done here. 
Fig. 16 Diagram schematizing a strong version of Calhoun's (2017) proposal with a syntax-less information structure-to-prosody mapping, cf. diagram in Fig. 14 of my proposal for comparison

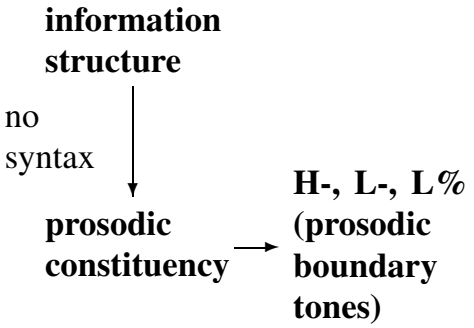

that an H- "typically" marks the end of a rheme with a following theme; in themerheme order, a prosodic boundary between the constituents is "optional"; $\mathrm{H}$ - tones "can" mark coordinated information units. Second, it is challenging to determine what the information structure is - in particular, how to identify and motivate the choice of the theme and rheme for any given sentence. The identification of the theme and rheme requires a precise theory of information structure, including what the relevant context for determining what the information structure is. And as Calhoun $(2017: 8)$ points out, establishing what the context in a linguistic elicitation is can be quite tricky. In addition, another challenge to testing the proposal is that it relies on categorical assessments of tonal events for diagnosing information structure, e.g., whether or not an accent is present. The presence of segmental perturbations in the f0 contour and allophonic variation due to tonal crowding and other factors can make it difficult to decide whether a pitch accent is present or not and also whether an L target is present or not, see e.g., the discussion of 'echo accents' in Pierrehumbert (1980:223). One other challenge is understanding how $\mathrm{H}_{\text {coord }}$ fits into the theme/rheme analysis.

Despite these issues, Calhoun's (2017) proposal clearly informs the challenge of understanding the distribution of edge tones in Samoan. While Calhoun (2017:37) emphasizes a separation between information structural and syntactic influences on prosodic phrasing, there are two potential ways to link our proposals. Under the VP-fronting analysis of Samoan, what determines if the subject gets ergative case is whether object shift occurs before VP-fronting. But what determines if object shift occurs? (In the terms of Calhoun 2017:38, this question is cast as: why do post-verbal absolutive arguments consistently mark the beginning of the theme?) In Niuean, it is specificity (Massam 2000, 2001), but this does not seem to be the case in Samoan, since the presence of $\mathrm{H}_{\mathrm{abs}}$ is unaffected by specificity (Sect. 4.3.1). However, in Dyirbal and Nez Perce, it is topicality that determines whether object shift occurs (Woolford 2015), based on Dixon (1972), Rude (1988). If the object is topical, then the subject is ergative; under a VP-fronting account, a topical object shifts out of the VP before VP-fronting. If the object is nontopical, it does not shift out of the VP before VP-fronting, and the subject is nominative. Under Calhoun's (2017) themerheme analysis, $\mathrm{H}_{\mathrm{abs}}$ occurs because absolutives (typically) mark the beginning of the theme. If topicality determined whether object shift occurs in Samoan, then the reason for an $\mathrm{H}_{\mathrm{abs}}$ might be because it is topical and has undergone object shift. ${ }^{35}$ In addition, an information structure account like Calhoun's (2017) is a starting point

${ }^{35}$ Thank you to Ellen Woolford for suggesting this possibility. 
for uncovering sources of variability in the distribution of prosodic boundary tones, e.g., $\mathrm{H} \%$ and $\mathrm{L} \%$.

\section{Conclusion}

The main empirical contribution of this paper has been to show that high edge tones reliably co-occur with absolutive arguments. The presence of this $\mathrm{H}_{\mathrm{abs}}$ is insensitive to the syntactic nature (subject of intransitive, object of transitive predicates, proper names, pronouns, and arguments internal to nominalizations), certain semantic properties (specificity and number), and certain aspects of pragmatic context (word order, informational/contrastive focus) of the marked nominal. Moreover, $\mathrm{H}_{\mathrm{abs}}$ does not appear where bare NPs are independently expected not to be case marked (pseudo noun incorporation; Massam 2001) or where ergative and oblique case marking are also banned (under focus-sensitive $n a$ ' $o$ and before ' $o$-marked fronted nominals). Yu and Özyıldız (2016) also shows that an optional segmental absolutive particle $i a_{\mathrm{abs}}$ is licit in syntactic configurations where the absolutive $\mathrm{H}$ - appears. However, $i a_{\mathrm{abs}}$ is illicit where $\mathrm{H}_{\mathrm{abs}}$ does not surface, as well as where $\mathrm{H}_{\text {coord }}$ and $\mathrm{H}_{\text {front }}$ appear. All together, this body of distributional evidence indicates that $\mathrm{H}_{\mathrm{abs}}$ is a case marker that is inserted in spellout as a reflex of the structural configuration of absolutive case.

There remains of course, much more empirical work to be done. I'll highlight one such strand of future work here. Studying the prosodic realization of further syntactic constructions, in concert with independent syntactic tests, could help refine hypotheses about syntactic triggers for Hs and perhaps even inform syntactic theory. As an example, I have found that an $\mathrm{H}$ also occurs at the right edge of weather verbs (Mosel and Hovdhaugen 1992:107), as shown in (35). Is a meteorological expression another distinct syntactic trigger for an $\mathrm{H}$ ? Or is it an instance of a more general syntactic configuration, such as the absolutive? Or perhaps even a more general syntactic configuration encoding something about information structure? Is the locative/temporal expression an adjunct, or can it be reified as an absolutive?

$$
\begin{aligned}
& \text { a. na }\left\{\text { timu / vevela } \mathbf{H} / *_{\mathrm{i}}\right. \text { Apia. } \\
& \text { PAST }\{\text { rain / hot }\} \text { ?/OBL Apia } \\
& \text { 'It rained in Apia.' / 'It was hot in Apia.' } \\
& \text { b. na }\{\text { timu / vevela }\} \mathbf{H} / *_{\mathrm{i}} \text { le Aso Sā. } \\
& \text { PAST }\{\text { rain / hot }\} \text { ?/OBL DET day sacred } \\
& \text { 'It rained on Sunday.' / 'It was hot on Sunday.' }
\end{aligned}
$$

The theoretical contribution of this paper is the explication of a proposal about the syntax-phonology interface in Samoan that fits the current data: (i) there are high edge tones in Samoan that are syntactically determined and inserted in the spellout of distinct syntactic configurations (absolutive case, non verb-initial fronted expressions, coordination), and (ii) there are also variably appearing high and low edge tones in Samoan that typically are followed by a pause, and these mark prosodic domains, perhaps at the intonational phrase level. My defense of this proposal brings up a number of foundational issues in prosody and the syntax-phonology interface that are sometimes overlooked. 
The first is that the phonetic alignment of tones with morphosyntactic word edges is often equated with the association of these tones to prosodic constituents in descriptions of the intonational phonology of languages. Slipping from the description of the edge-alignment of a tone immediately into the transcription of that tone as a prosodic boundary tone is not an inconsequential step. It assumes the fact that a tone is aligned to the edge-alone-is enough to diagnose some prosodic domain (as well as the existence of some prosodic hierarchy). While this may not be an unreasonable starting hypothesis, it remains a hypothesis, potentially to be revised. Adhering to the assumption can prevent us from considering other reasonable hypotheses that might fit the data (better). Moreover, the assumption that discrete tonal events are enough to diagnose a prosodic domain draws attention away from the search for additional phonological processes whose domains might coincide with the tonally marked one-or more generally, the search for any evidence that could bolster support for positing the prosodic domain. This is unfortunate. "Phonologists are often explicit about whether they subscribe to level ordering or output-output correspondence (rarely both). But we tend to help ourselves to prosodic domains without further comment" (Zuraw 2009:1).

The equation of edge tones with prosodic boundary tones is symptomatic of a larger issue: that work in syntax-phonology tends to be focused on the relation between syntactic domains and prosodic domains, e.g., evaluating if prosodic domains are needed for a proper description of phonological processes or if syntactic domains are enough, or what kind of syntactic domain is related to prosodic domains (e.g., phases or constituents). I have shown how approaching the high edge tones of Samoan with this focus traps us into forcing the contexts that trigger Hs to be unified syntactically and prosodically. Forcing this unified analysis might mislead us into considering a number of alternative syntactic analyses and proposals about syntax-prosody mapping or prosodic interfaces in general just to make the unification go through. But for Samoan high edge tones, I have shown that a proposal situated within the "two further core aspects" besides the relation between syntactic and prosodic domains mentioned in Selkirk's (2011:435) quote in Sect. 1-the spellout of morphemes and lexical items and the linearization of syntactic structure into pronounced surface strings - can fit the data. Work in these other aspects is still relatively limited, see, for instance Heath and McPherson (2013), McPherson and Heath (2016) on 'tonosyntax' in Dogon languages, "whereby words or phrases of particular syntactic categories (e.g., adjective, possessor NP) systematically impose tone overlays on other words or word strings" (Heath and McPherson 2013:265), and Elfner (2012), Bennett et al. (2016), Richards (2016), Kusmer (2019) on prosodic linearization.

I hope that my analysis of Samoan high edge tones as the spellout of particular syntactic configurations in this paper encourages further work attending to aspects of the syntax-phonology interface in addition to the relation between syntactic domains and prosodic domains. The "in addition to" in the previous sentence is quite deliberate: in this paper, I have proposed that high edge tones in Samoan are inserted in spellout as well as in association with prosodic domains. One does not preclude the other, as is evident from prosodic systems in many tonal languages, e.g., in the discussion of Thai final particles in Sect. 6.3.2, see also Michaud (2008), Downing and Rialland (2017), among others. The consideration of syntactic configurations in addition to 
prosodic domains as triggers for tonal events also widens the way in which prosody might be informative about syntax. Beyond telling us about syntactic constituency, prosody might also diagnose particular syntactic configurations in languages, even if the languages are sparsely tonal. We should be on the lookout for more cases like the one here.

Acknowledgements I gratefully acknowledge my primary consultants in Los Angeles, John Fruean and Kare'l Lokeni and thank Gladys Fuimaono and Peone Fuimaono for coordination of fieldwork in Apia, Samoa, and Jason Brown for coordination of fieldwork in Auckland and thank all of my Samoan consultants. I thank Rajesh Bhatt, Seth Cable, Sandy Chung, James Collins, Hilda Koopman, Lisa Selkirk, Ed Stabler, Ellen Woolford, and Kie Zuraw for numerous discussions about this work. I also thank six anonymous reviewers, Rachel Walker, and audiences at AFLA 16, 22, and 25; NELS 39, LSA 2009, ETAP 3, Morphosyntactic Triggers of Tone, AIMM 3, BLS 42, the Workshop on the Effects of Constituency on Sentence Phonology, and at UCSC, Harvard, the University of Maryland, the University of Auckland, Brown University, MIT, and Yale University for invaluable feedback and suggestions. This work was funded by the Department of Linguistics at University of Maryland College Park and the Department of Linguistics at University of Massachusetts Amherst.

Publisher's Note Springer Nature remains neutral with regard to jurisdictional claims in published maps and institutional affiliations.

Open Access This article is licensed under a Creative Commons Attribution 4.0 International License, which permits use, sharing, adaptation, distribution and reproduction in any medium or format, as long as you give appropriate credit to the original author(s) and the source, provide a link to the Creative Commons licence, and indicate if changes were made. The images or other third party material in this article are included in the article's Creative Commons licence, unless indicated otherwise in a credit line to the material. If material is not included in the article's Creative Commons licence and your intended use is not permitted by statutory regulation or exceeds the permitted use, you will need to obtain permission directly from the copyright holder. To view a copy of this licence, visit http://creativecommons.org/licenses/by/4.0/.

\section{Appendix A: Description of elicited data sets}

\section{A.1 Transitive sentences (see Sect. 4.1)}

Here is a full list of sentences used for the analysis in Sect. 4.1. Note that since the -ina suffix was optional, there were two variants of each sentence: one with -ina, and one without. I do not show both variants separately. Consultant m01 was recorded uttering two fluent tokens of each sentence. For three sentences, there were three fluent tokens that were used in the data.

Figure 4a contains data from each utterance of the sentences which did not contain -ina. Data to plot the solid black line come from utterances of the VOS sentences in (37). Data to plot the dashed line come from utterances of the VSO sentences in (36).

Figure $4 \mathrm{~b}$ contains data from each utterance of the sentences which contain -ina. Data to plot the solid black line come from utterances of the VOS sentences in (37). Data to plot the dashed line come from utterances of the VSO sentences in (36).

Figure $4 \mathrm{c}$ contains data from all utterances of all sentences (including both sentence variants, with or without -ina). Data to plot the solid line come from utterances of the VSO sentences in (36). Data to plot the dashed line come from utterances of the VOS sentences in (37). 
(36) VSO sentences

a. na tatala-(ina) e le tama $\mathbf{H}_{\mathbf{a b s}}$ le faitoto?a. PAST open-(INA) ERG DET boy ABS DET door 'The boy opened the door.'

b. sa: si?osi?o-(ina) e leoleo $\mathbf{H}_{\mathbf{a b s}}$ le fale. PAST surround-(INA) ERG police ABS DET house 'The police surrounded the house.'

c. Pua etoeto-(ina) e le maile $\mathbf{H}_{\mathbf{a b s}}$ le manini. PERF lick-(INA) ERG DET dog ABS DET fish 'The dog has licked the fish.'

d. na opo-(ina) e le tama $\mathbf{H}_{\mathbf{a b s}}$ le teine. PAST hug-(INA) ERG DET boy ABS DET girl 'The boy hugged the girl.'

(37) Corresponding VOS sentences

a. na tatala-(ina) $\mathbf{H}_{\text {abs }}$ le faitoto?a e le tama. past open-(INA) ABS DET door ERG DET boy 'The door was opened by the boy.'

b. sa: si?osi?o-(ina) $\mathbf{H}_{\mathbf{a b s}}$ le fale e leoleo. PAST surround-(INA) ABS DET house ERG police 'The house was surrounded by the police.'

c. Pua etoeto-(ina) $\mathbf{H}_{\text {abs }}$ le manini e le maile. PERF lick-(INA) ABS DET fish ERG DET dog 'The fish was licked by the dog.'

d. na opo-(ina) $\mathbf{H}_{\text {abs }}$ le teine e le tama. PAST hug-(INA) ABS DET girl ERG DET boy 'The girl was hugged by the boy.'

\section{A.2 Intransitive sentences (see Sect. 4.2)}

Here is the full list of intransitive sentences used in the analysis in Sect. 4.2. The transitive counterparts for (38) are shown in (39). These sentences were part of a data set designed to examine effects of tonal crowding and were recorded with consultant m01-two fluent utterances of each sentence, occasionally three. These sentences are the subset from the data set for tonal crowding with 3-syllable verbs (lagona, manogi) and arguments following the verb initiated with a determiner-here, le. Figure 5 contains data from all utterances of sentences in (38) and (39). Data to plot the solid black line come from utterances of the intransitive sentences in (38). Data to plot the dashed line come from utterances of the transitive sentences in (39).

\section{Intransitive sentences}

a. na manoni $\mathbf{H}_{\text {abs }}$ le manu $i$ le maile $\mathrm{i}$ le afiafi. PAST smelly ABS DET bird OBL DET dog obl DET evening 'The bird was smelly to the dog in the evening.' 
b. na manoni $\mathbf{H}_{\text {abs }}$ le manu i maile $\mathrm{i}$ le afiafi. PAST smelly ABS DET bird OBL dog OBL DET evening 'The birds were smelly to the dogs in the evening.'

c. na manoni $\mathbf{H}_{\text {abs }}$ le la: $i$ le liona $i$ le taeao. PAST smelly ABS DET sun OBL DET lion OBL DET morning 'The sun was smelly to the lion in the morning.'

d. na manoni $\mathbf{H}_{\text {abs }}$ le la: $\mathrm{i}$ liona $\mathrm{i}$ le taeao. PAST smelly ABS DET sun OBL lion OBL DET morning 'The sun was smelly to the lions in the morning.'

e. na manoni $\mathbf{H}_{\text {abs }}$ le la: $\mathrm{i}$ maile $\mathrm{i}$ le taeao. PAST smelly ABS DET sun OBL dog OBL DET morning 'The sun was smelly to the dogs in the morning.'

(39) Transitive counterparts

a. na layona e le manu $\mathbf{H}_{\text {abs }}$ le maile $\mathbf{i}$ le afiafi. PAST hear ERG DET bird ABS DET dog OBL DET evening 'The bird heard the dog in the evening.'

b. na lajona e le manu $\mathbf{H}_{\mathbf{a b s}}$ maile $\mathrm{i}$ le afiafi. PAST hear ERG DET bird ABS dog OBL DET evening 'The birds heard the dogs in the evening.'

c. na layona e le la: $\mathbf{H}_{\text {abs }}$ le liona $\mathrm{i}$ le taeao. PAST hear ERG DET sun ABS DET lion OBL DET morning 'The sun heard the lion in the morning.'

d. na layona e le la: $\mathbf{H}_{\mathbf{a b s}}$ liona $\mathrm{i}$ le taeao. PAST hear ERG DET sun ABS lion OBL DET morning 'The sun heard the lions in the morning.'

e. na layona e le la: $\mathbf{H}_{\text {abs }}$ maile $\mathrm{i}$ le taeao. PAST hear ERG DET sun ABS dog OBL DET morning 'The sun heard the dogs in the morning.'

\section{A.3 Specificity (see Sect. 4.3.1)}

All sentences were already listed in the body of the paper in Sect. 4.3.1, but I repeat them here for convenience. These sentences were recorded with f03 and f05.

(40) Specific, singular le (repeated from (11))

a. Context: Moana asked Manogi to pick the ripest melon at the market and bring it home.

e lePi momoli e Manoni $\mathbf{H}_{\text {abs }} \underline{\text { le meleni i }}$ PRES NEG deliver ERG Manogi ABS DET.SPEC.SG melon OBL le fale.

DET.SPEC.SG home

'Manogi didn't bring the melon home yet.' 
b. cf. intransitive

e le?i yalue $\mathrm{H}_{\mathrm{abs}}$ Melani i le mamanu $\mathrm{i}$

PRES NEG work ABS Melani OBL DET.SPEC.SG design OBL

le fale.

DET.SPEC.SG home

'Melani didn't work on the design at home yet.'

(41) Specific, plural $\varnothing$ (repeated from (12))

a. Context: Moana asked Manogi to pick the biggest three melons at the market and bring them home.

e le?i momoli e Manoni $\mathbf{H}_{\mathbf{a b s}}$ meleni i le fale.

'Manogi didn't bring the melons home yet.'

b. cf. intransitive e le?i yalue $\mathrm{H}_{\mathrm{abs}}$ Melani i mamanu i le fale.

'Melani didn't work on the designs at home yet.'

(42) Nonspecific, singular se (repeated from (13))

a. Context: Moana asked Manogi to pick any melon at the market and bring it home.

e le?i momoli e Manoni $\mathbf{H}_{\mathbf{a b s}}$ se meleni i le fale.

'Manogi didn't bring any melon home yet.'

b. cf. intransitive e le?i yalue $\mathrm{H}_{\mathrm{abs}}$ Melani i se mamanu i le fale.

'Melani didn't work on any design at home yet.'

(43) Nonspecific, plural $n i$ (repeated from (14))

a. Context: Moana asked Manogi to pick some melons at the market and bring them home.

e le?i momoli e Manoni $\mathbf{H}_{\mathbf{a b s}}$ ni meleni i le fale.

'Manogi didn't bring any melons home yet.'

b. cf. intransitive e le?i jalue $\mathrm{H}_{\mathrm{abs}}$ Melani i ni mamanu i le fale.

'Melani didn't work on any designs at home yet.'

\section{A.4 Pronominals (see Sect. 4.3.2)}

The full list of elicited stimuli partially exemplified in (15) and used to plot Fig. 6 follows.

(44) Pronoun as first (overt) argument

a. na momoli e ma:?ua $\mathbf{H}_{\text {abs }}$ malini. PAST take ERG 1.DU.EXC ABS marine

'We two dropped off the marines.'

b. na momoli e ma:?ua i malini. PAST take ERG 1.DU.EXC OBL marine

'We two delivered (it) to the marines.' 
c. na momoli $\mathbf{H}_{\mathbf{a b s}}$ ma:?ua e malini. PAST take ABS 1.DU.EXC ERG marine

'We two were dropped off by the marines.'

d. na momoli $\mathbf{H}_{\text {abs ma:?ua }} \mathrm{i}$ malini. PAST take ABS 1.DU.EXC OBL marine

'We two were taken to the marines by (pro).'

e. na momoli ja: ma:?ua e malini. PAST take OBL 1.DU.EXC ERG marine

'We two were delivered (pro) by the marines.'

f. na momoli ja: ma:?ua $\mathbf{H}_{\text {abs }}$ malini. PAST take OBL 1.DU.EXC ABS marine 'We two were delivered the marines to by (pro).'

(45) Pronoun as second (overt) argument

a. na momoli e malini $\mathbf{H}_{\mathbf{a b s}}$ ma:?ua.

PAST take ERG marine ABS 1.DU.EXC

'The marines dropped off us two.'

b. na momoli e malini ja: ma:?ua.

PAST take ERG marine OBL 1.DU.EXC

'The marines delivered (it) to us two.'

c. na momoli $\mathbf{H}_{\text {abs }}$ malini e ma:?ua.

PAST take ABS marine ERG 1.DU.EXC

'The marines were dropped off by us two.'

d. na momoli $\mathbf{H}_{\text {abs }}$ malini ja: ma:?ua.

PAST take ABS marine OBL 1.DU.EXC

'The marines were taken to us two by (pro).'

e. na momoli i malini e ma:?ua.

PAST take OBS marine ERG 1.DU.EXC

'The marines were delivered (pro) by us two.'

f. na momoli i malini $\mathbf{H}_{\text {abs }}$ ma:?ua.

PAST take OBL marine ABS 1.DU.EXC

'The marines were delivered us two to by (pro).'

I now list data used for each individual panel of Fig. 6.

For Fig. 6a, "f0 contour on [momoli] 'deliver' when followed by [ma:?ua] '1.DU.EXC' ": the data were all sentences of (44). Here, [ma:?ua] is always the first argument. I show these sentences again in (46). The portion shown in the figure panel, i.e., [momoli], is underlined in the sentences.

(46) Data used for Fig. 6a

a. na momoli e ma:?ua $\mathbf{H}_{\mathbf{a b s}}$ malini (44a), dashed line

b. na momoli e ma:?ua i malini (44b), dashed line

c. na momoli $\mathbf{H}_{\text {abs }}$ ma:?ua e malini (44c), solid line 


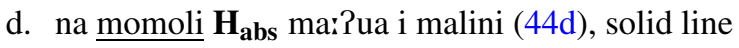
e. na momoli ja: ma:?ua e malini (44e), dotted line
f. na momoli ja: ma:?ua $\mathbf{H}_{\mathbf{a b s}}$ malini (44f), dotted line

For Fig. 6b, "f0 contour on 1st argument [ma:?ua] "1.DU.EXC" ": the data were again all sentences of (44). Here, [ma:?ua] is always the first argument. I show these sentences again in (47). The portion shown in the figure panel, i.e., [ma:?ua], is underlined in the sentences.

(47) Data used for Fig. 6b

a. na momoli e ma:?ua $\mathbf{H}_{\text {abs }}$ malini (44a), dashed line

b. na momoli e ma:?ua i malini (44b), dashed line

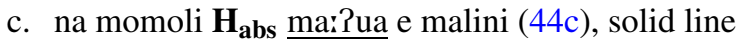

d. na momoli $\mathbf{H}_{\mathbf{a b s}}$ ma:?ua i malini (44d), solid line

e. na momoli ja: ma:?ua e malini (44e), dotted line

f. na momoli ja: ma:?ua $\mathbf{H}_{\mathbf{a b s}}$ malini (44f), dotted line

For Fig. 6c, "f0 contour on 1st argument [ma:Pua] '1.DU.EXC' ": the data were again all sentences of (44). Here, [ma:?ua] is always the first argument. I show these sentences again in (48). The portion shown in the figure panel, i.e., [ma:?ua], is underlined in the sentences. What's different between Fig. 6b and Fig. 6c is how the data is partitioned to plot the different lines. In Fig. 6c, we're looking at how the case of the second argument affects the f0 contour over the first argument [ma:?ua]. In Fig. 6c, we're looking at how the case of the first argument [ma:?ua] affects its own f0 contour.

(48) Data used for 6c

a. na momoli e ma:?ua $\mathbf{H}_{\text {abs }}$ malini (44a), solid line

b. na momoli e ma:?ua i malini (44b), dotted line

c. na momoli $\mathbf{H}_{\mathbf{a b s}}$ ma:?ua e malini (44c), dashed line

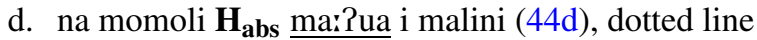

e. na momoli ja: ma:?ua e malini (44e), dashed line

f. na momoli ja: ma:?ua $\mathbf{H}_{\mathbf{a b s}}$ malini (44f), solid line

For Fig. 6d, "f0 contour on 2nd argument [ma:Pua] '1.DU.EXC" ": the data were all sentences of (45). Here, [ma:?ua] is always the second argument. I show these sentences again in (49). The portion shown in the figure panel, i.e., [ma:?ua], is underlined in the sentences.

Data used for Fig. 6d

a. na momoli e malini $\mathbf{H}_{\mathbf{a b s}} \underline{\text { ma:?ua, }}$ (45a), solid line

b. na momoli e malini ja: ma:?ua, (45b), dashed line

c. na momoli $\mathbf{H}_{\mathbf{a b s}}$ malini e ma:?ua, (45c), dotted line 
d. na momoli $\mathbf{H}_{\mathbf{a b s}}$ malini ja: ma:?ua, (45d), dashed line

e. na momoli i malini e ma:?ua, $(45 \mathrm{e})$, dotted line

f. na momoli i malini $\mathbf{H}_{\mathbf{a b s}}$ ma:?ua, (45f), solid line

At least two fluent repetitions of each of these sentences were recorded and analyzed from the six consultants-s13, s18, s19, s20, m01, s22c/s-with the following exceptions:

(50) Discarded repetitions

a. s18: one repetition each of (44c), (44e), (45b), (45c) discarded due to disfluencies with obvious prosodic junctures

b. s19: one repetition of 44d discarded due to disfluency

c. s20: only VSO sentences were included since consultant rejected other word orders; these were (44b), (44d), (45c) (one repetition disfluent; discarded), (45b), (45d)

d. m01: one repetition of (45e) discarded due to misreading sentence

For more details see the Rnw file in the file repository.

The imbalance between the number of utterances of each item type for each speaker caused slight global skewing of the mean f0 values within an item type in the fo contours in Fig. 6 since the speakers had different pitch ranges, but the overall comparative trends between mean f0 contours in a plot were no different than if further items were discarded for balance across item types across speakers.

\section{A.5 Case internal to nominalizations (see Sect. 4.3.3)}

The full nominalization stimulus set used for the plots in Fig. 7 is given here.

(51) Absolutive nominalizations

a. e $\{$ fa?a-le:-lelei / leana $\} \mathbf{H}_{\mathbf{a b s}}$ [le lalana mamanu a malini] PRES $\{$ do-NEG-good / bad $\}$ ABS DET weave design GEN marine i le afiafi.

OBL DET afternoon

'The marine's weaving of the design is not good in the afternoon (fa?ale:-lelei: poorly done, leana: superstition).' (based on Mosel and Hovdhaugen 1992:545, (13.100))

b. e iloa-atu e le malini $\mathbf{H}_{\text {abs }}$ [le momoli-ina o le

PRES spot DET ERG marine ABS DET deliver-INA gen DET

malala $]_{a b s}$ i le ala.

charcoal OBL the street

'The marine spots the delivering of the charcoal in the street.'

c. e iloa-atu e le malini $\mathbf{H}_{\text {abs }}$ [le momoli-ina e

PRES spot ERG DET marine ABS (ABS) DET deliver-INA

le liona $\mathbf{H}_{\mathbf{a b s}}$ (ia) le manini $]_{a b s} \mathrm{i}$ le ala.

ERG DET lion ABS DET fish OBL DET street

'The marine spots the delivering of the fish by the lion in the street.' 
(52) Oblique nominalizations

a. e matamata $\mathbf{H}_{\text {abs }}$ le malini [i le lalana o le mamanu] PRES watch ABS DET marine OBL DET weave GEN DET design] $]_{o b l}$ i le fale.

OBL DET house

'The marine watches the weaving of the design at home.'

b. e faPalonolono $\mathbf{H}_{\text {abs }}$ le malini [i le momoli-ina o le PRES listen ABS DET marine obl DET deliver-INA GEN DET malala $]_{o b l}$ i le ala. charcoal OBL DET street

'The marine listens to the delivering of the charcoal in the street.'

c. na faPaloyolojo $\mathbf{H}_{\text {abs }}$ le malini [i le momoli-ina e le PAST listen ABS DET marine DET OBL deliver-INA ERG DET liona le manini] $]_{o b l}$ i le ala. lion DET fish OBL DET street

'The marine listened to the delivering of the fish by the lion in the street.'

\section{A.6 Pseudo noun incorporation (see Sect. 4.4)}

There were four minimal sets used for plotting Fig. 8 in Sect. 4.4. In addition to pronominal sentences (not shown), the minimal set of "charcoal delivering" sentences used for plotting Fig. 8 also consisted of sentences with le malini as the subject:

(53) Charcoal delivering

a. na momoli e le malini malala i le teine. PAST deliver ERG DET marine charcoal OBL DET girl

'The marine delivered bags of charcoal to the girl.'

b. na momoli malala le malini i le teine. PAST deliver charcoal DET marine OBL DET girl 'The marine charcoal-delivered to the girl.'

In addition, I also elicited these minimal sets with both post- and preverbal pronominal subjects. Examples of VSO sentences with pronominal subjects are given in (54); examples of corresponding sentences with PNI are given in (55).

(54) VSO transitive sentences with pronominal subjects

a. Postverbal pronominal subject

na momoli e ia $\mathbf{H}_{\text {abs }}$ le malala $\mathrm{i}$ le teine. PAST deliver ERG 3.SG ABS DET charcoal OBL DET girl

'He delivered the bag of charcoal to the girl.' 
b. Preverbal pronominal subject

na ia momoli(-ina) $\mathbf{H}_{\mathbf{a b s}}$ le malala $\mathrm{i}$ le teine. PAST 3.SG deliver(-INA) ABS DET charcoal OBL DET girl

'He delivered the bag of charcoal to the girl.'

(55) PNI sentences with pronominal subjects

a. Postverbal pronominal subject

na momoli $*$ ia malala $\mathbf{H}_{\mathbf{a b s}}$ (ia) ia $\mathrm{i}$ le teine. PAST deliver *ABS charcoal ABS (ABS) 3.SG OBL DET girl

'He charcoal-delivered to the girl.'

b. Preverbal pronominal subject

na *ia ia momoli(-ina) $\left(\mathbf{H}_{\mathbf{a b s}}\right)$ (ia) malala $\mathrm{i}$ le teine. PAST *ABS 3.SG deliver(-INA) (ABS) (ABS) charcoal OBL DET girl

'He charcoal-delivered to the girl.'

Minimal sets like the "charcoal delivering" sentences, (53) and (54), were also elicited for (18), "badly melon washing", as well as "charcoal and blue chalk delivering" (56), and "badly lion hunting" (57).

(56) Charcoal and blue chalk delivering

a. na momoli e le malini $\mathbf{H}_{\mathbf{a b s}}$ (le) malala $\mathbf{H}_{\text {coord }}$ ma sioka PAST deliver ERG DET marine ABS (DET) charcoal CONJ CONJ chalk lanu-moana i le teine.

color-sea OBL DET girl

'The marine delivered the bag(s) of charcoal and blue chalk to the girl.'

b. na momoli malala $\mathbf{H}_{\text {coord }}$ ma sioka lanu-moana $\mathbf{H}_{\mathbf{a b s}}$ le PAST deliver charcoal CONJ CONJ chalk color-sea ABS DET malini i le teine. marine OBL DET girl

'The marine charcoal-and-blue-chalk-delivered to the girl.'

(57) Badly lion hunting

a. na tuli e le malini le liona leana. PAST hunt ERG DET marine DET lion bad 'The marine hunted the lion badly.'

b. na tuli liona leana le malini i lalo o le la?au. PAST hunt lion bad DET marine OBL under GEN DET tree 'The marine badly-lion-hunted under the tree.'

c. na tuli liona leana ia i lalo o le la?au.

d. na ia tuli(-ina) liona leana i lalo o le la?au. 


\section{A.7 Subject relatives (see Sect. 5.1.1)}

This included two different data sets.

Data for Fig. 13a contain minimal comparisons between extractions of ergative subjects and absolutive objects from s13, s18, m01, and s22c/s. Data for Fig. 13b are from $\mathrm{m} 01$ and contains minimal comparisons between extraction of ergative and absolutive subjects.

\section{A.7.1 Extraction of ergative subjects vs. absolutive objects: Fig. 13 a}

(58) Extraction of ergative subject vs. absolutive object, intransitive matrix clause $^{36}$

a. Extraction of ergative subject

na manoji i le liona $\mathbf{H}_{\text {abs }}$ [le malini $]_{i}$ [na lalana-ina $t_{i}$ PAST smelly OBL DET liona ABS DET marine [PAST weave-INA $t$

$\mathbf{H}_{\text {abs }}$ le mamanu].

ABS DET design]

'The marine that wove the design was smelly to the lion.'

b. Extraction of absolutive object

na manoni i le liona $\mathbf{H}_{\text {abs }}$ [le mamanu $]_{i}$ [na lalaya-ina

PAST smelly OBL DET liona ABS DET design [PAST $\overline{\text { weave-INA }}$

e le malini $t_{i}$.

ERG DET marine $\mathrm{t}$ ]

'The design that the marine wove was smelly to the lion.'

(59) Extraction of ergative subject vs. absolutive object, absolutive-oblique matrix clause

a. Extraction of ergative subject

na manogi le liona le malini [na lalaga-ina

PAST smell OBL DET.SG liona DET.SG marine [PAST weave-INA

le mamanu].

DET.SG design]

'The marine that wove the design smelled to the lion.'

b. Extraction of absolutive object

na manogi i le liona le mamanu [na lalaga-ina

PAST smell OBL DET.SG liona DET.SG design [PAST weave-INA

e le malini].

ERG DET.SG marine]

'The design that the marine wove smelled to the lion.'

\footnotetext{
${ }^{36}$ The sentences in (58) have oblique object - absolutive subject word order because this order was volunteered by two consultants. 
(60) Extraction of ergative subject vs. absolutive object, ergative-absolutive matrix clause

a. Extraction of ergative subject

na lalaga e le malini [na lagona-ina e le liona]

PAST weave ERG DET.SG marine [PAST hear-INA ERG DET.SG lion]

le mamanu.

DET.SG design

'The marine that heard the lion wove the design.'

b. Extraction of absolutive object

na lalaga e le malini [na lagona-ina le liona]

PAST weave ERG DET.SG marine [PAST hear-INA DET.SG lion]

le mamanu.

DET.SG design

'The marine that the lion heard wove the design.'

c. Extraction of ergative subject

na lagona e le liona le malini [na lalaga-ina

PAST hear ERG DET.SG lion DET.SG marine [PAST weave-INA

le mamanu].

DET.SG design]

'The lion heard the marine that wove the design.'

d. Extraction of ergative subject

na lagona e le malini [na lalaga-ina le mamanu]

PAST hear ERG DET.SG marine [PAST weave-INA DET.SG design]

le liona.

DET.SG lion

'The marine that heard the lion wove the design.'

\section{A.7.2 Extraction of ergative subjects vs. absolutive subjects: Fig. $13 b$}

The full set of sentences elicited from $\mathrm{m} 01$ for this data set is given below. It repeats the two examples included in the body of the paper in (26) for convenience. The sentences with ergative subject extraction were used for the dotted line in the figure. The sentences with absolutive extraction were used for the solid line in the figure. The portion of the sentence plotted in the figure, i.e., the (last three syllables of the) embedded verb, is underlined.

(61) Ergative subject extraction

a. e layona e le liona $\mathbf{H}_{\text {abs }}$ [le malini $]_{i}$ na momoli-ina $t_{i}$ PRES hear ERG DET lion ABS DET marine PAST deliver-INA $t$ $\mathrm{H}_{\text {abs le manini. }}$

ABS DET.GS fish

'The lion hears [the marine that delivered the fish].' 
b. e manoyi $\mathrm{H}_{\mathrm{abs}}$ le liona $\mathrm{i} \quad[\mathrm{le} \text { malini }]_{i}$ na momoli-ina PRES smell.to ABS DET lion OBL DET marine PAST

$t_{i} \quad \mathbf{H}_{\text {abs }}$ le manini.

deliver-INA $t$ ABS DET.GS fish

'The lion smells [the marine that dropped off the fish].'

c. e layona e le liona $\mathrm{H}_{\mathrm{abs}}[\text { le malini }]_{i}$ na momoli-ina

PRES hear ERG DET lion ABS DET marine PAST

$t_{i} \quad H_{\text {abs }}$ le mamanu.

deliver-INA t ABS DET.GS design

'The lion hears [the marine that dropped off the design].'

(62) Absolutive subject extraction

a. e layona e le malini $\mathbf{H}_{\text {abs }}[\text { le manini }]_{i}$ na manoni $t_{i}$ i

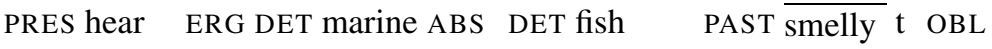

le liona.

DET lion

'The marine hears [the fish that was smelly to the lion].'

b. e yalo $\mathrm{H}_{\mathrm{abs}}$ le liona $\mathrm{i}$ [le manini $]_{i}$ na manoni $t_{i} \mathrm{i}$

PRES forget ABS DET lion OBL DET fish PAST $\overline{\text { smelly }} \mathrm{t}$ OBL

le malini.

DET marine

'The lion is forgotten by [the fish that the marine smelled to].'

c. e lajona e le malini $\mathbf{H}_{\text {abs }}$ [le manini $]_{i}$ na manogi $t_{i} \mathrm{i}$

PRES hear ERG DET marine ABS DET fish PAST smelly $\mathrm{t}$ OBL

le liona.

DET lion

'The marine hears [the fish that was smelly to the lion].'

\section{References}

Arvaniti, Amalia, Robert Ladd, and Ineke Mennen. 2006. Tonal association and tonal alignment: Evidence from Greek polar questions and contrastive statements. Language and Speech 49(4): 421-450.

Beckman, Mary E., Julia Hirschberg, and Stefanie Shattuck-Hufnagel. 2005. The original ToBI system and the evolution of the ToBI framework. In Prosodic typology: The phonology of intonation and phrasing, ed. Sun-Ah Jun. London: Oxford University Press.

Bennett, Ryan. 2015. Review of Sun Ah-Jun (ed.) (2014). Prosodic typology ii: The phonology of intonation and phrasing. Phonology 32: 337-350.

Bennett, Ryan, and Robert Henderson. 2013. Accent in Uspanteko. Natural Language and Linguistic Theory 31: 589-645.

Bennett, Ryan, Emily Elfner, and James McCloskey. 2016. Lightest to the right: An apparently anomalous displacement in Irish. Linguistic Inquiry 47(2): 169-234.

Bobaljik, Jonathan David. 2008. Where's $\phi$ ? Agreement as a post-syntactic operation. In Phi-theory, eds. Daniel Harbour, David Adger, and Susana Béjar, 295-328. Oxford: Oxford University Press.

Boersma, Paul, and David Weenink. 2012. Praat: Doing phonetics by computer (version 5.3.18) [computer program]. http://www.praat.org.

Breen, Mara, Laura C. Dilley, John Kraemer, and Edward Gibson. 2012. Inter-transcriber reliability for two systems of prosodic annotation: ToBI (Tones and Break Indices) and RaP (Rhythm and Pitch). Corpus linguistics and linguistic theory 8(2). 
Brown, Jason, and Karsten Koch. 2016. Focus and change in Polynesian languages. Australian Journal of Linguistics 36(3), 304-349.

Bruce, Gösta. 1977. Swedish word accents in sentence perspective. Lund: CWK Gleerup.

Bruggeman, Anna, Timo B. Roettger, and Martine Grice. 2017. Question word intonation in Tashlhiyt Berber: Is 'high' good enough? Laboratory Phonology 8(1): 5.

Calhoun, Sasha. 2014. The H- phrase tone in Samoan: A prosodic or syntactic marker? Presented at Exploring the Interfaces 3: Prosody and Constituent Structure.

Calhoun, Sasha. 2015. The interaction of prosody and syntax in Samoan focus marking. Lingua 165 Part B: 205-229.

Calhoun, Sasha. 2017. Exclusives, equatives and prosodic phrases in Samoan. Glossa 2(1): 11-143.

Cheng, Lisa Lai-Shen, and Laura J. Downing. 2016. Phasal syntax = cyclic phonology? Syntax 19(2): 156-191.

Chung, Sandra. 1978. Case marking and grammatical relations in Polynesian. Austin: University of Texas Press.

Clemens, Lauren, and Jessica Coon. 2016. Prosodic constituency of verb-initial clauses in Ch'ol. In 21st workshop on structure and constituency in languages of the Americas, ed. Megan Keough. Vancouver: University of British Columbia Working Papers in Linguistics.

Cole, Jennifer, Yoonsook Mo, and Soondo Baek. 2010. The role of syntactic structure in guiding prosody perception with ordinary listeners and everyday speech. Language and Cognitive Processes 25(7/8/9): 1141-1177.

Collins, James. To appear. Pseudo noun incorporation in discourse. In Austronesian Formal Linguistics Association (AFLA) 20.

Collins, James N. 2014. The distribution of unmarked cases in Samoan. In Argument realisations and related constructions in Austronesian languages: Papers from 12-ICAL, eds. I Wayan Arka and N. L. K. Mas Indrawati, Vol. 2, 93-110. Canberra: Asia-Pacific Linguistics.

Collins, James N. 2015. Diagnosing predicate fronting in Samoan. In West coast conference on formal linguistics (WCCFL) 32, ed. Ulrike Steindl et al.

Collins, James N. 2016. Samoan predicate initial word order and object positions. Natural Language and Linguistic Theory 35(1): 1-59.

Cook, Kenneth William. 1999. The Samoan transitive suffix as an inverse marker. In Lexical and syntactical constructions and the construction of meaning: Proceedings of the bi-annualICLA meeting in Albuquerque, July 1995, eds. Eve Sweetser, Marjolyn Verspoor, and Ki-dong Yi, 347-361. Amsterdam: Benjamins.

Dilley, L., and S. Shattuck-Hufnagel. 1996. Glottalization of word-initial vowels as a function of prosodic structure. Journal of Phonetics 24: 423-444.

Dixon, R. M. W. 1972. The Dyirbal language of Northern Queensland. Cambridge: Cambridge University Press.

Dobashi, Yoshihito. 2009. Multiple spell-out, assembly problem, and syntax-phonology mapping. In Interface explorations: Phonological domains: Universals and deviations, eds. Janet Grijzenhout and Baris Kabak, 195-220. Berlin: Mouton de Gruyter.

Downing, Laura J. 2010. An edge-based approach to the alignment of syntactic phases and prosodic phrases. Transactions of the Philological Society 108(3): 352-369.

Downing, Laura J., and Annie Rialland, eds. 2017. Intonation in African tone languages. Berlin: Mouton De Gruyter.

Dryer, Matthew S. 2013. Position of case affixes. In The world atlas of language structures online, eds. Matthew S. Dryer and Martin Haspelmath. Leipzig: Max Planck Institute for Evolutionary Anthropology. https://wals.info/chapter/51. Last accessed 30 March 2020.

DuBois, John W. 1987. The discourse basis of ergativity. Language 63(4): 805-855.

Duranti, Alessandro. 1981. The Samoan fono: A sociolinguistic study. Pacific linguistics series b. Canberra: Linguistic Circle of Canberra.

Duranti, Alessandro. 1990. Code switching and conflict management in Samoan multiparty interaction. Pacific Studies 14(1): 1-30.

Elfner, Emily. 2012. Syntax-prosody interactions in Irish. PhD diss., University of Massachusetts Amherst.

Elordieta, Gorka. 2008. An overview of theories of the syntax-phonology interface. Journal of Basque Linguistics and Philology 42: 209-286. http://www.ehu.es/ojs/index.php/ASJU/article/view/2309. Last accessed 30 March 2020. 
Gordon, Matthew. 2000. The tonal basis of weight criteria in final position. In Chicago linguistics society (cls) 36, eds. Akira Okrent and John P. Boyle, 141-156. Chicago: Chicago Linguistics Society.

Gordon, Matthew K. 2005. Intonational phonology of Chickasaw. In Prosodic typology, ed. Sun-Ah Jun, 301-330. Oxford: Oxford University Press.

Gordon, Matthew. 2014. Disentangling stress and pitch accent: Toward a typology of prominence at different prosodic levels. In Word stress: Theoretical and typological issues, ed. Harry van der Hulst, 83-118. Cambridge: Cambridge University Press.

Grice, Martine, Rachid Ridouane, and Timo B. Roettger. 2015. Tonal association in Tashlhiyt Berber: Evidence from polar questions and contrastive statements. Phonology 32: 241-266.

Gussenhoven, Carlos. 1990. Tonal association domains and the prosodic hierarchy in English. In Studies in the pronunciation of English: A commemorative volume in honour of A. C. Gimson, ed. Susan Ramsaran, 27-37. London: Routledge.

Gut, Ulrike, and Petra Saksia Bayerl. 2004. Measuring the reliability of manual annotations of speech corpora. In SP-2004, 565-568.

Halle, Morris. 1978. Knowledge unlearned and untaught. In Linguistic theory and psychological reality, eds. Morris Halle, Joan Bresnan, and George A. Miller, 294-303. Cambridge: MIT Press.

Hayes, Bruce. 1989. The prosodic hierarchy in meter. In Rhythm and meter, eds. Paul Kiparsky and Gilbert Youmans, 201-260. Orlando: Academic Press.

Hayes, Bruce. 1995. Metrical stress theory: Principles and case studies. Chicago: University of Chicago Press.

Heath, Jeffrey, and Laura McPherson. 2013. Tonosyntax and reference restriction in Dogon NPs. Language 89(2): 265-295.

Henderson, E. J. A. 1967. Grammar and tone in South-East Asian languages. Wissenschaftliche Zeitschrift der Karl-Marx Universität Leipzig 16(1-2): 171-178.

Himmelmann, Nikolaus P. 2014. Asymmetries in the prosodic phrasing of function words: Another look at the suffixing preference. Language 90(4): 927-960.

Himmelmann, Nikolaus P., and D. Robert Ladd. 2008. Prosodic description: An introduction for fieldworkers. Language Documentation and Conservation 2(2): 244-274.

Hirsch, Aron, and Michael Wagner. 2015. Rightward movement affects prosodic phrasing. In North East linguistic society (NELS) 45. Amherst: GLSA.

Hohaus, Vera, and Anna Howell. 2015. Alternative semantics for focus and questions: Evidence from Samoan. In 21st Austronesian formal linguistics association conference, University of Hawai' $i, 69$ 86.

Howard, Michael. 2018. The intonational phonology of Samoan questions. Poster presented at ProsLangWorkshop on the Processing of Prosody across Languages and Varieties.

Hovdhaugen, Even. 1987. From the land of näfanua: Samoan oral texts in transcription with translation, notes and vocabulary. Oslo: Norwegian University Press.

Hyman, Larry M. 2010. Kuki-Thaadow: An African tone system in Southeast Asia. In Essais de typologie et de linguistique générale, ed. Franck Floricic, 31-51. Lyon, France: Les Presses de 1'Ecole Normale Supérieure.

Hyman, Larry M. 2011a. Introduction: Partial draft chapter of tone systems: Typology and description. UC Berkeley Phonology Lab Annual Report.

Hyman, Larry M. 2011b. Tone: Is it different? In The handbook of phonological theory, eds. John Goldsmith, Jason Riggle, and Alan C. L. Yu, 197-239. Malden, MA: Wiley-Blackwell.

Hyman, Larry M. 2018. What tone teaches us about language. Language 94(3): 698-709.

Hyman, Larry M., and Kemmonye C. Monaka. 2011. Tonal and non-tonal intonation in Shekgalagari. In Prosodic categories: Production, perception and comprehension, eds. Sónia Frota, Gorka Elordieta, and Pilar Prieto, 267-289. Dordrecht: Springer.

Inkelas, Sharon. 1989. Prosodic constituency in the lexicon. PhD diss., Stanford University.

Ishihara, Shinichiro. 2004. Prosody by phase: Evidence from focus intonation- $w h$-scope correspondence in Japanese. Interdisciplinary Studies on Information Structure 1: 77-119.

Jun, Sun-Ah. 1996. The phonetics and phonology of Korean prosody. New York: Garland.

Jun, Sun-Ah. 1998. The accentual phrase in the Korean prosodic hierarchy. Phonology 15(02): 189-226.

Jun, Sun-Ah, ed. 2005. Prosodic typology. Oxford: Oxford University Press.

Jun, Sun-Ah. 2014. Prosodic typology II: The phonology and phonetics of intonation and phrasing. Oxford: Oxford University Press.

Jun, Sun-Ah, and Janet Fletcher. 2014. Methodology of studying intonation: From data collection to data analysis. In Prosodic typology ii: The phonology and phonetics of intonation and phrasing, ed. Sun- 
Ah Jun, 493-519. Oxford: Oxford University Press.

Kaisse, Ellen Maud. 1977. Hiatus in Modern Greek. PhD diss., Harvard University, Cambridge, MA.

Kaisse, Ellen. 1982. On the preservation of stress in Modern Greek. Linguistics 20(1-2): 59-82.

Kaisse, Ellen M. 1985. Connected speech: The interaction of syntax and phonology. Orlando: Academic Press.

Kaisse, Ellen M., and Arnold M. Zwicky. 1987. Introduction: Syntactic influences on phonological rules. Phonology Yearbook 4: 3-11.

Kiss, Katalin É.. 1995. Discourse configurational languages. New York: Oxford University Press.

Kisseberth, Charles W., and Mohammad Imam Abasheikh. 2011. Chimwiini phonological phrasing revisited. Lingua 121(13): 1987-2013.

Klavans, Judith L. 1985. The independence of syntax and phonology in cliticization. Language 61: 95120.

Koopman, Hilda. 2012. Samoan ergativity as double passivization. In Functional heads: The cartography of syntactic structures, Vol. 7, 168-180. Oxford: Oxford University Press.

Kratzer, Angelika, and Elisabeth Selkirk. 2007. Phase theory and prosodic spellout: The case of verbs. The Linguistic Review 24: 93-135.

Krivokapić, Jelena. 2007. Prosodic planning: Effects of phrasal length and complexity on pause duration. Journal of Phonetics 35: 162-179.

Krivokapić, Jelena. 2014. Gestural coordination at prosodic boundaries and its role for prosodic structure and speech planning processes. Philosophical Transactions of the Royal Society B 369: 20130397.

Kusmer, Leland. 2019. Optimal linearization: Prosodic displacement in Khoekhoegowab and beyond. PhD diss., University of Massachusetts Amherst.

Ladd, D. Robert. 1986. Intonational phrasing: The case for recursive prosodic structure. Phonology Yearbook 3: 311-340.

Ladd, D. Robert. 2008. Intonational phonology, 2nd edn. Cambridge: Cambridge University Press.

Legate, Julie Anne. 2008. Morphological and abstract Case. Linguistic Inquiry 39(1): 55-101.

Lewis, M. Paul, Gary F. Simons, and Charles D. Fennig, eds. 2014. Ethnologue: Languages of the world, 17th edn. Dallas: SIL International. Online version: http://www.ethnologue.com.

Liberman, Mark. 1975a. The intonational system of English. PhD diss., Massachusetts Institute of Technology.

Liberman, Mark. 1975b. On conditioning the rule of subj.-aux. Inversion. In North East linguistic society (NELS) 5, 77-91.

Marantz, Alec. 1991. Case and licensing. In Eighth eastern states conference on linguistics, escol '91, eds. Germán F. Westphal, Benjamin Ao, and Hee-Rahk Chae, 234-253.

Maskikit-Essed, Raechel, and Carlos Gussenhoven. 2016. No stress, no pitch accent, no prosodic focus: The case of Ambonese Malay. Phonology 33: 353-389.

Massam, Diane. 2000. VSO and VOS: Aspects of Niuean word order. In The syntax of verb initial languages, eds. Andrew Carnie and Eithne Guilfoyle, 97-116. Oxford: Oxford University Press.

Massam, Diane. 2001. Pseudo noun incorporation in Niuean. Natural Language and Linguistic Theory 19(1): 153-197.

McCarthy, John J., and Alan Prince. 1986/1996. Prosodic morphology, Technical report, Rutgers University Center for Cognitive Science, New Brunswick.

McPherson, Laura, and Jeffrey Heath. 2016. Phrasal grammatical tone in the Dogon languages: The role of constraint interaction. Natural Language and Linguistic Theory 34: 593-639.

Michaud, Alexis. 2006. Tonal reassociation and rising tonal contours in Naxi. Linguistics of the TibetoBurman Area 29(1): 61-94.

Michaud, Alexis. 2008. Tones and intonation: Some current challenges. In 8th international seminar on speech production (ISSP'08), ed. Susanne Fuchs, Yves Laprie, and Rudolph Sock, 13-18. Strasbourg. http://halshs.archives-ouvertes.fr/halshs-00325982/en/. Last accessed 30 March 2020.

Mosel, Ulrike, and Even Hovdhaugen. 1992. Samoan reference grammar. Oslo: Scandinavian University Press.

Myers, Scott. 2003. F0 timing in Kinyarwanda. Phonetica 60: 71-97. https://doi.org/10.1159/000071448.

Myrberg, Sara, and Tomas Riad. 2015. The prosodic hierarchy of Swedish. Nordic Journal of Linguistics 38(2): 115-147.

Nespor, Marina, and Irene Vogel. 1986. Prosodic phonology. Dordrecht: Foris.

Ochs, Elinor. 1982. Ergativity and word order in Samoan child language. Language 58(3): 646-671.

Ochs, Elinor. 1988. Culture and language development: Language acquisition and language socialization in a Samoan village. Cambridge: Cambridge University Press. 
Odden, David. 1987. Kimatuumbi phrasal phonology. Phonology Yearbook 4: 13-36. https://doi.org/10. $2307 / 4615409$.

Orfitelli, Robyn, and Kristine Yu. 2009. Intonational phonology of Samoan. Presented at Austronesian Formal Linguistics Association 16, University of California, Santa Cruz.

Ostendorf, Mari, Patti Price, and Stefanie Shattuck-Hufnagel. 1995. The Boston University Radio News Corpus, Technical Report ECS-95-001, Boston University.

Pak, Marjorie. 2008. The postsyntactic derivation and its phonological reflexes. $\mathrm{PhD}$ diss., University of Pennsylvania.

Pawley, Andrew. 1966. Polynesian languages: A subgrouping based on shared innovations in morphology. Journal of the Polynesian Society 75: 39-64.

Pawley, Andrew. 1967. The relationships of Polynesian Outlier languages. Journal of the Polynesian Society 76: 259-296.

Pierrehumbert, J. B. 1980. The phonology and phonetics of English intonation. PhD diss., MIT.

Pierrehumbert, Janet, and Mary Beckman. 1988. Japanese tone structure. Cambridge: MIT Press.

Pittayaporn, Pittayawat. 2007. Prosody of final particles in Thai: Interaction between lexical tones and intonation. Workshop on Intonational Phonology: Understudied or Fieldwork Languages, August 5, 2007.

Prieto, Pilar, Mariapaola D’Imperio, and Barbara Gili Fivela. 2005. Pitch accent alignment in Romance: Primary and secondary associations with metrical structure. Language and Speech 48: 359-396.

R Core Team. 2014. R: A language and environment for statistical computing. Vienna. R Foundation for Statistical Computing. http://www.R-project.org/.

Remijsen, Bert. 2001. Dialectal variation in the lexical tone system of Ma'ya. Language and Speech 44(4): 473-499. https://doi.org/10.1177/00238309010440040301.

Richards, Norvin. 2016. Contiguity theory. Cambridge: MIT Press.

Richards, Norvin. 2017. Some notes on Tagalog prosody and scrambling. Glossa 2(1): 21.

Rude, Noel. 1988. Ergative, passive, and antipassive in Nez Perce. In Passive and voice, ed. Masayoshi Shibitani, 547-560. Amsterdam: Benjamins.

Saeed, John Ibrahim. 1993. Somali reference grammar. Kensington: Dunwood Press.

Schultze-Berndt, Eva, and Candide Simard. 2012. Constraints on noun phrase discontinuity in an Australian language: The role of prosody and information structure. Linguistics 50(5): 1015-1058.

Selkirk, Elisabeth O. 1978/1981. On prosodic structure and its relation to syntactic structure. In Nordic prosody II, ed. Thorstein Fretheim. Trondheim: TAPIR.

Selkirk, Elisabeth O. 1986. Phonology and syntax: The relationship between sound and structure. Cambridge: MIT Press.

Selkirk, Elisabeth. 2009. On clause and intonational phrase in Japanese: The syntactic grounding of prosodic constituent structure. Gengo Kenkyu 136: 35-73.

Selkirk, Elisabeth. 2011. The syntax-phonology interface. In The handbook of phonological theory, eds. John Goldsmith, Jason Riggle, and Alan C. L. Yu, 435-484. Malden, MA: Wiley-Blackwell.

Selkirk, Elisabeth, and Seunghun J. Lee. 2015. Constituency in sentence phonology: An introduction. Phonology 32: 1-15.

Shue, Yen-Liang, Patricia Keating, Chad Vicenik, and Kristine Yu. 2011. Voicesauce: A program for voice analysis. In International congress of phonetic sciences (ICPhS) 16.

Shore, Bradd. 1977. A Samoan theory of action: Social control and social order in a Polynesian paradox, [PhD Thesis], University of Chicago.

Shore, Bradd. 1980. Speech styles and social context: A Samoan case study. Galveston, TX. Paper presented at the Symposium on Language and Politics in Oceania, Association for Social Anthropology in Oceania.

Silverman, Kim E. A., and Janet B. Pierrehumbert. 1990. The timing of prenuclear high accents in English. In Papers in laboratory phonology I: Between the grammar and physics of speech, eds. John Kingston and Mary E. Beckman, 72-114. Cambridge: Cambridge University Press.

Sun, Hongkai. 1996. Case markers of personal pronouns in Tibeto-Burman languages. Linguistics of the Tibeto-Burman Area 19.2: 1-15.

Truckenbrodt, Hubert. 1999. On the relation between syntactic phrases and phonological phrases. Linguistic Inquiry 30(2): 219-255.

Vonen, Arnfinn Muruvik. 1988. The noun phrase in Samoan and Tokelauan. PhD diss., University of Oslo. Wagner, Michael. 2005. Prosody and recursion. PhD diss., Massachusetts Institute of Technology.

Wagner, Michael. 2010. Prosody and recursion in coordinate structures and beyond. Natural Language and Linguistic Theory 28(1): 183-237. https://doi.org/10.1007/s11049-009-9086-0. 
Wickham, Hadley. 2009. ggplot2: Elegant graphics for data analysis. New York: Springer.

Woolford, Ellen. 2015. Ergativity and transitivity. Linguistic Inquiry 46(3): 489-531.

$\mathrm{Xu}$, Yi. 1999. Effects of tone and focus on the formation and alignment of f0 contours. Journal of Phonetics 27(1): 55-105. https://doi.org/10.1006/jpho.1999.0086.

Xu, Yi. 2001. Fundamental frequency peak delay in Mandarin. Phonetica 58: 26-52.

Yip, Moira. 2002. Tone. Cambridge: Cambridge University Press.

Yoon, Tae-Jin, Sandra Chavarria, Jennifer Cole, and Mark Hasegawa-Johnson. 2004. Intertranscriber reliability of prosodic labeling on telephone conversation using ToBI. In ISCA international conference on spoken language processing (Interspeech 2004), 2729-2732.

$\mathrm{Yu}$, Kristine M. 2011. The sound of ergativity: morphosyntax-prosody mapping in Samoan. In Аnпиal meeting of the North East linguistic society (NELS) 39, eds. Suzi Lima, Kevin Mullin, and Brian Smith, Vol. 2, 825-838. Amherst: Graduate Student Linguistic Association.

Yu, Kristine M. 2014. The experimental state of mind in elicitation: Illustrations from tonal fieldwork. Language Documentation and Conservation 8: 738-777.

Yu, Kristine M. 2019. Parsing with minimalist grammars and prosodic trees. In Minimalist parsing, eds. Robert C. Berwick and Edward Stabler, 69-109. Oxford UK: Oxford University Press.

Yu, Kristine M., and Deniz Özyıldız. 2016. The absolutive ia particle in Samoan. In Annual meeting of the Berkeley Linguistics Society (BLS) 42, 387-406. Berkeley.

Yu, Kristine M., and Edward P. Stabler. 2017. (in)variability in the Samoan syntax/prosody interface and consequences for parsing. Laboratory Phonology 8(1), 25.

Zuraw, Kie. 2009. Prosodic domains for segmental processes? Evidence from some Austronesian languages. Talk at Syntax Interfaces Research Group, McGill University. https://www.mcgill. ca/linguistics/files/linguistics/Handout_RevisedForMcGill.pdf.

Zuraw, Kie, Kristine M. Yu, and Robyn Orfitelli. 2014. The word-level prosody of Samoan. Phonology 31(2): 271-327. 